\title{
PERCEPCIONES DE LOS JÓVENES UNIVERSITARIOS EN RELACIÓN A LOS PROGRAMAS DE EMPRENDIMIENTO PROPIOS DE LAS POLÍTICAS DE EMPLEO
}

\section{MARÍA ALEJANDRA GÓMEZ BECERRA}

Trabajo de investigación para optar el título de Magíster en Protección Social

Línea de investigación Programas de Atención Social

\author{
Asesor \\ Manuel Vega Vargas
}

UNIVERSIDAD SANTO TOMÁS DE BOGOTÁ DIVISIÓN CIENCIAS ECONÓMICAS Y ADMINISTRATIVAS MAESTRÍA EL PROTECCIÓN SOCIAL 


\section{PERCEPCIONES DE LOS JÓVENES UNIVERSITARIOS EN RELACIÓN A LOS PROGRAMAS DE EMPRENDIMIENTO PROPIOS DE LAS POLÍTICAS DE EMPLEO}

Esta tesis fue evaluada y aprobada para la obtención del título de Magíster en protección Social por la Universidad Santo Tomás de Bogotá

Nombres de quiénes aprueban:

Manuel Vega Vargas. Asesor de Tesis

Yenny Carolina Ramírez. Jurado

Sandra Barrios. Jurado 


\section{SALVEDAD INSTITUCIONAL}

La Universidad Santo Tomás de Bogotá no se hace responsable de los conceptos emitidos por la investigadora en su trabajo, solo velará por el rigor científico, metodológico y ético del mismo en aras de la búsqueda de la verdad y la justicia. 


\section{AGRADECIMIENTOS}

A mis padres por los valores enseñados y el apoyo incondicional que ha permitido la construcción de mi vida integral y profesional, sin ellos no hubiera sido posible realizar y construir mis metas y lograr ser quién soy ahora. 


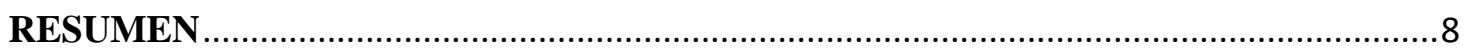

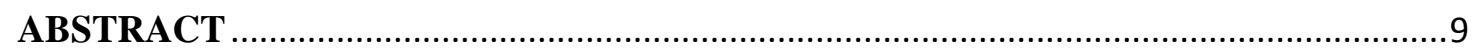

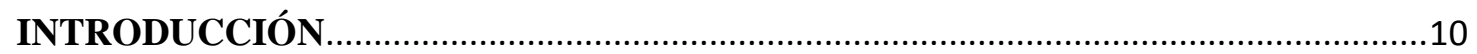

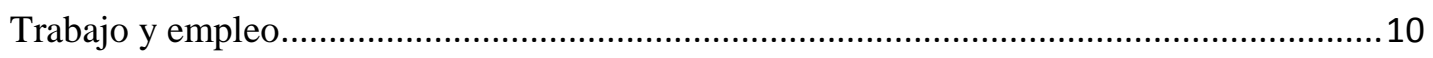

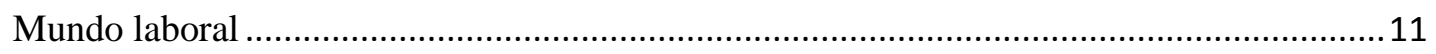

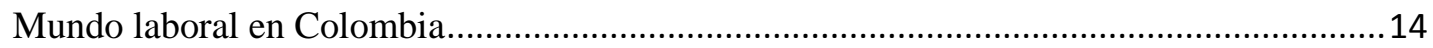

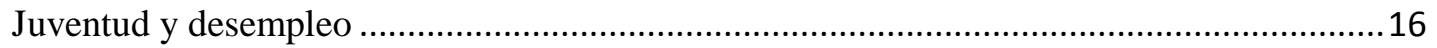

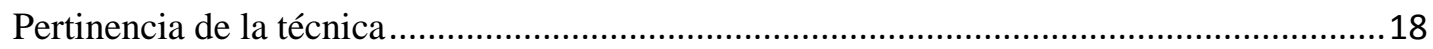

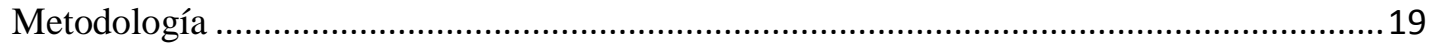

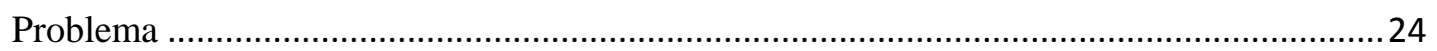

Factores determinantes del ingreso al mercado laboral......................................................22

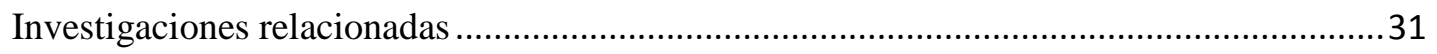

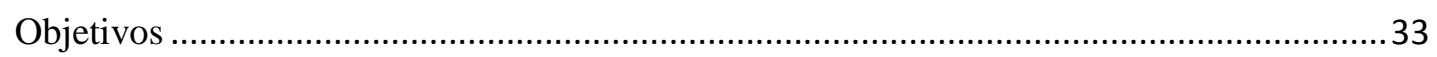

Objetivos específicos ........................................................................................ 33

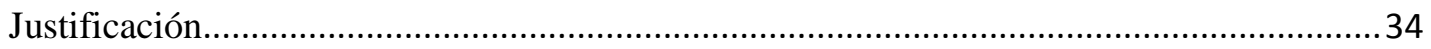

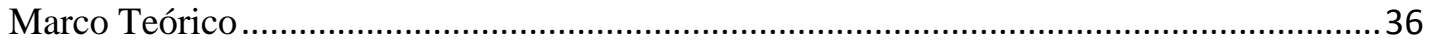

CAPÍTULO 1. CONTEXTO DEL EMPLEO: MUNDO, AMÉRICA LATINA Y

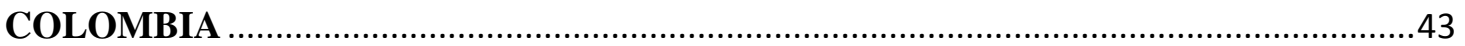

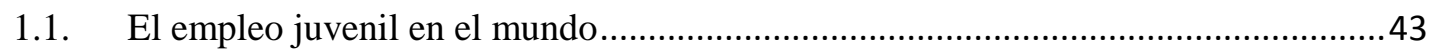

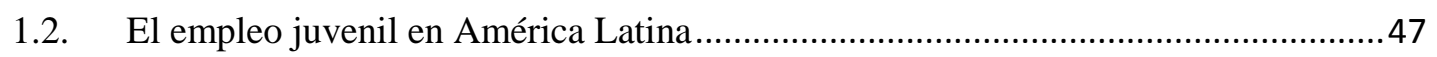

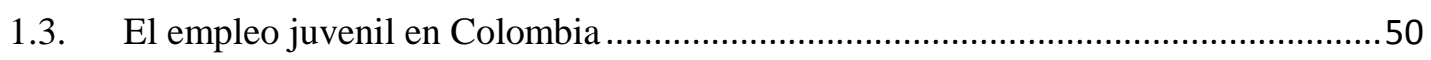

CAPÍTULO 2. PROBLEMAS, TRABAJO DECENTE Y CARACTERIZACIÓN DE

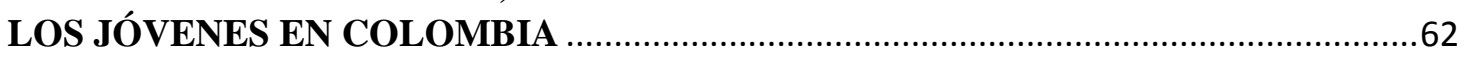

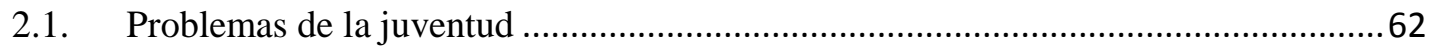

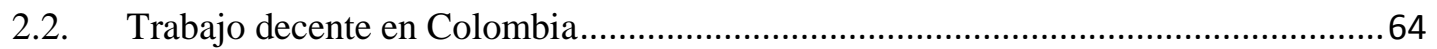

2.3. Caracterización del empleo y los jóvenes en Colombia .............................................66

CAPÍTULO 3. JÓVENES EN BOGOTÁ Y CONDICIONES LABORALES ....................80

CAPÍTULO 4. PERCEPCIONES DE LOS JÓVENES....................................................91

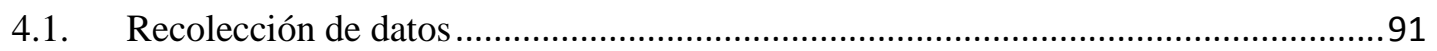

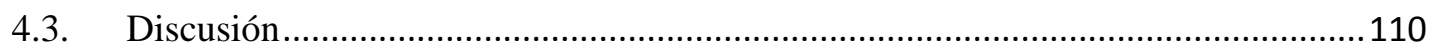

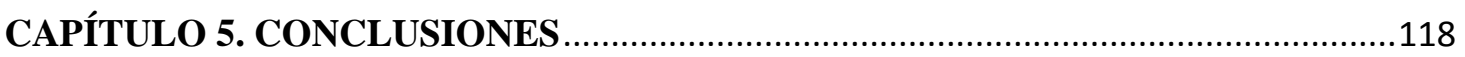

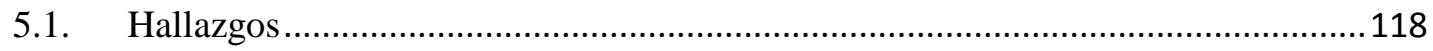




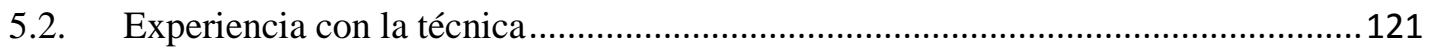

5.3. Problemas de investigación que se abren para la Protección Social ........................124

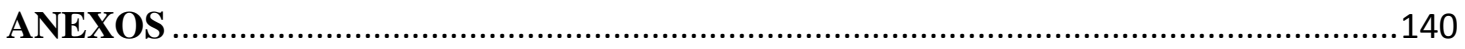

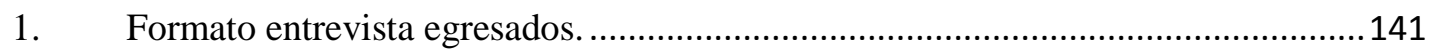

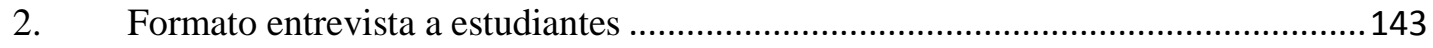




\section{LISTA TABLAS Y GRÁFICAS}

GRÁFICA 1. EL DESEMPLEO MUNDIAL JUVENIL, 1995-2015

GrÁFICA2. PROPORCIÓN DE POBLACIÓN OCUPADA INFORMAL TOTAL 13 Y 23 CIUDADES Y ÁREAS METROPOLITANAS TRIMESTRE JULIO - SEPTIEMBRE (2010-2016)

GrÁFICA 3. PROPORCIÓN DE LA POBLACIÓN OCUPADA INFORMAL SEGÚN CIUDAD 23 CIUDADES Y

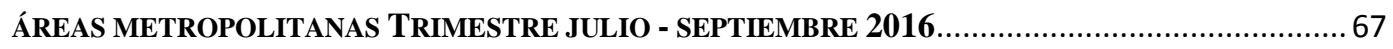

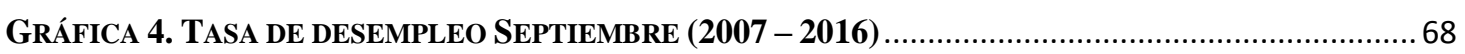

ILUSTRACIÓN 5. TASA GLOBAL DE PARTICIPACIÓN SEPTIEMBRE (2007 - 2016) ...............................69

GRÁFICA 6. TASA DE DESEMPLEO DE LOS JÓVENES DE 14 A 28 AÑOS SEGÚN SEXO TRIMESTRE MÓVIL JUNIO - AGOSTO (2015 - 2016) TOTAL NACIONAL Y TOTAL 13 CIUDADES Y ÁREAS METROPOLITANAS. 70

GRÁFICA 7. TASA GLOBAL DE PARTICIPACIÓN, DE OCUPACIÓN Y DE DESEMPLEO DE LOS JÓVENES DE 14 A 28 AÑOS SEgÚN SEXO TRIMESTRE MÓVIL JUNIO - AgOSTO 2016 TOTAL.

GRÁFICA 8. DISTRIBUCIÓN PORCENTUAL DE LA POBLACIÓN DE 14 A 29 AÑOS DE EDAD SEGÚN NIVEL EDUCATIVO ALCANZADO DE LOS JÓVENES, SUS PADRES Y MADRES TOTAL 13 CIUDADES $2015 . .72$

GrÁFICA 9. DISTRIBUCIÓN PORCENTUAL dE LA POBLACIÓN DE 14 A 29 AÑOS DE EDAD SEGÚN EXPECTATIVA DE OCUPACIÓN EN EL FUTURO TOTAL 13 CIUDADES 2013 Y $2015 \ldots \ldots \ldots \ldots \ldots \ldots . . . . .73$

GRÁFICA 10. DISTRIBUCIÓN PORCENTUAL DE LA POBLACIÓN OCUPADA INDEPENDIENTE DE 14 A 29 AÑOS DE EDAD SEGÚN RAZONES PARA TRABAJAR COMO INDEPENDIENTE TOTAL 13 CIUDADES 2013 Y 2015

GRÁFICA 11. DISTRIBUCIÓN PORCENTUAL DE LA POBLACIÓN DE 14 A 29 AÑOS DE EDAD OCUPADA SEGÚN SEGURIDAD SOCIAL TOTAL 13 CIUDADES 2013 Y 2015.

GRÁFICA 12. DISTRIBUCIÓN PORCENTUAL DE LA POBLACIÓN DESOCUPADA DE 14 A 29 AÑOS DE EDAD SEGÚN TIEMPO DE BÚSQUEDA DE EMPLEO TOTAL 13 CIUDADES 2013 Y 2015.

GRÁFICA 13. DISTRIBUCIÓN PORCENTUAL DE LA POBLACIÓN DESOCUPADA DE 14 A 29 AÑOS DE EDAD SEGÚN PRINCIPAL OBSTÁCULO PARA ENCONTRAR UN TRABAJO TOTAL 13 CIUDADES 2013 Y 2015 .

Gráfica 14. Tabla Beneficios 1429 de 2010. "Ley de Primer EMPLeO .. .81

GRÁFICA 15. POBLACIÓN POR RANGOS DE EDAD Y SEXO EN PORCENTAJES SOBRE TOTAL POBLACIÓN CIUDAD

GráFiCA 16. PoblaCión total de 15 A 29 AÑos EN Bogotá 2010 - 2014 .86

GRÁFICA 17. DESEMPLEO JUVENIL EN BOGOTÁ Y COLOMBIA (\%) TRIMESTRE MÓVIL NOVIEMBRE ENERO (2008-2016)

GRÁFICA 18. TABLA DE CARACTERIZACIÓN SUJETOS PARTICIPANTES EGRESADOS ...........................992

GRÁFICA 19. TABLA DE CARACTERIZACIÓN SUJETOS PARTICIPANTES ESTUDIANTES.........................92 


\section{RESUMEN}

El presente trabajo tiene como finalidad tener un primer acercamiento al tema laboral juvenil en Colombia. Teniendo en cuenta que es un campo amplío y reciente, pero que aun así permite abordar problemáticas actuales de la sociedad.

Se realiza un análisis exploratorio de la situación laboral juvenil en el mundo, principalmente en Latinoamérica y, posteriormente, en Bogotá, Colombia. Es así como, el estudio se centra en los jóvenes residentes de la capital colombiana, específicamente, en los jóvenes universitarios. Lo anterior, con la intención de conocer su perspectiva frente a la Ley 1429 de 2010, propuesta por los dos gobiernos del Presidente Juan Manuel Santos o sus referentes sobre Primer Empleo.

El interés por realizar este estudio parte de la creación de políticas o leyes con intereses diferentes a los programas creados para las mismas. Este es el caso de la ley antes mencionada, más conocida como la "Ley de Primer Empleo".

En cuanto a la metodología utilizada para el presente trabajo, se llevó a cabo once entrevistas que permitieron analizar y describir las percepciones de la población seleccionada frente al tema laboral.

\section{Palabras claves}

Protección Social, empleo, trabajo, jóvenes, percepciones, experiencia, oportunidades. 


\begin{abstract}
This paper aims to approach youth labor issues in Bogota, Colombia considering it to be a large and recent field which through which current problems of society may be solved.

An exploratory analysis of the youth employment situation in the world is made, primarily in Latin America and later in Bogotá, specifically in college students. The main objective of the study is to know their perspective about the law 1429 of 2010 , proposed by the two governments of President Juan Manuel Santos and also their concerning about government First Job proposal.

The motivation of this study arises from creation of policies and laws none targeted to programs created for the youth ones such as the "First Employment Act".

As for the methodology used through the study, an interview was made multiple times and its results allowed to analyze and describe the perspective of the youth people about the employment issues.
\end{abstract}

\title{
Key words
}

Social Protection, Employment, Job, Young people, perspective, Experience, Opportunities. 


\section{INTRODUCCIÓN}

Constantemente los países enfrentan crisis económicas o sociales que han dado lugar a la formulación y gestión de programas a nivel nacional e internacional, dirigidos a mitigar, combatir o erradicar las problemáticas sociales existentes. Un elemento determinante de esta realidad es la economía mundial. Sus desequilibrios y desigualdades han aumentado el desempleo, transformando así el contexto laboral a nivel mundial. Se han ampliado necesidades tanto en la producción de bienes, como en la generación de recursos (ingresos) y condiciones de bienestar. El empleo constituye una de las tareas pendientes para muchos países y la necesidad de repensar el trabajo adquiere un protagonismo central en las agendas de los gobiernos y las instancias internacionales.

\section{Trabajo y empleo}

Mientras el trabajo es conocido como la actividad que permite al ser humano hacer parte de la sociedad y desarrollarse dentro de la misma, el empleo por su lado es el medio por el que se reconoce el trabajo de la persona considerada como asalariada (1).

El trabajo juega un papel importante en el desarrollo de cualquier sociedad. Pierre Rosanvallon (2), lo define como el medio por el cual el hombre puede vivir e insertarse en una sociedad. En cuanto al tema laboral, menciona que el Estado tiene un alto grado de implicación, pues es el encargado de ofrecer garantías a sus ciudadanos, en especial a quién más lo necesitan.

De igual manera, este autor concibe la nueva cuestión social como una consecuencia de lo que se ha buscado desde la década de los ochenta con la economía mundial de libre mercado, la cual se orienta a producir incrementos en la tasa de ganancia flexibilizando el mercado laboral, privatizando lo público y desestructurando los soportes con los que se entendía el mundo social desde un punto de vista filosófico (2).

La destrucción de la solidaridad en la exclusión laboral evidencia la necesidad de reinventar las nuevas dinámicas de la economía, teniendo en cuenta la necesidad de ser justos y equitativos. A pesar que, los casos entre Europa y América Latina son distintos, 
se hace visible la urgencia de apropiarse de estas falencias particulares para encontrar soluciones masivas, que involucren a todos con igualdad de condiciones y exista una inserción equitativa de los jóvenes al mundo laboral.

\section{Mundo laboral}

Uno de los aspectos que generaron gran importancia para la época, fue el tema de poder solventar las problemáticas existentes en el campo laboral, las desigualdades y la desestabilización de la economía. Por lo tanto, a partir de la Segunda Guerra Mundial los países más influyentes idearon y adoptaron un plan de desarrollo que contenían ideas keynesianas, mediante las cuales buscaban la intervención estatal como medio regulador de los problemas de desempleo y precariedad laboral. Estas mismas ideas fueron implementadas luego en América Latina, a través de las políticas de la Comisión Económica para América Latina y el Caribe (CEPAL), también con una fuerte intervención estatal (3). Marcela Agudelo (3) ilustra el desarrollo histórico básico sobre la historia del trabajo, la cual se referencia desde los años setenta, expresando las transformaciones y sus fenómenos,

"Después de la década de los setenta, la crisis del Estado benefactor, la introducción de un nuevo patrón de acumulación, el surgimiento de nuevos modelos de desarrollo de libre mercado y el impulso de nuevas tecnologías de la comunicación e información han suscitado una serie de transformaciones en el sistema económico mundial que han penetrado la industria fabril, apalancando modificaciones en los sistemas de producción y en la articulación laboral.

Estas transformaciones han repercutido en el mundo del trabajo, donde se ha evidenciado el aumento de la tercerización de la economía, así como la flexibilización, precarización y eliminación de puestos de trabajo, junto a nueva formas de contratación temporal, subcontratación o contratos por prestación de servicios" (3).

En la década de los 70 se presentó un colapso de los modelos económicos por el déficit en la balanza de pagos que tenía Estados Unidos y la imposibilidad del pago de la deuda de países de América Latina. En esta misma década se generaron nuevos empleos y formas de contratación, esto mediante la creación y desarrollo de tecnologías y 
comunicación, dotación de recursos que fueron acogidos por las industrias. Durante los años ochenta se da inicio a:

"Una transformación en el sistema capitalista, con el surgimiento del neoliberalismo se modifican las relaciones capital-trabajo, apoyándose en una mayor liberalización del comercio mundial, reducción de obstáculos comerciales, financieros y costes de transporte, menor regulación estatal, reducción del gasto público, aumento en la movilidad de capital financiero que ubica como nuevo patrón de acumulación al capital financiero-especulativo, desestimando la capacidad del sector real de ser el impulsor de la creación de la riqueza” (3).

La capacitación, entendida como capital humano, fue captada como beneficio, tanto para los empleados, como para los empleadores. Con ella se desarrollaban mejoras en la producción y un nuevo interés por conseguir nuevas habilidades, conocimientos y capacidades en los trabajadores para ser aceptados y lograr acceder al mercado laboral existente. Sin embargo, desde los años 80 se viene dando un fenómeno de desempleo que está asociado con diversos factores como son una economía variable, más capital humano, abandono escolar, entre otras. Según la CEPAL (4), el capital humano hace referencia a: El recurso con un origen innato o adquirido. Por su parte, El capital humano innato comprende las aptitudes de tipo físico e intelectual, las cuales pueden estar modificadas por condiciones de salud o alimentarias. Por otro lado, el capital humano adquirido es el que se va construyendo a lo largo de la vida de cada individuo, por medio de la educación formal y/o informal y de la experiencia acumulada. Lo cual condiciona la instrucción laboral y el sistema de valores de los sujetos, que determinarán, junto a las aptitudes innatas, su rendimiento en el trabajo.

Cabe resaltar que, la instrucción laboral estará acompañada por los conocimientos adquiridos sobre una determinada tarea. Por ejemplo:

"El aprendizaje del manejo de un ordenador personal constituirá una clase de conocimiento, adquirido en la escuela, el hogar o el entorno de trabajo, aprovechable para muy diferentes puestos laborales. Otras veces, un determinado tipo de instrucción laboral solo será útil para el desempeño de una función concreta, como, por ejemplo, la recibida para pilotar un avión. En este último caso, los empleados que poseen una formación específica son 
difícilmente sustituibles por otros, siendo necesario, en muchas ocasiones, incurrir en elevadas inversiones para dotar a los nuevos trabajadores de dichos conocimientos" (4).

En cuanto al sistema de valores de los individuos, también se evidencia un origen adquirido, en donde dichos valores conforman un elemento clave de la capacidad laboral de los sujetos, puesto que de ellos dependerá la motivación, la fidelidad, la integridad, la diligencia o la constancia del trabajador a la hora de realizar su trabajo.

Las Naciones Unidas, por su lado, en el resumen ejecutivo de la Situación y perspectiva de la economía mundial 2015, hace referencia al crecimiento bajo que tiene el PIB en el mundo, además de los problemas geopolíticos que no están previstos en la búsqueda del camino a la recuperación. El desempleo y la informalidad siguen siendo una problemática en el mundo, problemática que depende del PIB y sus balances, puesto que es mediante su crecimiento que la generación de empleo aumenta. Para el surgimiento de oportunidades laborales y enfrentar estas afectaciones económicas, se hace necesaria la generación de políticas que permitan crear empresas y crear empleos formales, esto acompañado de programas de protección social que "permitirían contribuir a mejorar las condiciones de mercados laborales y apoyar la demanda agregada." (5).

A nivel internacional el tema se ha desarrollado gracias a los aportes de organismos de naciones unidas como la Organización Internacional del Trabajo (OIT), la cual surge con el fin de promocionar justicia social en el reconocimiento de las normas fundamentales del trabajo; "la labor de la OIT gira alrededor de su Programa de Trabajo Decente cuyo objetivo es la promoción de los derechos sociales y laborales, del empleo, de la protección social y del diálogo social a escala internacional” (6). Donde además un tema importante es que para poder hablar de trabajo decente, es necesario que las personas cuenten con trabajo.

El concepto de trabajo decente se dio a partir de la idea de la promoción de oportunidades de empleo, que además estuviera acorde con condiciones de calidad y respeto hacia el diálogo social y los derechos de los trabajadores. Además de comprender tanto trabajos formales, como informales pues estos últimos no se pueden omitir al tener un gran porcentaje quiénes se encuentran inmersos en este sector (7). 


\section{Mundo laboral en Colombia}

El sistema laboral colombiano reposa y se basa en dos fuentes jurídicas y teóricas, la primera: la Constitución Política de Colombia de 1991 (8), la cual establece derechos y deberes de nuestra sociedad, así como la organización de la misma. Su artículo 25 refiere al trabajo como un "derecho y una obligación social y goza, en todas sus modalidades, de la especial protección del estado. Toda persona tiene derecho a un trabajo en condiciones dignas y justas”, la segunda fuente es él: Código Sustantivo del Trabajo del año 2011 (9), mediante el cual se establece toda la reglamentación relacionada al trabajo; en el cual el artículo 11 hace referencia al derecho al trabajo como: "Toda persona tiene derecho al trabajo y goza de libertad para escoger profesión u oficio, dentro de las normas prescritas por la Constitución y la Ley".

Asimismo, en los artículos 8, 10, y 13, el Código Sustantivo de Trabajo reafirma la libertad de trabajo, la igualdad y el mínimo de derechos y garantías a favor de los trabajadores y trabajadoras, temas cruciales en este proyecto.

El Ministerio de la Protección Social (10) a través de la Dirección General de Promoción del Trabajo-Observatorio al Mercado del Trabajo, hace interpretación de las dos fuentes mencionadas anteriormente. Sobre el artículo 25 aclara que, no solo consiste en el acceso a un trabajo, sino que también señala que el mismo debe darse en condiciones dignas y justas. Asistiendo de igual manera otras condiciones que involucren distintas labores que encomienden al trabajador, permitiendo involucrar al Estado como ente regulador, para que interfiera en todas las relaciones que puedan afectar al trabajador. Y el artículo 11 relacionado directamente con el derecho al trabajo, estipulado en la Constitución Política de Colombia.

La problemática del desempleo en Colombia afecta el desarrollo de la sociedad. Como menciona Margaret Maruani, "La crisis del empleo: la irrupción de un desempleo masivo y la multiplicación de «formas peculiares de empleo» han producido una situación de racionamiento y desestabilización del empleo que afecta al conjunto de los activos. El trabajo ya no es lo que era" (11).

Según la Oficina Internacional de los Derechos Humanos Acción Colombiana (OIDHACO), Colombia enfrenta actualmente una crisis en materia de condiciones en 
el empleo, "el 68 por ciento de los trabajadores no gozan de condiciones de trabajo decentes" (12), Estos datos son para el año 2015, según refiere la fuente. Las empresas por su parte están haciendo contrataciones con vínculos laborales débiles con el trabajador, fortaleciendo de esta forma el trabajo informal y la subcontratación. De acuerdo a esto, es posible identificar uno de los elementos que contribuye a la crisis del empleo en Colombia. Como menciona Marcela Agudelo (3), en este país las modalidades de contratación son un factor negativo, pues su funcionamiento se realiza a través de la contratación temporal. Colombia ha dejado a un lado el sector industrial para acoger la prestación de servicios como sector de mayor participación en el país. Los jóvenes por ende se están enfrentando a un mundo laboral sin las garantías sociales propias de los Estados de Bienestar del siglo XX, ya sea en su versión del industrialismo que produjo el intervencionismo latinoamericano, o en la versión del keynesianismo europeo.

La institución directamente encargada en Colombia de todo lo relacionado con el trabajo es el Ministerio de Trabajo (13). Esta institución vela no solo por la creación de oportunidades laborales, por la regulación de formas de vinculación laboral, por la protección de los trabajadores y por los derechos fundamentales del trabajo, sino que además acoge cuatro objetivos importantes que se encuentran establecidos por la OIT (14):

1. El acceso al empleo con condiciones de dignidad.

2. El respeto de los derechos fundamentales en el trabajo, incluyendo la erradicación del trabajo infantil y sus peores formas.

3. La inclusión en el Sistema de Protección Social.

4. El Diálogo Social, que promueve el fortalecimiento de los actores del Tripartismo (Gobierno, empleadores y trabajadores).

En adición, la Protección Social según la OIT propone tres dimensiones como parte de sus objetivos estratégicos:

1. Aumentar la eficacia y extender la cobertura de los sistemas de seguridad social. 
2. Promover la protección de los trabajadores, que incluye: condiciones de trabajo decentes, como salarios, tiempo de trabajo y salud y seguridad en el trabajo, todos componentes esenciales del trabajo decente

3. Promover la protección de grupos vulnerables, como los trabajadores migrantes, sus familias y los trabajadores en la economía informal, mediante programas y actividades específicos. Además, se utilizará todo el potencial del mundo del trabajo para responder a la pandemia del SIDA, con especial atención al fortalecimiento de la capacidad de los mandantes tripartitos.

Lo anterior se enfoca en la implementación de políticas de empleo exhaustivas, que se encargan de garantizar servicios y transferencias sociales a lo largo de todo el ciclo vital de las personas, centrándose principalmente en la población vulnerable.

El Ministerio de Trabajo como ente regulador, no solo se encarga de lo mencionado, sino que da prevalencia e identifica la población vulnerable (13), sobre la cual busca brindar apoyo para el acceso al mercado laboral, incluyendo dentro de esta población jóvenes trabajadores. Según la Ley 1622 de 2013 (15) expedida por el Congreso de la República, por la cual se expide el estatuto de ciudadanía juvenil, en el artículo $5^{\circ}$, Joven es toda persona "entre 14 y 28 años cumplidos en proceso de consolidación de su autonomía intelectual, física, moral, económica, social y cultural que hace parte de una comunidad política y en ese sentido ejerce su ciudadanía”.

\section{Juventud y desempleo}

El desempleo en la población joven cada día aumenta más, esta población se está viendo obligada a emplearse en cualquier tipo de empleo, para obtener experiencia y recibir un ingreso mensual, tema contraproducente pues las empresas se aprovechan de estas situaciones con el fin de reducir a su favor los costos laborales. Las desigualdades son cada vez más notorias y esta población es quién más las enfrenta. El Heraldo.com hace referencia en su artículo Más jóvenes dejaron de buscar trabajo formal en Colombia a la situación que enfrenta el país hoy en día:

La situación laboral para la población joven todavía es más difícil: la tasa de desempleo para personas entre 14 y 28 años, durante el segundo trimestre de 
2014, fue de 15,5\%, según el DANE. Un punto porcentual por debajo de la tasa para el mismo período en 2013. Aun así, solo el 57,9\% de esta población es económicamente activa; cifra medio punto porcentual inferior al mismo trimestre del año anterior. Es decir, que hoy un mayor número de jóvenes se han retirado del mercado laboral y están la informalidad.

Esto se relaciona con la oferta de empleos en sectores de baja productividad. Por ejemplo, las ramas de actividad que concentraron la mayor proporción de jóvenes ocupados fue el de comercio, restaurantes y hoteles $(27,8 \%)$ y el de servicios comunales, sociales y personales (19,2\%). Igualmente, $50 \%$ de los jóvenes laboran como trabajadores manuales en el sector manufacturero y de construcción (16).

Se demuestra una vez más que la situación de los jóvenes frente al empleo es compleja y que solo algunos sectores se encuentran fortalecidos para ofrecer empleo, en muchas ocasiones, empleo informal.

Aunque en Colombia se ha intentado optimizar el tema de formalización del empleo, en especial para los jóvenes que se encuentran en edad de 18 a 28 años de edad (bachilleres, técnicos, tecnólogos y profesionales), no se ha considerado que esta población se encuentra en crecimiento (bono demográfico) y que las necesidades van más allá de crear empresas, pues, no todos se encuentran dispuestos a ello y no todos tienen los recursos para hacerlo. Por tanto la demanda laboral, está por encima del rango de la oferta que pueda existir.

En los dos períodos de gobierno de Juan Manuel Santos, se viene trabajando sobre la situación permanente y la dificultad de acceso al mercado laboral para jóvenes, en muchos casos producto de la falta de experiencia para acceder al mismo mercado. Por ello se creó la Ley 1429 de 2010, mediante la cual se estableció la formalización y generación de empleo, más conocida como "Ley de Primer Empleo". Esta ley se encarga de favorecer a todas aquellas personas que tienen pequeñas y medianas empresas, o que deseen crear empresa aumentando los beneficios y disminuyendo costos en la búsqueda de su crecimiento empresarial, a cambio de ampliar la oferta 
laboral a los jóvenes. Asimismo, incluye oportunidades de empleo para personas menores de 28 años de edad y mujeres mayores de 40 años.

De acuerdo a la referencia de esta ley, existe una propuesta dirigida y divulgada por el Ministerio de Trabajo, bajo el lema: 40.000 nuevos empleos: es talento no palanca. Esta iniciativa consiste en involucrar a las cajas de compensación, la cuales deberán ofertar empleos y serán lugares donde las personas pueden hacer su inscripción para la búsqueda de empleo.

Este estudio se centra en las percepciones de jóvenes universitarios sobre los programas de emprendimiento propios de las políticas de empleo donde no se encuentran acciones $\mathrm{u}$ objetivos dirigidos a las garantías de estos nuevos trabajadores, no se ajusta a las necesidades de estos actores sociales, sino que se centran en impulsar nuevas expectativas y crecimiento empresariales, esto para sectores claramente definidos (sectores económicos empresariales).

La ley 1429 de 2010 o la Ley de Primer Empleo, se presenta como una ley basada en dar beneficios para la creación de empresas y Pymes, más que a la generación de puestos de trabajo dignos y formales para los jóvenes. Por lo anterior, surge la necesidad de realizar una revisión y conocer la percepciones de los jóvenes sobre lo que ofrecen las leyes, para así poder accionar frente a ellas desde el punto de vista de resultado de un trabajo investigativo.

\section{Pertinencia de la técnica}

En primer lugar y luego del proceso académico, se buscó un tema que tuviera campo de investigación en protección social, desde un inicio se buscó que fuese relacionado con los jóvenes y el primer empleo, pues es el primer empleo el más difícil de conseguir y las políticas no van dirigidas a ellos de esta manera, sino que se están desarrollando, de tal forma que sean más individuales tema preocupante, pues en vez de mitigar el efecto de la problemática de empleo, hace que aumente y genere más gasto público para solventar las necesidades de esta población.

El tema logró delimitarse de tal manera que se pudiese tener un acercamiento a los jóvenes universitarios y sus percepciones en relación a los programas de emprendimiento propios de las políticas de empleo. La delimitación en la población objeto se hizo primero porque es una población muy grande, segundo por sus 
necesidades, tercero por su ubicación en el territorio nacional y cuarto por sus niveles de estudio, determinando respectivamente así: la población joven es grande, y se encuentran en condiciones de estudiantes, empleados, desempleados o inactivos (no trabajan, no estudian, no hacen nada) dejando universitarios que mostraran estos rangos como tema importante para reconocer las diferencias en el ámbito de empleo/desempleo, la siguiente por su condición socioeconómica (eligiendo jóvenes de estratos 3 y 4 que permitieran ver el tema de necesidades y metas de empleabilidad), necesidad de laboral tanto por experiencia como por dinero para cubrir los gastos en la sociedad, la ubicación sin duda debía delimitarse, pues el territorio nacional es muy grande y por facilidad de acercamiento a las fuentes era necesario que fuese la capital; y la última se decidió por nivel educativo, pues existen bachilleres, técnicos, tecnólogos, profesionales, especiales, magísteres.

Luego de tener claro y definido el tema de investigación se realizó una mirada desde donde podría revisarse la problemática (desempleo juvenil) y lo que habría que investigar para realizar dicho trabajo. La problemática se basa principalmente en el tema laboral al que deberán enfrentarse los jóvenes, para este proceso se inició una investigación a nivel mundial con el fin de demostrar que esta problemática se presenta en todo el mundo, luego se hizo acercamiento a Latinoamérica en la que se logró demostrar que en esta región existe esta problemática, pero además que se acentúa. Se revisó además la problemática en Colombia, situación en cifras, antecedentes y por último se revisó la experiencia del tema de empleo en Bogotá.

Todo lo anterior permitiría obtener información relevante para la construcción de la metodología de la investigación y así realizar las preguntas acertadas al público objeto.

\section{Metodología}

Como se mencionó en el inicio de este trabajo el tipo de estudio que se realizó es de carácter descriptivo - explicativo. El primer elemento define cómo es y cómo se manifiesta determinado fenómeno, estudiando temas concretos sobre personas, grupos comunidades y otros que puedan ser analizados, mientras que el segundo busca estudiar un tema no abordado anteriormente (17). 
Con lo anterior, se analizaron las percepciones que tienen los jóvenes universitarios frente a los programas de emprendimiento propios de las políticas de empleo de acuerdo al objeto del trabajo.

Se eligió como método la entrevista y es de aclarar que la misma se encuentra en un enfoque cualitativo, diferenciándose del enfoque cuantitativo en cuanto a que desde su inicio existe una realidad por revelar o descubrir, la premisa es la realidad del fenómeno social y se construye a partir de los seres humanos y el significado que estos le brindan, en cuanto a los datos, en vez de medir y cuantificar, pretende buscar la expansión de la información brindada frente a temas ya sean expliciticos o implícitos, a través del lenguaje como dato exclusivo del método, la finalidad se enmarca mediante querer entender al sujeto y sus puntos de vista.

Se implementó triangulación de fuentes secundarias recogidas en este trabajo, con la información proveniente de las entrevistas realizadas, los informes que hacen referencia al tema del empleo y la ley. Sobre esta base se hizo el análisis y las conclusiones.

Es importante mencionar que los tópicos a indagar, analizar y discutir en este trabajo son: la protección social, el empleo, los jóvenes y las percepciones de los mismos, sin dejar de mencionar que pueden surgir otros conceptos emergentes sobre los cuales exista mayor énfasis y relevancia de acuerdo a las experiencias de los entrevistados.

\section{Diseño de modelo:}

Se realizó una entrevista semi estructurada como herramienta para obtener resultados acordes al planteamiento del problema de este proyecto. Esta entrevista se basó en la combinación de preguntas estructuradas y abiertas de acuerdo a la información necesitada.

Se tuvieron en cuenta algunos factores para la construcción del cuestionario como:

- Elección para elegir una carrera universitaria, mediante la cual se buscaba revisar si las personas tienen definido lo que les gusta hacer o si influyen los entornos sociales para la realización de esta elección y la búsqueda de sus gustos. Es importante además conocer si para esta elección se mencionaba algo relacionado carrera/empleo para tomar la decisión en su elección.

- La situación de nivel académico de estudiantes/profesionales se hizo de tal forma que se pudiera hacer un acercamiento sobre lo que opinan los jóvenes mientras 
se encuentran estudiando, sus influencias, sus necesidades, sus intereses y lograr hacer una diferenciación con los egresados que ya se están o se han enfrentado a la búsqueda de empleo.

- Sin duda alguna en esta sociedad y para la búsqueda de empleo la universidad elegida es clave para las contrataciones, además en algunos casos define el sector socioeconómico al que pertenecen las personas. Con esto no se pretende generalizar, pero si poner puntos de vistas diferentes desde las perspectivas de personas que ingresan a instituciones públicas, privadas y privadas de alto reconocimiento. Con esto se lograría conocer si es lo mismo estudiar en una universidad prestigiosa, sin necesidades o estudiar en una universidad normal o pública con necesidades.

- Las expectativas de empleo sin duda alguna representaban algo importante para este trabajo, aunque los jóvenes no mostraron interés, sino hasta que se les hacía las preguntas concretas de empleo; permitía saber si reconocen la situación que vive el país, sin antes hacer un preámbulo sobre lo que se les preguntaría concretamente.

- Las preguntas de empleo y de la Ley 1429 de 2010 se hicieron sin dar un preámbulo y se estudiará sobre la misma, esto con intencionalidad, pues se necesitaba revisar si todo es conocido, si la información es bien divulgada o si no hay interés alguno sobre el campo del empleo como se mencionó en la hipótesis de este trabajo.

Alcance: Tener una visión más asertiva sobre la problemática, que permita generar nuevas propuestas, brindando ideas e iniciativas que conlleven a posibles soluciones mediante nuevas prácticas de generación de conocimientos para los jóvenes de nuestro país.

Es necesario ver cómo está siendo representada la realidad laboral y la ley por los jóvenes. Estos factores permitirían reconocer falencias existentes en la construcción de conocimiento y en la construcción de políticas públicas.

Limitaciones: Inicialmente se planteó que al ser una ley relativamente reciente, la divulgación de publicidad de la misma se hizo por poco tiempo, por lo que puede existir algún grado de desconocimiento frente al tema. Sin embargo, tras casi seis años, esta 
ley tiene un tiempo prudente para que haya conocimiento de la misma, de hecho para el año 2013 se creó el decreto 0489 reglamentario parcial de esta, el cual dice: "De igual forma, se reglamenta la aplicación de los beneficios en materia de emprendimiento para empresas creadas por jóvenes menores de veintiocho (28) años tecnólogos, técnicos o profesionales de que trata la Ley 1429 de 2010” (18).

Precisamente uno de los hallazgos de este trabajo es que a pesar de un periodo prudente de implementación, el desconocimiento de la ley por parte de la población objeto es evidente así como el acceso a información o el interés por ella y la solución de esta problemática no se evidencia con el accionar de esta ley que tiene un enfoque empresarial, más que para los jóvenes.

\section{Fuentes de información}

\section{Fuentes primarias:}

Once Entrevistas que sirven para obtener información y tener acercamiento a las fuentes primarias quiénes brindaran conocimientos acerca del tema a tratar, realizadas a jóvenes de 18 a 28 años de edad que pueden ser beneficiados por la ley o pueden tener acceso a la misma a través de información divulgada en redes sociales.

La entrevista realizada fue estructurada con conocimientos previos y de acuerdo a la información que se necesitaría para conocer las percepciones de la población objeto. Con el fin de no distorsionar la población objeto de estudio, se entrevistó población que se encuentra entre estratos 3 y 4 , siendo un grupo elegido casi equitativo en esta clasificación económica de los hogares (6 personas de estrato 3 y 5 de estrato 4).

\section{Sobre las clases sociales, justificando la muestra poblacional:}

Las clases sociales tienen relación con varios conceptos como lo es clase, ocupación, status, estilo de vida, formación, lugar de vivienda, ámbito social, entre otras mediante los cuales se puede realizar estudios sobre esa estratificación social que caracteriza a las personas (19), mediante la cual, además, el ser humano hace parte de una sociedad y se consagra dentro de estos rasgos, para pertenecer y poder ser observado y estudiado y así realizar un enfoque sobre sus grupos y desde sus oportunidades y necesidades.

El tema de clases sociales se habla desde Marx y Weber, donde se encuentra que existen clase sociales como bajas, medias y altas, donde en las bajas se clasifican aquellas 
personas que cuentan con más necesidades como lo son los más pobres y altas quiénes cuentan con todo lo necesario para vivir. La media por otro lado, es conocida también como la población sándwich al encontrarse en el medio y no ser ni pobre, ni rico donde tiene necesidades, pero también tiene condiciones para solventar las mismas.

La clase social media nace como una de las "principales bases sociales" que promueven políticas desarrollistas y en gran medida en la composición y modificación de dichas políticas, donde además gracias a esta población se generó aumento de empleo público y movilidad social durante el desarrollismo latinoamericano (19).

Cabe precisar que como mencionó Giddens la población que se encuentra dentro de esta clase social, es toda esa población profesional y técnica que además ocupa cargos administrativos y comerciales. Esta clase social tiene en cuenta todas las cualificaciones educativas para la inmersión a los mercados laborales, la formación es prescindible para ocupar los cargos, pero además esta población es una población que se reconoce además por sus prácticas de consumo en las viviendas que son desarrolladas por estos sectores y que determinan/asocian un determinado reputación social (19) (20).

Según lo que menciona Giddens se puede afirmar que la población que se eligió para este trabajo, es esa población que quiere realizar inmersión al mercado laboral, donde quiere ocupar puestos según sus conocimientos, habilidades, experiencias, entre otros, que permitan mejorar sus condiciones de vida según lo adquirido.

Los estilos de vida de la población de estrato 3 y 4 en Colombia son particulares y vale la pena mencionar que los jóvenes cuentan con desigualdades estrechamente relacionadas con sexo, competencias, salarios, reconocimientos, privilegios (para quiénes tienen mejores condiciones), comportamientos, etc, y que además, es una población que encuentra fortaleciendo la formación para adquirir habilidades y poderse desenvolver en los diversos mercados esto con el fin de mantener su estatus social o mejorarlo. El estatus social se determina mediante las funciones/ocupaciones sociales desempeñadas por las personas, en este caso el grupo de estudiantes objeto de este trabajo que lo hace mediante la formación o capital humano, generando así una posición social, en particular a las ocupaciones que desempeñe. 
Se puede decir entonces, que las clases sociales se identifican por un conjunto de categorías socio-ocupacionales, que además dependen de niveles socioeconómicos sobre los cuales se establecen en la sociedad y se desarrollan en la misma (19) (21).

\section{Fuente secundarias:}

Se emplearon para el desarrollo de la investigación artículos científicos, periodísticos, informes, revistas, páginas web, libros, normas, los cuales deben ir relacionados con el tema de investigación.

Tratamiento de la información: Toda la información obtenida se manejó de forma cualitativa de tal manera que se permitió categorizar, sistematizar, jerarquizar, analizar e interpretar, para la de construcción de conocimiento a partir de saberes de experiencias frente al objetivo de este proyecto.

Aunque se eligió una muestra poblacional pequeña y los participantes no demostraron mayor interés, se obtuvo información que permitió un análisis y un resultado esperado según lo propuesto e investigado en este trabajo.

\section{Problema}

Existe una preocupación clara sobre la inclusión social de los jóvenes en los sistemas de protección social como se hacía anteriormente, es decir desde la lógica del aseguramiento (Primero con el aseguramiento del trabajador y luego del aseguramiento no solo del trabajador, sino también de su familia), como producto de la participación formal en el trabajo.

En la actualidad, la realidad que viven los jóvenes es una problemática de empleo que ha afectado la inmersión del mercado laboral de los mismos por diversos factores como los obstáculos para la contratación de jóvenes sin experiencia por parte de los empleadores, las deficiencias del mercado laboral colombiano, la informalidad y la flexibilización laboral producto de las reformas políticas de las últimas dos décadas. Adicional a esto las nuevas modalidades de contratación no permiten que los jóvenes se incluyan en el mundo económico y laboral por lo que tampoco acceden a la protección ideal, pues estas condiciones ya no existen. 
La determinación del Estado de desligarse de la protección de los trabajadores, dando paso a la protección individualista en un grupo etario que sufre enormemente en la inmersión del empleo agudiza esta situación. Pese a que se han hecho esfuerzos normativos para mejorar la empleabilidad de los jóvenes, como la Ley 1429 de 2010, dos factores no permiten valorar positivamente sus resultados. El primero, por ser una ley reciente su implementación no es completa y no se puede valorar sus impactos y segundo, se encuentra más en función de beneficio de los empresarios y la generación de empresas bajo la lógica del emprendimiento, que ofrecer oportunidades de inmersión de los jóvenes al mercado laboral.

Ante la ausencia de información sobre los resultados de la política en Colombia y teniendo en consideración que en otros países se han aplicado políticas similares sin resultados favorables, pero además sabiendo que el problema de empleabilidad para los jóvenes sigue vigente en nuestro país, es necesario conocer las experiencias de los jóvenes y sus conocimientos sobre el tema, de este modo se formula la pregunta: ¿Cuáles son las percepciones de los jóvenes universitarios con relación a los programas de emprendimiento propio de empleabilidad que se han generado en el marco de la política 1429 de $2010 ?$

\section{Factores determinantes del ingreso al mercado laboral}

Colombia cuenta con 48.613.657 personas, esta cifra según el reloj de población del año 2016 del DANE (22), además, de evidenciar un crecimiento de niños y jóvenes, hace pensar que, para finalizar el año 2016, la población tendrá un gran crecimiento, situación preocupante, puesto que, la cifra de personas que están en edad de laborar es muy elevada y se enfrentarán a una competencia laboral compleja.

Si bien, en Colombia hay un aumento en las cifras de desempleo, se reconoce también que existe aumento en la informalidad como último medio para subsistir en la sociedad de consumo. Es de resaltar el esfuerzo de las personas para formarse y capacitarse con el fin de poder integrarse de algún modo al mundo laboral formal, sin embargo, en el camino la mayoría se enfrenta con la escasez de oportunidades. Esto deriva en diversos problemas que podrían explorarse por medio de una indagación a quiénes viven la situación de la búsqueda de empleo; especialmente en Bogotá, donde se encuentra una población que experimenta posibles realidades relacionadas a este trabajo. A 
continuación se exponen una serie de factores que determinan el ingreso al mercado laboral (23).

El factor principal determinante al momento de ingresar al mercado laboral es la oferta de la fuerza de trabajo, el cual, en términos generales, se compone de tres factores: el tamaño y la estructura de la población por edad (fecundidad y mortalidad), la migración y las tasas de actividades específicas por edad, sexo, educación, entre otros; que están a su vez ligados con factores de carácter económico, social y cultural.

Con el fin de medir el empleo el Centro de Investigaciones Sociojurídicas de la Universidad de los Andes (Cijus) se necesita tener en cuenta 3 aspectos como las oportunidades de empleo existentes, donde se logra detectar si son suficientes para la sociedad en términos de cantidad y variedad, otro aspecto es la aceptabilidad de la remuneración como medio por el cual la persona se incentiva para realizar un trabajo y así poder mejorar sus condiciones de vida, para esto se revisan los indicadores como la tasa de pago inadecuado y la medida de la pobreza absoluta y el último aspecto y no menos importante, diría el más importante que sería las condiciones de trabajo, pues es importante tener un trajo decente, para medirlo de deben tener en cuenta la duración de las jornadas laborales, descanso, existencia de medidas de protección a la salud ocupacional, entre otros (7).

Por otro lado, como factor determinante se encuentra la clasificación de la población según criterios económicos, lo que permite abordar comportamientos y avances del mercado de trabajo y realizar comparaciones nacionales, además de asignar clasificación a las personas ocupadas según su actividad productiva, ocupación, niveles salarias, entre otros.

Como lo menciona el DANE (24), en Colombia la clasificación económica que se implementa desarticula la población, hasta el punto en que se puede reconocer su tamaño y estructura para definir la fuerza de trabajo. Este ejercicio es llevado a cabo semanalmente para trece ciudades y áreas metropolitanas y mensualmente a nivel nacional.

Dentro de dicho estudio se define que la población normalmente en edad de trabajar (PET), es el grupo de personas a partir de los 12 años y más en las zonas urbanas y de 10 años para las zonas rurales. Esta población se reconoce por ser económicamente 
activa o inactiva. Este grupo poblacional es conocido también como fuerza laboral y se conforma por personas que se encuentran en edad de trabajar o están en la búsqueda de empleo.

La población económicamente inactiva (PEI), se compone de los estudiantes, jubilados, rentistas, personas que no quieren laborar, etc. Los cuales se encuentran en edad de laborar pero que no necesitan, no pueden o no se encuentran interesados en conseguir una actividad remunerada (empleo).

Por su parte, como lo menciona el DANE (24), los ocupados (OC), son esa fracción de la población que se encuentran en alguna de las siguientes situaciones: trabajó como mínimo una hora remunerada en dinero o en especie a la semana, los que no trabajan la semana de referencia según se hacen los estudios pero que cuentan con un trabajo y trabajadores familiares que no reciben remuneración, pero que trabajaron en la semana de estudio por lo menos una hora. Mientras que los ocupados temporales (OT), son todas aquellas personas que realizan un trabajo esporádico. Trabajos temporales o por épocas o cuando tienen contrato hasta por un año.

Por otro lado, la población desocupada (DS), se caracteriza por encontrarse en un desempleo abierto, lo que se refiere a ese grupo de personas que se encontraban sin empleo en la semana que se hace el estudio; o en un desempleo oculto: quiénes no tenía empleo en la semana de estudio, pero que tenían un razón válida para justificarlo y disponibilidad.

De igual manera, la población desempleada recibe una clasificación, la cual se distingue de la siguiente forma: Cesante, es la persona que habiendo trabajado antes por dos semanas consecutivas, se encuentra desocupada y buscando empleo y Aspirante, es la persona que se encuentra buscando empleo por primera vez.

Para poder tener un análisis complejo y completo del comportamiento laboral, a continuación se definen ciertos elementos que son utilizados por el DANE para el estudio del nombrado fenómeno:

"El porcentaje PET, se define por el número de personas que conforman la población en edad de trabajar frente a toda la población total. La Tasa global de participación es la relación porcentual entre la población entre la población 
económica activa y la que se encuentra en edad de trabajar, es la presión de la población sobre el mercado laboral.

La Tasa bruta de participación por su lado es el indicador que muestra la relación porcentual entre el número de personas que integran la población total y las que componen el mercado laboral.

Por otro lado, la Tasa de desempleo se define por la relación de personas que están buscando empleo DS y el número de personas que hacen parte de la fuerza laboral (PEA). Se compone por: Tasa de desempleo abierto, Tasa de desempleo oculto. La Tasa de ocupación es definida igual que la anterior por la relación de dos factores como: la relación porcentual entre la población ocupada (OC) y la cantidad de personas que integran la población en edad de trabajar (PET). Por último, la Tasa de subempleo se define por la relación entre el número de personas que se encuentran subempleadas (S), y el de las personas que constituyen la fuerza laboral (PEA)” (24).

De acuerdo a los anteriores elementos, se permite conocer el comportamiento laboral de un país. El análisis del mercado laboral es de aclarar, se realiza de la misma forma que el de los bienes: interacción entre oferta y demanda. El mercado laboral, se diferencia de los demás mercados porque posee características que otros no poseen, como lo son: salario mínimo, se rige por una legislación que además ayuda a determinar horas extras, aportes a la seguridad social, derechos de los trabajadores, entre otros.

Lo anterior es importante cuestionar sobre los tiempos laborados para considerar cifras de empleo y desempleo en el país, pues una semana u horas laborales no determinan una estabilidad laboral, por lo tanto no podrían estar dentro del rango porcentual de datos estadísticos. Estos subgrupos de poblaciones que se emplean solo por tiempos cortos (horas, días, meses) deberían poder tener unos datos estadísticos diferentes que hagan sobresalir la problemática laboral del país. No se pueden seguir considerando ocupados quiénes tuvieron unos días de trabajo (remunerado).

Es importante mencionar que el estado de Bienestar como dice César Giraldo (25), se consolidó sobre asalaramiento, pero este ha venido cambiando; primero en la posguerra el trabajo material empezó a perder acción y se dio más fuerza al campo administrativo, hay un regreso de la precarización laboral y un aumento en el desempleo. Sin duda 
alguna y apoyando la idea de este autor, el primer logra brindar a las políticas algo acorde a lo que se propone y una organización en los sistemas, sin embargo, los otros dos lo que permiten es que la problemática de empleo en el país se acentúe, cosa que ha venido pasando en los últimos años, afectando sin duda alguna más a los jóvenes que se ven sometidos al ingreso y fortalecimiento del sector informal.

Lo que permite ser asalariado es obtener una individualización, método que quita responsabilidad sobre el Estado. "La individualización de las tareas impone movilidad, adaptabilidad, disponibilidad, lo que debilita el carácter colectivo del trabajo lo que trae como consecuencia un deterioro del pacto social sobre el cual se construyen los Estados de Bienestar" (25).

La nueva era laboral permite que tanto el Estado como ente regulador, como las empresas y empleadores no tengan responsabilidades sobre los trabajadores y los derechos que tienen, esto mediante las nuevas formas de contratación que se dan en el país. Los trabajadores en Colombia presentan grandes desigualdades que es lo que ha traído consigo estas formas de contratación, pues las necesidades son disimiles y no se puede tratar de poner a equilibrarse de la misma forma. El trabajador se ha visto desprotegido y se ve aún más en la población joven que se enfrenta a una problemática y una situación económica no estable.

Si bien se sabe es importante conocer sobre las percepciones que tienen los jóvenes, parte de las propuestas y empleos que se les están ofreciendo, pues aunque estas personas se encuentran en formación es de reconocer que no se les está brindando oportunidades dignas debido al problema de la individualización que menciona César Giraldo en su libro ¿Protección o desprotección social? (25), pues además de que no se les valora la capacitación, se les ofrece contrataciones que ya no tienen concordancia con el campo laboral, sino que se vuelven vendedores de sus servicios por tiempos y horas laboradas, permitiendo que esta población asuma cada uno de los riesgos como lo son riesgos profesionales, salud y pensión. En el caso de los jóvenes que deben someterse a trabajos informales quedarán sin protección para poder mitigar estos riesgos y de paso el gasto de recursos de la asistencia social. Pues si bien, pasan a ser más los del régimen subsidiado y la cotización pierde su poder adquisitivo, lo que no permitiría poder prestar una asistencia social por no contar con fuentes de financiación. 
Con estas nuevas concepciones de lo laboral y la individualización de este, nacen políticas para que las personas generen sus propias empresas y generen su propio bienestar, pero no es posible hacer esto cuando hay tantas diferencias en las necesidades de toda la población, por lo que se hace necesario abarcar este campo en cuanto que no toda la población desea crear empresa o tiene la capacidad de crear empresa para comenzar a competir con el mercado.

Es de saber que de acuerdo a esta problemática y las necesidades que tienen los jóvenes que se encuentran capacitando para mejorar sus condiciones de vida y ofrecerles garantías de derechos y de aseguramiento de riesgos; se les debe ofrecer trabajos formales y estables, pues la transitoriedad laboral en esta población, los salarios no dignos y poco equitativos, no permite mejoras y si acentúa las problemáticas.

Los jóvenes se están enfrentando a políticas que no determinan el tema a tratar, su contenido no coincide con el nombre, además, están destinados a esas políticas que no son universales; y que el primer empleo solo sea para quiénes van a emplearse por primera vez (aspirantes) y no para quiénes se emplearon una vez y no pudieron volver a conseguir, o que simplemente tuvieron que someterse a otros tipos de trabajos en condiciones paupérrimas.

Una de las hipótesis planteadas en este documento es, demostrar que la Ley de Primer Empleo específicamente en los programas de emprendimiento no están enfocados en solucionar la problemática del empleo juvenil, y tampoco ha logrado atracción y el interés de esta población para el conocimiento de la misma.

Este documento pretende analizar las distintas ideas que tienen los jóvenes profesionales de la capital colombiana acerca de los programas de emprendimiento impuesta por el gobierno con el objetivo de conocer si la ley pretende mejorar la situación actual de la población juvenil en cuanto a desempleo e informalidad existentes en el país.

Existe un problema grande en el mundo, América Latina y Colombia en específico, y es el desempleo juvenil que se encuentra asociado además, con otros problemas como: la población joven cada día busca mejorar su formación académica, la capital de Colombia, Bogotá sufre constantes migraciones que se da por diversos factores (desplazamiento forzoso, búsqueda de mejores oportunidades, estudio, entre otras), los derechos de empleo están desapareciendo, el Estado está dejando de lado las responsabilidades de 
garantizar los derechos laborales y protegerlos, en este caso mediante políticas individualistas (crear empresa, siendo algo universal sin considerar las necesidades y oportunidades de otros y contratación a población sin experiencia, brindando beneficios a las empresas que haga la contratación y dejando la responsabilidades de las personas contratadas a estas empresas). Sobre lo anterior existe desconocimiento por parte de los jóvenes y no existe mayor interés.

\section{Investigaciones relacionadas}

Para la realización de la investigación, se indagó sobre si existían investigaciones que impidieran la realización de esta o que tuvieran un acercamiento; se logró encontrar investigaciones que se acercaban a temas relacionados. Aunque no son temas iguales, son temas que tienen un acercamiento y que además son pertinentes para este trabajo. El tema de programas propios de empleabilidad de la política de primer empleo, es muy reciente, por ende información concreta sobre resultado o con mayor empatía no se lograron encontrar.

De acuerdo a lo buscado sobre estudios relacionado con este trabajo, se encontró una investigación hecha por María Alejandra Moya, IMPACTO DEL PROGRAMA "LEY DEL PRIMER EMPLEO” EN LA INCIDENCIA EN LA INFORMALIDAD Y EN EL SUBEMPLEO JUVENIL EN COLOMBIA (26) en el que aborda temas de informalidad, mercado laboral colombiano, problemática de afectación de la población joven al ingresar al mercado laboral. En este se encontró que el estudiar, no significa ingresar al mercado laboral con condiciones dignas (empleo formal) y que el ingreso a la educación cada vez aumenta más.

Se encontró algo relevante en sus resultados y es que:

“Las intervenciones estatales mediante políticas públicas son necesarias en el sentido que tienen que generar incentivos para que el acceso al mercado laboral sea más fácil y menos excluyente. Es así, como programas como la "Ley del Primer Empleo" que buscan reducir la informalidad mediante ciertos beneficios para las firmas, son útiles y sobre todo pertinentes para analizar el impacto que estas han tenido sobre el mercado laboral. De los resultados encontrados hubo una disminución de la tasas de informalidad en 4 años, como se deduce del análisis descriptivo. Por esta razón se quiso corroborar esta información 
mediante un análisis econométrico, el cual sugirió que esta disminución de las tasas de informalidad no fue por efecto de la ley como tal" (26).

Si bien, estos resultados se encontraron, dos años después del lanzamiento de la ley y antes de que el Ministerio de Trabajo lanzará su programa 40.000 Mil Primero Empleos. Es talento no palanca, sin embargo cinco años después de que la ley saliera y un año luego de que el programa comenzará a funcionar, los temas de precarización laboral, desempleo, informalidad, siguen siendo un tema de que hablar, pues los riesgos, siguen en riesgo valga la redundancia y son más pronunciados para la población sin experiencia y menos valorizada.

“Entre las limitaciones de este estudio se puede ver que este solo tiene en cuenta un momento en el tiempo ya que dos años después de la implementación de la ley es difícil observar un resultado positivo inmediato. Otras limitaciones se presentan en la base de datos, la gran encuesta integrada de hogares del Departamento Administrativo Nacional de Estadística colombiano (DANE), la cual no proporciona diferencia alguna entre los técnicos y tecnólogos en su encuesta y además presenta sesgo de selección frente a las personas que no tienen ningún nivel educativo o uno menor al terciario y que pueden ser informales o subempleadas" (26).

Y concuerdo con que la medición de la fuerza de trabajo y las leyes, deben ser ajustadas a la realidad del país. De acuerdo a esto, si se hace pertinente investigar las percepciones que tienen los jóvenes en relación a los programas de emprendimiento propios de las políticas de empleo, pues no se encuentra un estudio que sea igual a este trabajo, es de aclarar que el campo del empleo y en especial del empleo juvenil que es el más sufrido debe ser abordado constantemente y se debe buscar un acercamiento para poder cambiar los nuevos métodos de contratación que no generan una buena renta para el país y si crea más necesidades en la población.

Otro trabajo acertado y muy cercano para este trabajo es la investigación DILEMAS ACTUALES DE LA JUVENTUD FRENTE AL TRABAJO (27). Formas de inserción socio-laboral juvenil en Manizales (Colombia), el cual realiza aportes y además se acerca temas que se mencionan en este trabajo como: la población joven es la más afectada para conseguir empleo, el ingreso del mercado laboral al sector informal, los bajos ingresos y las condiciones deficientes en las contrataciones. 
Además de mencionar como se viene deteriorando el tema laboral, un ejemplo claro es la ley 789 de 2002, la que según la investigación representó altos costos para la sociedad respecto a la calidad de empleos, la disminución de la formalidad laboral y el aumento de la tercerización y la flexibilización. Esta ley disminuye beneficios para los trabajadores y se le dan más a la clase empresarial con la idea de mejorar la economía del país.

Luego la Ley 1429 de 2010 también genera más beneficios para los empresarios o nuevos creadores de empresas, más que para los trabajadores. Las leyes están siendo creadas para favorecer los grupos políticos y económicos como habla el trabajo aquí relacionado y que además los principales perdedores son los trabajadores y los jóvenes.

Además en este trabajo se refleja las diferencias socioeconómicas, el transito educativo al laboral como el más difícil y donde los jóvenes además comienza a tomar responsabilidades y habilidades y la educación superior vista como una forma de salir adelante y mejorar las condiciones de vida, mediante una inversión realizada y no vista como medio para perfilarse como lo verían personas con mejores condiciones económicas.

Algo que es necesario resaltar y es muy importante para este trabajo es lo que menciona una persona entrevistada en su trabajo: Uno no puede proyectar una empresa que no se proyecta con uno en el futuro" (Entrevista P08, hombre, 28 años) (27).

Es tan importante porque las leyes no pueden dirigirse a crear empresa cuando las condiciones de las personas son tan distintas y las proyecciones también.

\section{Objetivos}

Analizar las percepciones que construyen los jóvenes universitarios de Bogotá sobre los programas de emprendimiento propios de empleabilidad.

\section{Objetivos específicos}

1. Describir la cuestión laboral en el mundo, América Latina y Colombia.

2. Caracterizar la situación laboral actual de los jóvenes en Colombia.

3. Identificar las percepciones construidas por jóvenes universitarios en relación a los programas de emprendimiento propio de empleabilidad. 
4. Analizar el papel de divulgación que cumple el Estado y los medios de comunicación en la construcción de las percepciones de los jóvenes universitarios en relación a los programas de emprendimiento propios de empleabilidad.

\section{Justificación}

Según el Sistema de Información de Juventud y Adolescencia de Colombia (JUACO) (28), la cifra de jóvenes en la ciudad de Bogotá es de 1'943.119. Este grupo poblacional se encuentra en constante crecimiento, no solo en Bogotá, sino en todo el país, por lo que se hace importante hablar sobre empleo y desempleo y relacionarlos con el tema de empleabilidad el cual es reciente en Colombia y se apoya en la Ley 1429 de 2010. Dicha norma está enfocada en el crecimiento empresarial de pequeñas y medianas empresas, y no enfatiza, ni específica las garantías de los trabajadores beneficiarios.

Se busca obtener una idea acertada sobre la línea de la política de emprendimiento y las percepciones que tiene los jóvenes universitarios con relación a los programas propios de empleo; además de la búsqueda, revisión de fuentes y medios que se encargan de divulgar información sobre el tema de emprendimiento y dar conclusiones sobre lo propuesto.

Es necesario plantear un análisis que evidencie y permita demostrar las falencias existentes en la construcción de los programas de emprendimiento propios de las políticas de empleo y como esto se ve reflejado en las percepciones que pueden estar creando los jóvenes y las necesidades de los mismos, la posible precariedad en la divulgación de la información y las relaciones con el trabajo como derecho fundamental; derechos y necesidades que necesitan ser abarcadas, para brindar un reconocimiento a estas debilidades y poder fortalecerlas, de tal modo que se permita una mejora en la sociedad.

Es necesario para la protección social estudiar el campo del empleo y sus problemáticas, las percepciones que existen sobre el tema, el crecimiento de la población y la juventud que se encuentra en edad para acceder al mercado laboral como presente y futuro de la sociedad, con el fin de detectar los posibles problemas que abarcan las nuevas propuestas de los gobierno y la necesidad de crear ideas, proyectos, iniciativas que permitan mitigar estos efectos negativos del país. Pues el encontrarse desempleado, 
genera gastos al país y requiere de subsidiar y ayudar a la nueva población que se encuentre en afectación económica, social y cultural. El caso del desempleo tanto en América Latina como para Colombia según datos no demuestra tener una solución cercana.

Las cifras son preocupantes en cuestión de empleo, según el artículo Empleo informal se ubicó en 47,2 \% en el último trimestre de 2015 (29), las cifras de desempleo juvenil para el año 2015 se ubicaban en un 15,3\%. Adicionalmente, Según el Observatorio de Desarrollo económico, la cifra de desempleo para el primer trimestre del año se encontraba en $16,8 \%$ en la ciudad, pero si se revisan algunas otra fuentes como la anterior del tiempo han "bajado estas cifras" de desempleo y además publican que esto "se debe a la Ley 1429 de 2010". Como lo expresa Dimas:

"La tasa de desempleo juvenil en Bogotá es la quinta más baja en el país al compararse con las 13 ciudades principales y es mucho menor con respecto a los registros de desempleo juvenil en ciudades como Medellín (18,2\%) y Cali $(18,4 \%)$.

A su vez, se observa que, para las personas de 29 a 45 años la tasa de desempleo fue de $8,1 \%$, presentando un aumento de 1,3 puntos porcentuales respecto al mismo periodo del año anterior. Para el rango etario de personas con más de 46 años, la tasa de desempleo se ubicó en 6,9\%, con un incremento de un punto porcentual respecto al mismo periodo de hace un año.

Otros indicadores del mercado laboral juvenil evidencian que la Tasa Global de Participación (TGP) fue de 68,4\%, disminuyendo 1,8 puntos porcentuales respecto al mismo periodo del año anterior. Así mismo, la Tasa de Ocupación (TO) presentó una caída anual de 3,9 puntos porcentuales, ubicándose en $56,9 \%$.

Por ramas de actividad, el sector comercio presentó una reducción de 12,4\% con relación a los jóvenes ocupados durante el mismo periodo del año anterior. De igual forma, cayó el empleo juvenil en sectores como los servicios (-16,9\%), actividades inmobiliarias (-5,1\%) e industria (-15,1\%) (30). 
Como complemento, del total de desocupados cesantes en la ciudad en este periodo (439.130), donde el 58,9\% son mujeres y el 41,1\% hombres.

En cuanto a sectores económicos, el comercio al por menor, las actividades de servicios sociales de salud y las actividades de restaurante y hoteles, fueron los que más aportaron al aumento de los cesantes de un año a otro en la capital".

Frente a lo anterior, queda en el aire un cuestionamiento, el cual señala que, si estas son las cifras, ¿cuáles datos son más precisos y reales cuando estos cálculos varían de acuerdo a las ocupaciones que tienen las personas, sin importar el tiempo que laboren o lo días? ¿Hay interés por parte del gobierno y del Estado dar solución a la problemática laboral juvenil? ¿El tema de laboral es importante para toda la sociedad en general?

Tiene pertinencia este trabajo, en cuanto a que no existen investigaciones cualitativas similares que tengan en cuenta las percepciones de los jóvenes frente al empleo y el programa de emprendimiento que es muy reciente, tiene un poco más de un año de haber salido a la luz: 40.000 primeros nuevos empleos, es talento no palanca, promovido por el Ministerio de Trabajo.

\section{Marco Teórico}

El bono demográfico de la población joven en Colombia se muestra en aumento, situación preocupante, ya que en unos años se dará un crecimiento de población de tercera edad, que deberá contar con aseguramiento de salud y pensión como mínimo para solventar sus necesidades. Por tanto, el tema de empleo en Colombia se hace pertinente y necesario. Se requiere interés por parte del gobierno, instituciones educativas, sociedad e industrias sobre la población joven y se deben enfocar políticas que estén dirigidas a presentar proyectos que aumenten el empleo y generen condiciones dignas para las personas a lo largo de todo su ciclo vital.

Para abarcar la de protección social es necesario no solo tener en cuenta los riesgos a los que se enfrentan las personas, sino que es de gran importancia reconocer que más allá de esto, este concepto tiene en cuenta dimensiones como política pública la cual pretende integrar medidas que garanticen niveles básicos de vida para todas las personas y la construcción de sociedades que se desarrollen más justas e inclusivas. Mediante 
esta política social se permite promover derechos sociales que ayudan a mitigar la pobreza y combatir las desigualdades.

Este concepto permite además como menciona Simone Checchini en Protección social con enfoque de derechos para la América Latina del siglo xxi (31), detectar elementos centrales que se asocian con el enfoque de derechos permitiendo realizar evaluación a las políticas públicas donde se incluye la igualdad y no discriminación, participación ciudadana, transparencia, rendición de cuentas, entre otras; teniendo en cuenta que es mediante estas características que se permite detectar lo que afecta la inversión social y el manejo correcto de los recursos para obtener lo que se desea en términos de bienestar.

"En particular, la protección debería garantizar un nivel de bienestar suficiente que posibilite sostener niveles de calidad de vida considerados básicos para el desarrollo de las personas, facilitar el acceso a los servicios sociales y fomentar el trabajo decente (32)." (33)

Con el fin de mejorar estos efectos el Estado debe hacer intervención, más desde lo público y su responsabilidad asumiendo y adoptando medidas que tengas fuertes impactos sobre lo que la población requiere para enfrentarse de manera positiva sobre las diversas adversidades, entre esto se hace necesario inversiones en: capacitación, salud, entre otras, que permitan que el ser humano viva bien y promueva su buen vivir para afrontar las diversas eventualidades.

Sin duda alguna, lo anterior depende de cómo se generen las políticas y de aquí es necesario entender la importancia de los derechos tanto sociales, como económicos, además de contar con la experiencia propia del país para la construcción de las mismas, que sean políticas no solo de períodos de gobierno las cuales puedan modificarse y ajustarse con una intervención participativa de toda la sociedad en general y de temas concretos que permita tener en cuenta las nuevas ideas, referentes, propuestas, personas, apoyo financieros, etc., y de esta forma intentar resultados sobre las necesidades del país, haciendo inversiones que demuestren cambios positivos a las necesidades que enfrenta el país.

No se puede seguir acogiendo políticas, leyes, normas, entre otros que no dan solución a la problemática y es así como se recae en dificultades y mal uso de recursos que se destinan a la solución a las necesidades existentes en el país (31). 
Invertir en los social no solo tiene que ver con el enfrentamiento y solución de crisis en condiciones de vida de los ciudadanos, también requiere la creación de estrategias que promuevan el bienestar y las condiciones económicas de todas las personas en la región, además, como política social se requeriría que la construcción de estas nuevas propuestas sean universales, este último concepto basados en que todos tenemos derechos (31).

Desde el punto de vista de (31), "El enfoque de derechos en la protección social implica que las políticas públicas deben tener por objeto facilitar un mayor disfrute de los derechos económicos y sociales de toda la población, basándose en las normas y los principios de derechos humanos consagrados en constituciones, leyes y tratados internacionales".

En la etapa juvenil el concepto de la protección social se traslada a la importancia de los roles que comienzan a asumir estas personas, los cuales se definen así: "la salida al sistema educativo, el ingreso al mercado laboral, el abandono del hogar de origen, la formación de pareja y el inicio de la fase reproductiva o tenencia del primer empleo" (33). Es obvio, que estos tipos de roles que asumen las personas, son obtenidos en procesos de vida, donde no cuentan con experiencias previas, quedando así en desventaja, pues estos amenazan a la población que debe asumir papeles de manera individual y enfrentarse ya sin apoyo y atención de la familia, en muchos casos convirtiéndose esta última en invisible o poco perceptible, dando fin a la protección de riesgos a los que se tenían acostumbrados en ciertas etapas de la vida, riesgos que comienzan a caer en manos del Estado y del mercado (laboral).

Las vulneraciones en este grupo etario difieren de las diferencias socioeconómicas y esto porque no todos pueden acceder de la misma forma a la educación y al empleo, no todos cuentan con las mismas oportunidades y no todos están preparados a enfrentar las diversas problemáticas que deben enfrentar en los diversos campos, más las económicas que las sociales. La población joven aunque es una población con mayor educación, es la población con menos oportunidades de ingreso al mercado laboral y a un trabajo decente con garantías. Se necesitan protección de derechos tanto económicos y sociales en esta población, población que se encuentra en edad activa, que se le permita poder enfrentar riesgos y se le reconozca su existencia como personas de derechos. 
Cabe mencionar que los conceptos de empleo y de trabajo difieren. Según el libro Actividad, empleo y desempleo. Conceptos y definiciones (34), el trabajo es la actividad humana mediante la cual el ser humano produce bienes o prestación de un servicio, con el fin de satisfacer las necesidades, es decir es la actividad que requiere esfuerzo físico o mental que desempeña un ser humano. Como menciona Pierre Rosanvallon (2) el trabajo es el medio por el cual el hombre puede vivir e insertarse en una sociedad, a diferencia del empleo que es mediante el cual el ser humano obtiene un ingreso económico, encontrándose en calidad de asalariado, sin importar si lo hace de forma independiente. Es entonces mediante el empleo que el ser humano ingresa al mundo laboral (34).

En el caso de los jóvenes, estos pueden acceder a mercados laborales dignos y con las mejores condiciones, se deben considerar sus problemáticas, necesidades y aspiraciones para poderles brindar mejores oportunidades. Bajo este orden de ideas, no se les puede considerar un subgrupo sin capacidades. Es importante que a la nueva generación se les brinde la oportunidad de adquirir experiencia, ya que de esta manera pueden aprender o reforzar el conocimiento de un oficio. Frente a esto, la CEPAL determina la importancia de la población joven:

"La juventud adquiere relevancia al considerarse las demandas específicas de cada subgrupo etario. Por ejemplo, entre los más jóvenes es mayor el porcentaje que estudia y no trabaja, o que busca su primer empleo, mientras que el segmento de más edad es mayor la proporción de los que ya han ingresado en el mercado laboral y luchan por conquistar su autonomía material, y que han constituido o están en vías de establecer su hogar propio” (35).

Es significativo conocer las percepciones que tienen los jóvenes sobre el tema laboral, en cuanto no hay duda que esta población se encuentra en alto riesgo económico por las escasas oportunidades laborales con las que cuentan, tema crucial para permitir un desarrollo de la sociedad.

Para Esta tesis también es importante definir lo que se asumirá como percepciones. Las percepciones según Schiffman y Kanuk en el documento, el proceso por el cual una persona selecciona, organiza e interpreta los estímulos de tal forma que pueda crear una imagen con significado y que además sea coherente para el mundo (36). 
Además según el documento Sobre el concepto de percepción, se encuentra que "En el proceso de la percepción se ponen en juego referentes ideológicos y culturales que producen y explican la realidad y que son aplicados a las distintas experiencias cotidianas para ordenarlas y transformarlas.

Es importante además decir que para la percepción el reconocimiento es un elemento importante, pues mediante este se permite traer a memoria experiencias y conocimientos antes adquiridos con los que se podrán comparar las nuevas experiencias y conocimientos. Es preciso decir que las percepciones van ligadas a las experiencias del entorno de los seres humanos y mediante las cuales se pueden relacionar y reconocer su significado (37).

Por último es importante ver y reaccionar de acuerdo a la Ley 1429 de 2010: Formalización y Generación de Empleo, desde el punto de empleabilidad. Estos beneficios se dan con la eliminación de algunos trámites laborales y comerciales, pago progresivo de impuestos, descuentos parafiscales y descuentos en el registro mercantil (38).

El trabajo, el empleo, las percepciones y la protección social, sin duda alguna se encuentran relacionados, todas se ven afectadas en su relación. Sin experiencia, no puede ofrecer trabajo para conseguir empleo y entraría a ser sujeto vulnerable, esto genera costos adicionales al país, pues se deben brindar garantías para sobrevivir en la sociedad.

Se sabe que ya las responsabilidades de derechos laborales no están recayendo sobre el Estado, entonces quién se hará cargo de esta problemática que afecta a todo el país desde el ámbito social, cultural y sin duda alguna el más importante, el económico. Puesto que, los efectos negativos pueden ser que las contrataciones se hagan por los beneficios más que por las personas que entran a capacitarse. Además es importante mencionar que las necesidades de los jóvenes son otras y que la reducción de costos para mejorar los sectores económicos, no son lo mismo que crear empresas. Impulsar empleo no es recargar de alguna forma la problemática a la empresa, impulsar el empleo requiere de investigaciones profundas y nuevos mecanismos para solventar las necesidades, a partir de la experiencia propia del país. 
Por último, un eje central en este trabajo es la informalidad, que si bien ha demostrado por años se ha dado un amplio espacio en el campo laboral casi que para competir con la formalidad entregando a los trabajadores salarios bajos, inestabilidades, pocas oportunidades de avances, entre otras tantas características que fortalecen este sector.

El nacimiento del concepto "sector informal" como lo menciona la OIT en Informalidad, Calidad del empleo y segmentación laboral en Argentina (39) fue creado por Hart en la década de 1970 mediante el cual hacía referencia a unidades de baja productividad, denominando así que las economías de menor desarrollo el problema no se basaba en el desempleo, sino en lo que tenían los trabajadores, explicando que así estando empleados sus salarios eran muy bajos y esto por la escasa productividad laboral.

La informalidad en América Latina es una característica estructural de la economía, que ha ejercido presión y muestra preocupación desde 1980 en Europa Occidental como menciona la OIT, esto debido a las nuevas modalidades de contratación que llaman “formas atípicas" de empleo que generar la precariedad laboral trayendo consigo este concepto inestabilidad laboral, control de salarios, condiciones laborales, seguridad social no cubierta, despidos injustos, etc., volviendo así más vulnerables a quiénes no tienen acceso a una economía estable. Las reformas laborales en América Latina son las que han dado paso a la flexibilización laboral esto desde finales de 1980 y comienzos de 1990 creyendo que con estas nuevas modalidades la competitividad laboral mejoraría.

La OIT refiere de la informalidad laboral que esta puede ser visualizada desde 2 perspectivas, la primera que tiene que ver con la "lógica de la supervivencia" constituyendo dentro de esta la "presión de excedente de mano de obra por empleo", donde los más necesitados o quiénes no logran hacer inmersión al mercado laboral deben ingresar si o si y la segunda tiene que ver con la "descentralización productiva", en la que se encuentra una demanda más inestable en la estrategias de adaptación de las empresas donde se puede dar más olvido a las obligaciones laborales. Como sea, cualquiera de estas dos acoge poblaciones vulneradas, donde ayudan a generar más necesidades entre los más necesitados y abre campo a quienes quieran integrarse a este sector por la poca oportunidad que existe dentro del mercado laboral.

Es de resaltar que los países en desarrollo se encuentran en vísperas de crecimiento informal, de fortalecimiento del sector y esto es porque es este sector quién abre las 
puertas laborales a personas que no logran hacer inmersión al mercado laboral como lo menciona el informe VI El trabajo decente y la economía informal (40).

Los empleos en las nuevas modalidades de contratación sin duda alguna no pueden destacarse como empleos decentes y muchos menos todos aquellos empleos informales, donde no hay garantías de derechos laborales, estabilidades, protección ante riesgos y una economía estable para el trabajador con reconocimiento de un sueldo digno. Entre estos trabajadores se encuentran los vendedores ambulantes, trabajadores de servicios generales, domiciliarios, trabajadores independientes, entre otros. Se denominan trabajadores informales por estar protegidos por marcos jurídicos, reglamentarios y sociales.

Las Tecnologías de la Información y de las Comunicaciones (TIC) tienen una importante relación en la flexibilización y la informalidad pues por estas se ha cambiado la organización laboral, permitiendo eliminar puestos de trabajo y las estructuras de empleo (oficinas) para así dar lugar a una individualización laboral donde se puede responsabilizar de asignación de tareas especializadas desde la comodidad de la casa, sin el cumplimiento de una jornada laboral.

Las personas que se encuentran dentro de este sector difícilmente logran obtener acceso a propiedad privada, a la formación y muy seguramente estarán endeudados con el fin de realizar acceso a algunas necesidades básicas, porque la población más pobre y vulnerada es la que se encuentra en dentro de este sector y más las mujeres por el problema de inequidad de género que se vive en el mundo. 


\section{CAPÍTULO 1. CONTEXTO DEL EMPLEO: MUNDO, AMÉRICA LATINA Y COLOMBIA}

\subsection{El empleo juvenil en el mundo}

Constantemente los países presentan altibajos económicos, frente a los cuales se ven obligados a generar planes que permitan solventar las diversas necesidades que afrontan los sectores económicos y sociales. Implicación que se hace más fuerte cuando se reconoce que debe existir una organización del trabajo.

Esta fue notoria y efectiva en la época de la industrialización, reflejando a partir de la misma un fuerte cambio en la distribución de la clase obrera tradicional (41). Un ejemplo claro para entender la organización del trabajo en ese momento, es la película de Charles Chaplin, titulada: Tiempos modernos (42). El fuerte predominio de los sindicatos es inherente a la época, siendo enérgica lucha por la adquisición de los derechos de los trabajadores, además de la inserción laboral de la mujer. 
En Colombia y en el mundo capitalista en general, los temas sociales, políticos, ambientales y hasta de los económicos, adquieren gran centralidad al valorar las acciones de una sociedad:

Es importante mencionar que para el tema laboral "El Estado desempeño un papel fundamental en la reestructuración del viejo capitalismo posbélico para favorecer a las fuerzas del mercado como rectoras del proceso de acumulación de capital. Cumplida esta tarea, la lógica de la acumulación y las políticas del Estado y del capital implementaron, mediante reformas neoliberales, la reestructuración productiva y la flexibilización de la fuerza de trabajo. La gestión de ésta última dejó de depender cada vez más, en cuanto a derechos, prestaciones y dinámica salarial, de la gestión directa del Estado, para pasar a gravitar en torno de las políticas empresariales en representación directa de los intereses estratégicos del Fondo Monetario Internacional, del Banco Mundial y de las corporaciones multinacionales" (43).

Cabe recordar que el empleo nace como un medio a partir del cual el ser humano puede generar bienes con el fin de conseguir alimento, obtener objetos o satisfacer necesidades y así subsistir en una sociedad, desde mucho antes en que se organizara el trabajo.

Es de reconocer que en épocas anteriores bajo el modo de producción esclavista, las condiciones de trabajo eran inhumanas, sin embargo, el sistema se fue transformando. Lo modelos económicos fueron integrando diversos modelos de producción en la época de la industrialización, pese a esto, se vio la necesidad de buscar un estado de bienestar con el fin de generar un mecanismo de protección para los empleados, que luego se ampliaron para cubrir a toda una familia.

Los primeros avances respecto al tema surgieron en Alemania a inicios del siglo XX, con la adopción de la seguridad social, buscando la protección de la vejez y el "seguro a la enfermedad", además de mantener estable la economía del país. Este programa fue diseñado por Otto Von Bismarck y fueron incluidos poco a poco en diversas regiones del mundo. Luego de la Primera Guerra Mundial, la protección es acogida por instituciones internaciones como la Organización Internacional del Trabajo (OIT) (44).

Para el año 1941, en plena Segunda Guerra Mundial, Lord Beveridge crea el Plan que lleva su nombre, el cual originó un nuevo modelo de seguridad social en Inglaterra (44), 
y logró la inserción de la totalidad de la sociedad al mercado laboral, protegiéndose así de los diversos riesgos económicos existentes, frente a la vejez, el desempleo y la salud.

Sin embargo, estas protecciones se han ido debilitando recientemente, de modo que en el siglo XXI los jóvenes en el mundo deben enfrentarse a una crisis estructural del desempleo, que si bien intenta ocultarse tras cifras de aumentos de empleo, es claro que las cifras de desempleo son más elevadas y que existe una problemática reconocida por todos los gobiernos y por la academia. Como lo refirió Robert Castel, (45) aún no hay un camino claro para dar solución a esta situación a nivel mundial. Todo lo anterior, encaminado a trabajos formales y de calidad; es necesario referenciar que en diversos países, el sector informal se está impulsando fuertemente, más que el formal. Una muestra del desempleo corresponde a la Gráfica 1, que además visibiliza el movimiento del desempleo juvenil y la tasa del mismo:

\section{Gráfica 1. El desempleo mundial juvenil, 1995-2015}

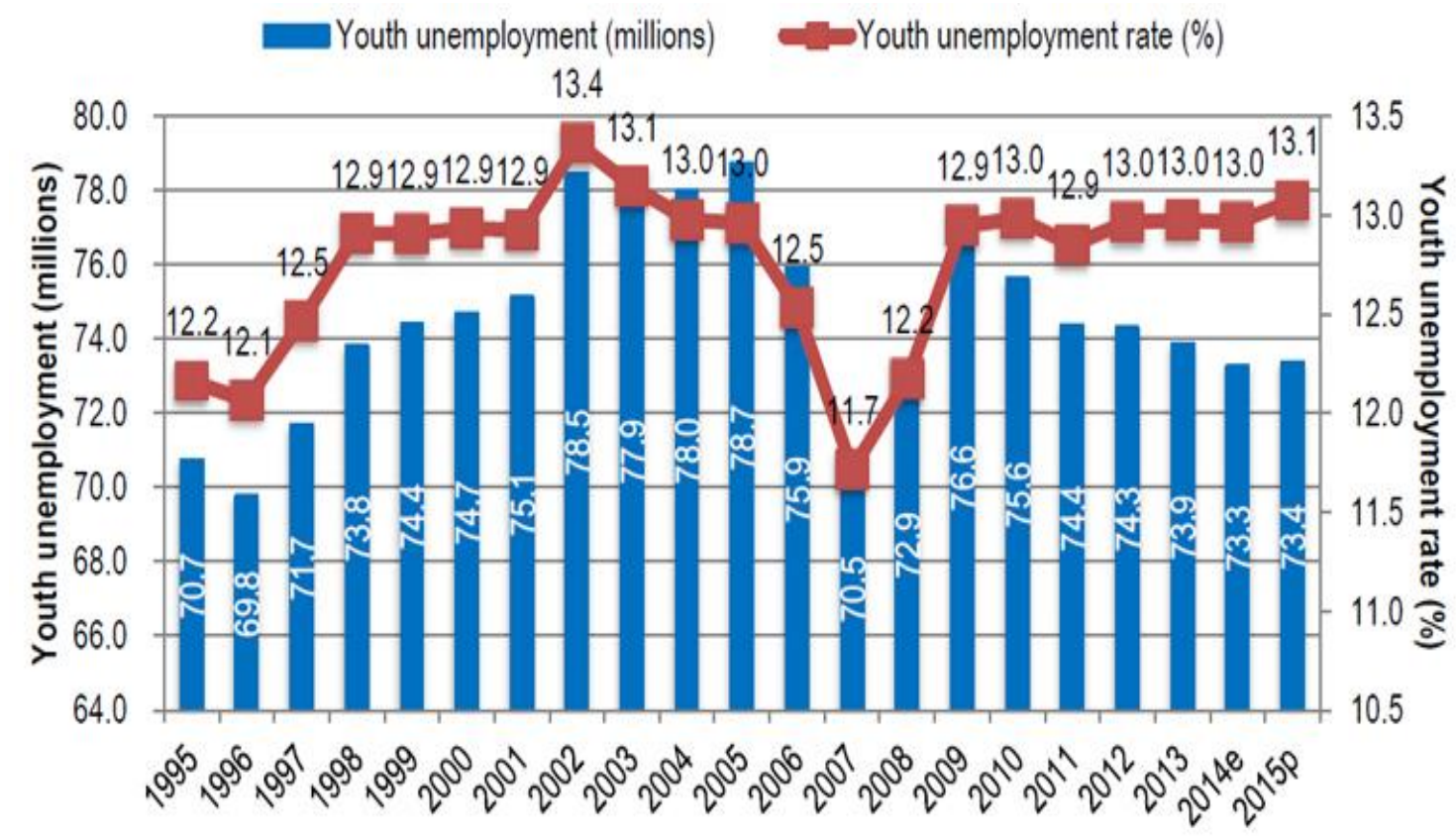

$\mathrm{e}=$ estimate $; \mathrm{p}=$ projection

Source: ILO, Trends Econometric Models, April 2015

Tomado de: Organización Internacional del Trabajo (46)

Según la Organización Internacional del Trabajo (OIT) (47) "La crisis del empleo juvenil se atenúa, pero está lejos de terminar", aún si los jóvenes se preocupan por formarse, el mercado sigue siendo igual de complejo como se ha venido dando por años; 
más aún para los jóvenes que tienen menores condiciones económicas, pues quiénes cuentan con una buena condición económica en su familia no deben enfrentarse a tantas necesidades, como tampoco tienden a ver la educación como una manera de salir adelante y mejorar su condición social.

Una gran problemática mundial es que muchos jóvenes se están capacitando, mientras que, los jóvenes de bajos ingresos están renunciando a estudiar con el fin de integrarse más temprano al mercado laboral; he aquí, un factor de la problemática, el cual se puede agravar debido a la ausencia de oferta laboral. Es por esto que los sistemas de protección social se crean enmarcadas de acuerdo a las diversas necesidades que tienen este grupo etario en el que no solo trabaja como política pública para mejorar el tema de empleabilidad en esta población, sino que se tienen en cuenta otros factores que determinan su estructura y sus necesidades. El Estado trabaja por cuatro (4) pilares para esta población según Cecchini: 1. Provisión de bienes y servicios para la atención de la salud, específicamente la salud sexual y reproductiva, 2. Protección de ingresos (mediante transferencias) de las familias con adolescentes y jóvenes para estimular su permanencia en el sistema educativo o favorecer el acceso al mercado laboral sin que este se presente tan ausente, 3. Políticas educativas que van dirigidos a los jóvenes y 4. Políticas dirigidas a la inserción y oportunidades de empleo para esta población (33).

Muchas condiciones de trabajo e ingresos laborales en el mundo en desarrollo son paupérrimas si se comparan con los existentes en los países desarrollados, ya que las necesidades básicas no se logran cubrir, por lo que es necesario, según lo mencionado en la OIT:

Ofrecer a los jóvenes una mejor oportunidad de acceder a un empleo decente implica invertir en educación y formación de la mejor calidad posible, proporcionando las competencias que corresponden a las exigencias del mercado laboral; acceso a la seguridad social y servicios básicos, independientemente del tipo de contrato, y garantizar la igualdad de condiciones de manera que todos los jóvenes que buscan trabajo puedan encontrar un empleo productivo sin importar su género, nivel de ingresos o procedencia socioeconómica (47).

Sin duda alguna, un factor que influye en la problemática del empleo es la forma en que se desarrollan las políticas en los países, donde sus enfoques están dirigidos a favorecer 
solo algunos de los sectores económicos que solo benefician a unos cuantos. Como se menciona en el artículo, "La falta de empleo es ahora un problema mundial del Banco Mundial" (48), las políticas pocas veces van encaminadas a favorecer a la totalidad de la sociedad, lo cual evidencia la necesidad de desarrollar políticas públicas que tengan como objetivo primordial los derechos y las garantías dignas de las personas futuras a emplearse, en este caso visto desde el primer empleo que presenta una crisis a nivel mundial.

Para la construcción de las políticas públicas, se necesita trabajo direccionado por el Estado de acuerdo a las necesidades, que estas no sean solo de Gobierno, pero que además involucren a toda la sociedad, sociedad que es garante de derechos.

Es evidente, que la problemática mundial de desempleo en los jóvenes, se ha vuelto estructural en todos los países, pero cuenta con particularidades de acuerdo a los contextos nacionales y a los niveles de desarrollo. Los jóvenes en este siglo son más propensos que los adultos a estar desempleados, como se menciona en el artículo, el Empleo Juvenil de la OIT en el programa para la justicia social y una globalización equitativa (49). Esto se debe a la autonomía que asumen al tener que asumir sus propios riesgos, sin ninguna experiencia para hacerlo y sometiéndose a cambios inesperados, que los hacen insertarse a una sociedad de mercado y de políticas sobre las cuales deben re direccionarse.

\subsection{El empleo juvenil en América Latina}

Si bien, el mundo enfrenta situaciones de desempleo juvenil, Latinoamérica, en específico, no se queda atrás. Es claro que esta región cuenta con países en vía de desarrollo, donde la economía y sus balances no son estables, además de las diversas problemáticas internas que existen en cada caso en específico.

Lo anterior introduce una gran dificultad para que los jóvenes puedan insertarse en el mercado laboral latinoamericano, puesto que, la demanda de jóvenes en busca de un empleo formal sobrepasa la oferta de empleo, sin contar la población mayor que también se encuentra con la misma necesidad.

La juventud de los países en desarrollo según el Banco Mundial "conforman el segmento de mayor crecimiento de la población mundial, pues más de la mitad de los 5.000 
millones de personas que viven en estos países son menores de 25 años", por tanto no solo esta población "es futuro, sino también el presente" (50).

Pero además, los jóvenes no solo se caracterizan por ser una población en crecimiento, sino que en temas de empleo son las que más se enfrentan a las crisis de desempleo, a

Condiciones inseguras, sin protección social, con bajos ingresos y sin representación adecuada. Se resalta que los jóvenes están bajo presión creciente de competir en mercados globalizados, y que períodos prolongados de desempleo o de informalidad e inestabilidad laboral pueden llevarlos a una exclusión social permanente (51).

Un aspecto importante sobre la problemática en Latinoamérica, es el acceso a la educación y a la capacitación. La formación académica ha generado espacios de ascenso social, que facilitan el acceso al conocimiento para poder tener oportunidades dentro de la competencia por la inserción al mercado laboral; donde antes eran pocos los que iban detrás de una vacante, pero hoy en día ha aumentado la cifra. La capacitación frente a la demanda laboral es muy importante, sin embargo, "La enseñanza está profundamente estratificada en América Latina, situación que no corrige sino que perpetúa las desigualdades de ingreso" (52).

Otro aspecto influyente en la problemática laboral en Latinoamérica se refiere al gran índice de deserción escolar y universitaria, puesto que los jóvenes van solo en busca de obtener ingresos económicos sin un mayor esfuerzo académico. No obstante, cabe aclarar que no siempre se renuncia a estudiar por gusto a la generación de ingresos, sino por necesidades como cubrir gastos de riesgos que se comienzan a asumir desde temprana edad como la canasta básica familiar que en muchas ocasiones no pueden ser cubiertas por una sola cabeza del hogar, también por la necesidad de cubrir gastos de embarazos prematuros, o el caso de la población que le gusta permanecer inactiva, temas complejos en el desarrollo de una sociedad donde se busca igualdad, equidad y bienestar para todos (53).

Hay que reconocer también que los gobiernos y las acciones de los gobernantes en muchas ocasiones no permiten avances que traten la problemática del acceso al mercado laboral, ejemplos claros son Venezuela y Colombia. En Venezuela se evidencia el conflicto político entre chavistas y opositores, una gran incertidumbre política, además 
de una emergencia económica y cierres de pasos fronterizos con Colombia. Lo que puede dar paso al aumento de desempleo (54).

Por su parte, Colombia, enfrenta un conflicto que involucra un sinfín de actores sociales, entre los que se encuentran los grupos al margen de la ley que controlan regiones enteras y despojan de sus tierras a millones de personas. De igual manera, se evidencia un problema de corrupción en el poder político, el cual influye negativamente en la formulación de las directrices de políticas y leyes, las cuales deberían estar enfocadas a solucionar las problemáticas sociales, como ocurre con la corrupción en salud. Los recursos económicos del país se están desviando y quiénes administran los mismos se están favoreciendo, como es el caso del carrusel de las ambulancias con el llamado "paciente SOAT", por el cual buscan beneficios económicos en la prestación de un servicio, poniendo vidas, saltando todos los procesos para la atención de las personas y poniendo en peligro con traslados a instituciones que les conviene.

Se necesita actuar frente a las problemáticas existentes en los países, que sí bien son diversas hay que trabajar en ellas y presentar soluciones efectivas para cada caso en específico. Esto desde un enfoque de derechos que tenga en cuenta las diferencias que existen en los grupos etarios y las diversas necesidades de los mismos. Para esto se necesita una involucración activa de todos los entes (personas, mercados, instituciones) para así efectuar cambios de políticas de acuerdo a las experiencias vividas dentro del país, de esta forma se educa también a una población garante derechos sobre las realidades existentes del país.

En el caso del empleo, es necesario revisar las problemáticas de cada país y accionar planes de acuerdo a las experiencias propias de cada uno. No se pueden seguir trayendo planes que se crearon y se experimentaron en otros países y que no mostraron soluciones efectivas. Es preciso mostrar nuevas cosas a la sociedad con efectos positivos frente a la problemática del empleo, en especial la problemática del empleo juvenil.

En este apartado se ha evidenciado cómo los jóvenes constituyen un grupo poblacional con serios problemas de inserción en el mercado laboral. Particularmente aquellos que sufren una integración desfavorable en este ámbito, pues componen una parte significativa de la población en situación de riesgo de exclusión social (53). 


\subsection{El empleo juvenil en Colombia}

La población joven total en el país actualmente es de 12.735.084 personas, donde 6.502.996 son hombres y 6.232.088 son mujeres (55). La población joven es definida en Colombia por la misma Ley Estatutaria en el Título I, Artículo $5^{\circ}$ como: "Toda persona entre 14 y 28 años cumplidos en proceso de consolidación de su autonomía intelectual, física, moral, económica, social y cultural que hace parte de una comunidad política y en ese sentido ejerce su ciudadanía" (15). Y define de la misma forma las juventudes como el:

Segmento poblacional construido socioculturalmente y que alude a unas prácticas, relaciones, estéticas y características que se construyen y son atribuidas socialmente. Esta construcción se desarrolla de manera individual y colectiva por esta población, en relación con la sociedad. Es además un momento vital donde se están consolidando las capacidades físicas, intelectuales y morales (15).

La ley Estatutaria 1622 de 2013 Estatuto de Ciudadanía Juvenil en la Introducción de la misma menciona que: "Colombia está pasando por una época histórica. Los cerca de 13 millones de jóvenes, representan el 27\% de la población" (15), lo que refiere, es que esta población ha aumentado en comparación con los anteriores años y que sin duda alguna sigue en aumento.

En Colombia, la población joven actual resalta por su interés en el acceso a la educación profesional, debido a la existencia de métodos más asequibles como la financiación de las carreras, endeudamiento de padres o ahorros de los mismos para ofrecerles y "garantizar" a sus hijos de alguna forma, oportunidades para la vida adquisitiva. Anteriormente se consideraba y era valioso obtener hasta el título de bachiller para poder acceder a trabajos (56). Sin embargo, este nivel educativo ha perdido fuerza y se hace menos importante para la contratación laboral.

Los perfiles de técnicos, tecnólogos y profesionales, son ahora los más requeridos en el país, sin duda alguna, es por esto que se requiere de la exigencia individual de ingreso a estudios superiores, con el fin de lograr integrarse a mercados laborales formales. Asimismo, se ha evidenciado la exigencia de niveles de posgrados para acceso a trabajos de alto nivel. 
Una problemática sobre el tema de profesionales/especializados en la contratación, es que los trabajos que ofrecen remuneraciones altas tienen demasiada exigencia de experiencia para poder hacer la contratación, por lo que en muchas ocasiones se debe desistir de aplicar a las mismas. Otros por su lado, se han encargado de ofertar las famosas "prácticas profesionales", que se hacen con salarios mínimos o sin salario para los estudiantes, fenómeno que puede convertirse en una forma de obtener mano de obra calificada gratis o a un muy bajo costo. Y en otras ocasiones, por no encontrarse trabajo se debe aplicar a ofertas de trabajos informales o trabajos que no corresponden a sus estudios, con el fin de hacer una inmersión al trabajo y obtener una remuneración económica para suplir las necesidades, lo anterior sin duda alguna puede relacionarse con el desempleo, situación que viven los jóvenes desde años anteriores y que se siguen presentando (57).

Por lo anterior, la problemática de desempleo colombiano sin duda es notoria. Las regiones poseen distintos niveles económicos y profundas diferencias de desarrollo. Existen ciudades más vulnerables y marginadas, y otras con mejores oportunidades y mejor nivel de desarrollo que otras. Hay una gran diversidad de dilemas para el manejo funcional del país para los gobiernos y la sociedad.

En la situación laboral del país cada vez más se suman los elevados costos de vida, donde la mayoría de contrataciones se están realizando con pagos de salarios mínimos y hasta inferiores. Este año (2016), el mínimo en Colombia se estipulo en $\$ 689.454$ pesos, de acuerdo al salario del año anterior el incremento de este fue de $\$ 45.104$ pesos, con un auxilio de $\$ 77.700$ pesos. Si se evalúa, las oportunidades en este país son escasas y los costos elevados. Un ejemplo es una persona cabeza de hogar que se encuentre laborando de domingo a domingo lejos de su hogar y deba tomar transporte (Transmilenio costo: $\$ 2.000$ pesos por trayecto), ida y regreso por 30 días son $\$ 120.000$ pesos, que tenga familia compuesta por esposa ama de casa sin empleo e hijo(a) estudiante, de seguro este salario lo hace permanecer por debajo de la canasta básica familiar porque sus ingresos no le permiten acceder a muchas cosas.

Es necesario tener en cuenta que los gastos representados no son solo los de comida, sino que en ocasiones se suman otros de urgencia como gastos médicos. Si se calcula, seguramente esta familia vive en condiciones de pobreza e incluso pueda aguantar hambre, si se cuenta que al inicio del año debe comprar uniformes para su hijo(a), útiles 
escolares, además, el vestuario se hace necesario para cada integrante de la familia y más para su hijo que posiblemente se encuentre en crecimiento, sumado a esto onces para que su hijo pueda llevar a la institución educativa, entre otros.

Esta situación no solo la viven los adultos, sino que también se refleja en los jóvenes. En muchas ocasiones los mismos deben asumir los gastos de sus estudios o responder por las necesidades de su propia familia, formada a temprana edad. No es conveniente y tampoco sostenible seguir asumiendo los gastos que representan estas condiciones dentro de la sociedad.

La población joven también debe preocuparse por lograr una vida con condiciones dignas, sin embargo, se deben enfrentar a problemáticas como elegir qué estudiar al salir del colegio, cuáles serán sus propósitos y expectativas de vida, trabajar y estudiar o solo trabajar o estudiar según las posibilidades económicas que tenga su familia o a nivel individual. Pero además, es importante que reconozcan que son sujetos pertenecientes a una sociedad y que es necesaria su activa participación en la toma de decisiones para la mitigación de problemáticas que involucran a toda la población, en especial la de los jóvenes.

La edad de la población joven, los requerimientos de la misma y las exigencias de capacitación para salir al mercado laboral son grandes, por tanto, esta misma población se ha interesado por la capacitación, porque los medios son ahora más factibles para el ingreso a la educación y porque las necesidades existentes dentro de la sociedad así lo requieren.

Es preciso decir que el primer empleo es el más difícil de conseguir y que además la población joven transita de manera continua de empleo a desempleo y así sucesivamente (58). Esto tiene diferentes variables, entre las cuales se encuentra la insatisfacción del empleador respecto a los servicios de su empleado, las contrataciones de duraciones cortas y la necesidad de las personas de generar crecimiento de experiencia e ingreso económico entre otras.

Lo anterior genera problemáticas asociadas con el no estar asegurado frente a diversas eventualidades que se presentan a lo largo de la vida de un ser humano. En la formación debería existir la obligación de enseñar la importancia que tiene prevenir los riesgos económicos; riesgos que no solo son individuales, sino también sociales (salud, pensión 
y seguro al desempleo). Allí se han demostrado falencias educativas en los jóvenes, pues sus intereses no están enfocados en este aspecto ni en los efectos negativos que pueden traer para su vida.

Hay que decir que en Colombia el acceso al trabajo esta mediado por un evidente tráfico de influencias, a través de intermediaciones, como los amigos, conocidos de familiares, profesores, etc., las personas consiguen sus empleos. No quiere decir que sea la forma de conseguir trabajo, pero si la más usada, aunque en muchas ocasiones los medios tecnológicos aportan de forma positiva para la aplicación de ofertas laborales y el contacto de empleado y empleador. Los medios impresos quizás hayan perdido un poco la frecuencia de consulta, sin embargo, son aún consultados en el país para este tipo de búsquedas (58).

En muchas ocasiones se conoce cómo el poder que ejercen funcionarios públicos ubicados en cargos de nivel directivo juega un papel importante en las contrataciones, ofrecen vacantes laborales y asignan puestos de trabajo a partir de favores realizados. No cabe duda que en Colombia en muchas ocasiones se debe recurrir a este método, pues es la única forma de acceder a un trabajo digno y decente y poder adquirir la experiencia que exige el mundo laboral.

Los datos arrojados por el DANE en el Informe Mercado Laboral de la Juventud, (edades entre 14 y 28 años) señalan que:

"Para el trimestre móvil mayo - julio 2016, la población joven representó el 32,0\% de la población en edad de trabajar. La tasa global de participación fue $57,2 \%$ presentando una disminución de 1,2 puntos porcentuales respecto al mismo período del año anterior (58,4\%); la tasa de ocupación se ubicó en 47,9\% disminuyendo 1,5 puntos porcentuales respecto al trimestre mayo - julio 2015 (49,5\%); y la tasa de desempleo fue 16,2\%.

La tasa de desempleo de las mujeres jóvenes fue de 20,6\%, y la de los hombres jóvenes de un 12,8\%. Asimismo, el 42,8\% de la población de 14 a 28 años correspondió a población económicamente inactiva. En el trimestre móvil mayo - julio 2016, la población de 14 a 28 años representó 31,4\% del total de la población en edad de trabajar. 
La tasa global de participación fue 61,3\%, la tasa de ocupación fue 51,1\% y la tasa de desempleo se ubicó en 16,8\%. La tasa de desempleo para las mujeres jóvenes fue 19,0\%, mientras que la tasa de desempleo de los hombres jóvenes fue 14,8\%. Por último, el 38,7\% de la población entre 14 y 28 años correspondió a población económicamente inactiva” (59).

Sin duda alguna estas cifras siguen siendo alarmantes, más que el tema de generar y recargar a las empresas el tema laboral de los jóvenes, se debe pensar en cómo mitigar todas estas necesidades. Las necesidades de los jóvenes son diversas y no solo se deben pensar además en aquellos aspirantes (personas que buscan su primer empleo) y en los que quieren crear empresas, debe revisarse desde las diferencias socioeconómicas y garantizar derechos para esta población.

El panorama nacional es complejo, sin embargo, en búsqueda de ofrecer insumos para construir políticas al país en el tema central de este trabajo, nace una propuesta mediante la cual se intenta abordar la política referida al "primer empleo" y las problemáticas y factores que se derivan del desempleo juvenil y las percepciones, intereses y conocimientos que tienen los jóvenes frente al tema laboral. Es necesario resaltar que el primer empleo es el más difícil de conseguir, por tanto el riesgo al que se enfrentan los jóvenes es demasiado alto. En Colombia la mayoría de empleadores exigen una experiencia amplia y certificada. Producto de la búsqueda propia en la web de ofertas laborales (páginas dedicadas a la publicación de ofertas laborales, redes sociales,

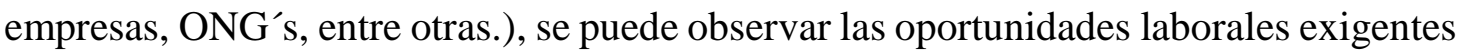
y con salarios ofrecidos bajos, u otros empleos con unos buenos salarios pero con experiencias que solo alcanzan quiénes lleven un largo tiempo ejerciendo, no para los jóvenes recién egresados de carreras profesionales. Lo que hace pensar que debería regularse en los sectores, público, privado y mixto las ofertas laborales y los salarios con el fin de controlar el desempleo existente.

\section{La ley 1429 de 2010}

En el tema laboral el Congreso de la República, durante el período de gobierno de 2010 - 2014, produjo la Ley 1429 de 2010: Formalización y Generación de empleo. Esta ley en su artículo primero expresa: 
La presente ley tiene por objeto la formalización y la generación de empleo, con el fin de generar incentivos a la formalización en las etapas iniciales de la creación de empresas; de tal manera que aumenten los beneficios y disminuyan los costos de formalizarse (60).

De acuerdo a lo anterior en los planes de desarrollo de gobierno del Presidente de Colombia, Juan Manuel Santos 2010-2014, 2014-2018 han propuesto temas laborales mediante los cuales se permita obtener crecimiento económico para solventar la problemática de desempleo en el país.

En la propuesta del Plan Nacional de Desarrollo del período de 2010-2014 se encuentran lineamientos claves dentro de la "Formalización laboral y empresarial":

- Diseñar e implementar mecanismos y estímulos para la formalización laboral: (i) fortalecer las instituciones del mercado de trabajo y los servicios de protección social, (ii) adecuar la política salarial y las formas de contratación a los propósitos de generación de empleo y formalización laboral, y (iii) promover una política activa para el acceso al primer empleo, en el marco de la Ley de Formalización y Primer Empleo.

- Desarrollar herramientas para facilitar la formalización laboral: (i) intervenir en el mercado laboral en períodos de crisis con medidas que fomenten la flexibilidad en el mercado de trabajo y la expansión de políticas activas y pasivas de empleo, (ii) desarrollar el sistema de protección al cesante, (iii) definir los lineamientos de los Beneficios Económicos Periódicos, y (iv) diseñar e implementar el Sistema Nacional de Intermediación Laboral.

- Diseñar un esquema tributario simplificado para reducir la complejidad del sistema y automatizar y virtualizar los trámites; continuar y diseñar programas para la formalización empresarial y proponer reformas al código de comercio para facilitar la reorganización y liquidación de empresas.

- Establecer mecanismos de inspección, vigilancia y control empresarial a través del Registro Único Tributario y la Planilla Integrada de Liquidación de Aportes a la Seguridad Social (PILA) (61).

Lo anterior refiere a la propuesta de la Ley 1429 de 2010, que abarca lo referente a las mejoras de condiciones para el sector económico y creación el Estado, dejando 
atractivos beneficios para los nuevos sectores con disminución de costos y "cambio de porcentaje en el desempleo juvenil".

Además de crear exigencia y regulación a los diferentes sectores para contratación y propuestas para que no se permitan salarios por debajo de la canasta familiar y se sigan enriqueciendo los mismos sectores de siempre a raíz de la mano de obra menos calificada o calificada pero obligada a integrarse al mercado laboral existente para poder recibir un ingreso monetario.

"Por último, sobre los estímulos para la contratación de jóvenes hasta los 28 años de edad, de personas desplazadas, discapacitadas, en proceso de reintegración social, trabajadores de bajos ingresos y mujeres mayores de 40 años existe una sombra de incertidumbre en cuanto a los requisitos y procedimientos para su reconocimiento. Por lo pronto, los beneficiarios, bien sean empresas o nuevos trabajadores, no están sujetos a alguna obligación de registro y por lo tanto es imposible discernir el impacto ocupacional ocasionado por la ley. Sin embargo, desde ya pueden formularse algunas consideraciones. El hecho de fundamentarse en un principio de adicionalidad hace suponer que su contribución al empleo nacional no podrá ser de mayor tamaño. Y tampoco puede descartarse un efecto desplazamiento que afecte las posibilidades de empleo de los demás trabajadores no beneficiarios.

En fin, de la información disponible hasta el momento se puede inferir que el impacto de la Ley 1429 sobre la informalidad laboral ha sido menor y ha estado muy por debajo de lo estimado. Es más, las cifras de informalidad del DANE no registran progresos durante los primeros seis meses de su aplicación (62).

El Plan Nacional de Desarrollo del período 2014-2018, teniendo en cuenta lo que se venía trabajando anteriormente, apuesta más por hacer referencia al empleo en los jóvenes, pero sin mencionar la ley sobre la que reposarán estas nuevas ideas, realiza una mención sobre la articulación que se generará con el Ministerio de Trabajo para desarrollar programas que permitan emplear a jóvenes a través de diferentes métodos, entre los cuales se encuentran: 
- Desarrollar componentes especiales de atención para jóvenes en los puntos de servicio público de empleo y la promoción de la empleabilidad en los consejos territoriales de juventud.

- Crear mecanismos para la formalización de los sectores que tengan una mayor participación de la mujer.

- Promover campañas u estrategias comunicativas que promuevan cambios en los estereotipos culturales en relación con los roles de los hombres y las mujeres al interior del hogar y la conciliación de la vida familiar y laboral (63).

Sin embargo, aunque el Plan Nacional de Desarrollo dirige a la población joven ciertos temas, quedan por fuera temas de garantías de contratación para estos nuevos jóvenes que se insertarán al mercado laboral, en el que no solo ofrezcan una estabilidad laboral, sino que sus ingresos retribuyan sus esfuerzos. La igualdad de condiciones debe incluir la igualdad monetaria, donde no siempre los mismos vean frutos y crezcan económicamente y donde no ofrezcan beneficios a empresas en las contrataciones disminuyendo costos, sino que ofrezcan oportunidades dignas para el ser humano.

También se indica cómo se articula el tema de empleo de jóvenes con el Ministerio de Trabajo, mediante el cual se conseguiría divulgar en el año 2015, la propuesta de Ley conocida como "Ley de Primer Empleo" por esta misma institución.

Ahora bien, es inevitable precisar que esta Ley va dirigida a sectores económicos, a la creación de empresa como se conoce en la Cámara de Comercio de Bogotá:

El 29 de diciembre de 2010 el Gobierno Nacional promulgó la Ley 1429 de 2010 o Ley de Formalización y Generación de Empleo, que brinda beneficios e incentivos a los empresarios para disminuir los costos de formalizarse y apoyarlos en el crecimiento de sus negocios (64).

Y se sabe que el Ministerio de Trabajo fue el encargado de promocionar y divulgar el programa que va dirigido a jóvenes en busca de empleos, propuesta que fue promovida en el primer cuatrimestre del año 2015 con el nombre de "40 mil primeros empleos" (65), empleos que no muestran las garantías que tendrán los nuevos jóvenes al emplearse durante y después de los seis meses.

Es notorio ver cómo además la Cámara de Comercio de Bogotá concibe la ley de una manera más empresarial, mientras el Ministerio de Trabajo la concibe más como 
oportunidades para los jóvenes "Primer Empleo". Las garantías expresadas dentro de la ley, sin duda alguna van más dirigidas a lo que menciona la Cámara de Comercio de Bogotá, que a lo que refiere el Ministerio de trabajo con la propuesta de "Ley de Primer Empleo".

Es necesario hablar también de la falta de divulgación de esta propuesta, pues la misma estuvo presente en medios de comunicación, solo para el lanzamiento y días después. Ahora bien, ¿Cómo pretenden que en un país sin memoria a largo plazo, tenga presente lo que se menciona tan superficialmente? Es preciso hacer trabajo de divulgación y elegir los canales precisos y necesarios para que esta nueva propuesta sea tenida en cuenta y la ciudadanía pueda opinar frente a la misma.

\section{Experiencia de la ley en otros países y en Colombia}

La Ley de Primer Empleo es un modelo que se viene implementando en América Latina, mediante la cual se ofrecen beneficios de contratación y generación de empresas. En Brasil la Ley de aprendiz (Ley 10.997), la cual plantea la introducción de un contrato no mayor a dos años a jóvenes entre los 14 y 24 años de edad, beneficios económicos a las empresas que realicen estas contrataciones y Chile con el programa de aprendices (1998) el cual planteaba que los contratos no podrían ser inferiores a seis meses, ni mayor a dos años, las empresas recibían como beneficio el 50\% del salario mínimo para cubrir el costo de contratación del aprendiz, la población objeto eran jóvenes entre 15 y 21 años de edad; este programa solo funcionó hasta el año 2013 (66).

El problema de desempleo juvenil no solo se da en Colombia y sus regiones, sino que también ha demostrado falencias en Chile, Argentina, México y Paraguay, países que implementaron la Ley de Primer Empleo hace algunos años y que siguen mostrando Problemas en el empleo.

Desde la década pasada algunos países de América Latina han optado por iniciativas legales para promover el empleo juvenil, bien a través de la introducción de regímenes laborales especiales para jóvenes o de legislación de contratos de primer empleo.

La lógica detrás de estas iniciativas legales es que para promover el empleo de jóvenes, con poca o mala formación para el trabajo o que no cuentan con experiencia laboral, se requiere reducir los costos laborales salariales y/o no 
salariales de modo que se genere un incentivo para su contratación por parte de las empresas. En la práctica, esto implica la reducción o eliminación de varios de los beneficios que las legislaciones laborales confieren de manera general a todos los trabajadores. En buena parte, los argumentos a favor y en contra de estas iniciativas giran precisamente en torno a si al reducir costos los regímenes laborales especiales para jóvenes restringen beneficios o derechos laborales y si esta reducción constituye un incentivo efectivo para incrementar la demanda de trabajo joven (66) .

Es necesario revisar si el modelo implementado en Colombia sobre la Ley de Primer Empleo es una buena adecuación o si por el contrario se necesita la implementación de nuevos modelos que partan de la experiencia propia del país y que se adecuen directamente a las diversas necesidades que tienen los jóvenes que están en desempleo continúo. Es importante generar credibilidad frente a temas de educación y trabajo con el fin de evitar las migraciones, que generan costos grandes a regiones del país (67).

La experiencia de Chile reconoce que son los jóvenes más pobres quiénes deben enfrentarse a las barreras del ingreso al mercado laboral, reconociendo que existe desigualdad de educación y porque además puede existir discriminación por cierto origen social y su herencia cultural como menciona el documento Políticas y Programas de Apoyo a La Inserción Laboral de Los y Las Jóvenes en Chile, donde además se mencionan las dificultades que existen con los programas de empleabilidad que se aplicaron en este país como lo es Chile-Joven y Fosis, donde se encontró: que el intentar reclutar los grupos más vulnerables era difícil, además de la participación masiva de las mujeres en estos programas, existen además demasiadas diferencias en las expectativas laborales de las jóvenes y la realidad del mercado.

Por otro lado se encontraba el Programa Chile Califica en el cual se relacionaba la educación y el trabajo, donde se demostró que hay sujetos con condiciones desiguales en relación su economía y las políticas destinadas a ellos, no existe conocimiento de los puesto de trabajo existentes o de las competencias que se deben tener para realizar la inmersión al mercado laboral, construyendo así tendencias al desempleo juvenil según documento ¿DE QUÉ HABLAMOS CUANDO HABLAMOS DE EMPLEABILIDAD JUVENIL? De Universidad de Chile, donde se caracteriza esta tendencia por una gran participación para empeorar la situación laboral de los jóvenes en lo que refiere a la 
cantidad y calidad de las condiciones laborales dejando diferencias entre género, nivel educativo, entre otros.

Lo anterior según este documento sirve para dejar claro porque las políticas de empleo no funcionan y porque no han logrado responder a esta compleja situación. Y claro que si se apoya en cuanto a que estas políticas no van enfocadas a los trabajadores y sus beneficios, si su beneficio va más enfocado por los beneficios de los empleadores que se encargarán ahora de ofrecerles trabajo a los jóvenes.

La OIT en un artículo brinda importancia a este trabajo lo que permite ver la situación laboral de los jóvenes y el panorama desde las políticas y programas propios de emprendimiento dejando entre ver, que estas propuestas no han sido efectivas.

"En el caso de los programas de primer empleo basados en subsidios a la contratación, que se han multiplicado en tiempos recientes, estos pueden diseñarse para promover la permanencia en el puesto de trabajo por un lapso suficiente para generar mejoras en la empleabilidad de los jóvenes. Los mecanismos de selección y supervisión deben enfocarse en la pertinencia y calidad de la formación que pueden ofrecer las empresas de manera que los jóvenes realmente adquieran competencias laborales que mejoren su perfil profesional. Por su parte los mecanismos de certificación de la experiencia y de las competencias pueden facilitar las transacciones entre empleos al permitir que los jóvenes acumulen experiencia verificable y que acrediten sus competencias entre nuevos empleadores a lo largo de sus itinerarios laborales.

La efectividad de los regímenes laborales especiales para jóvenes está aún por verse. Aunque se ha ido intentado en varios países, la experiencia de la región es que este tipo de iniciativas no han prosperado. En cualquier caso, si algo hemos aprendido de estas experiencias es que cualquier iniciativa de este tipo debe estar basada en un contexto de diálogo social; que se debe tener cuidado en no generar incentivos equivocados con posibles efectos de desplazamiento o sustitución de un tipo de trabajador por otro y en evitar posibles tratos discriminatorios contra los jóvenes" (68). 
Sin duda alguna lo que esperan los jóvenes es poder integrarse a trabajos de calidad donde estén asegurados, pero que además puedan tener permanencia dentro de estos empleos donde hacen inmersión laboral. La idea de los jóvenes no es enfrentarse a riesgos que no pueden cubrir por la falta de oportunidades y por la inexperiencia para generar empresa, además de en muchos casos no querer hacerlo o no contar ni con el más mínimo capital (69) (70).

Los jóvenes se encuentran capacitando con el fin de ingresar a competir en el mercado laboral y lograr propósitos de vida, pero las garantías son mínimas, las ofertas laborales escasas, las necesidades son superiores a los ingresos y los trabajos informales ofrecen puestos que se deben tomar por obligación, más que por gusto. Es la necesidad de sobrevivir en una sociedad que busca tener más crecimiento económico y esto a través de los mercados, que darle condiciones dignas a un ser humano en los trabajos.

Los jóvenes además de querer conseguir trabajos decentes y dignos, quieren involucrarse en trabajos que tengan relación con su capacitación y con lo que de acuerdo a sus experiencias educativas pueden hacer. De algún modo sería interesante poder exigir que las instituciones educativas propongan un mayor equilibrio entre la formación práctica y la formación teórica, de tal modo que la práctica en todo el proceso educativo tome más valor para enfrentar el mundo laboral.

En cuanto a las políticas que se están generando en el país, con lo anterior se puede ver, como estas están teniendo diversos enfoques, además el Estado está olvidando la responsabilidad pública y está asumiendo una intervención pública privada, olvidando su labor e involucrando temas que si bien deben tener una conexión, no deben tratar de solucionarse con un solo enfoque (beneficios empresariales, económicos). Las necesidades son diversas y se pueden abordar con estrategias nuevas, que se creen desde el conocimiento, desde lo que representan las necesidades en nuestro país, asumiendo lo que está plasmado en la constitución y teniendo en cuenta a toda la población en general, sin focalizar grupos, aunque si se debe reconocer que no todas las personas cuentan con las mismas oportunidades y que existen grandes brechas de desigualdades. Estas nuevas estrategias deben abordarse y tratarse más como Estado, de un continuo desarrollo en búsqueda de beneficios y mejoras, no se pueden seguir permitiendo trabajos diversos de gobiernos, donde lo que van dejando en el camino son necesidades 
sobre necesidades existentes y recursos destinados a una regresión por no recibir avances positivos en las problemáticas que enfrenta el país.

\section{CAPÍTULO 2. PROBLEMAS, TRABAJO DECENTE Y CARACTERIZACIÓN DE LOS JÓVENES EN COLOMBIA}

\subsection{Problemas de la juventud}

En los anteriores capítulos se ha mostrado el problema laboral existente, se ha demostrado que son los jóvenes los más afectados y se ha hablado de las políticas de empleo creadas para ayudar a mitigar este efecto negativo para los países, sin embargo, estas políticas no han mostrado ser las mejores opciones, pues en varios países de América Latina no han dado fruto; en el caso de Colombia en especial se evidencia la individualización de los derechos de los trabajadores y en otros casos dejando la responsabilidad de beneficios de los empleados sobre las empresas que los contratan.

No existe ahora una regulación sobre los derechos y los más jóvenes que están obligados a acceder a un mercado laboral escaso y con cualquier actividad, debe someterse a muchas vulnerabilidades, malos tratos y pagos paupérrimos. Por tanto no hay una garantía efectiva que pueda reclamarse sobre los derechos adquiridos por naturaleza, donde se juega la construcción de un bienestar de la vida propia, por medio de derechos reconocidos y protecciones ante riesgos que determinan calidad de vida como lo son salud, educación, empleo, entre otros.

Un problema grande que se evidencia sobre la juventud es el paso de la vida escolar a la vida laboral, pues debe enfrentarse a tratar de conseguir empleo y competir con otros jóvenes en un mercado que se cierra a la posibilidad de contratar personal sin 
experiencia y lo suficientemente capacitados, en otros casos se puede decir que es un mercado que está ligado por el poder y las relaciones sociales donde el conseguir empleo se realiza a través de estos vínculos existentes, ya sea desde la familia o propios.

El desempleo en el país sin duda alguna está relacionado con los temas latentes de extrema pobreza, la falta de oportunidades laborales, la desescolarización o la poca facilidad de acceso a la educación, la falta de trabajos que representen condiciones decentes y dignas para el ser humano y las desigualdades. Por tanto significa adoptar enfoques de derechos, la protección social entonces por Cecchini menciona que se debe ser más eficiente en el uso de los recursos públicos.

Es preciso además decir que el tema de empleo para muchos jóvenes no representa lo mismo por las condiciones, pues existe diversidad de necesidades; tampoco significa lo mismo la inversión y el ingreso a la educación, esto derivado de las condiciones económicas de cada familia.

Los jóvenes y sus familias que cuentan con menos recursos, la educación como se menciona en el trabajo DILEMAS ACTUALES DE LA JUVENTUD FRENTE AL TRABAJO: Formas de inserción socio-laboral juvenil en Manizales (Colombia) (27), es una inversión que servirá para poder salir adelante, para mejorar sus condiciones sociales y económicas; incluso sirven para demostrar que se es alguien en la vida y que se ha triunfado. Esta inversión es considerada como la forma de poder suplir necesidades existentes, el ingreso a la educación superior requiere de esfuerzos ya sean familiares o propios.

Para jóvenes con recursos, simplemente la educación es la forma de poderse perfilar por un enfoque académico elegido, su ingreso a la educación superior en este caso no requiere de esfuerzos y tampoco se dificulta la inversión económica.

Sin duda alguna, luego de entrar a ver las condiciones que sufren los jóvenes con menos recursos, es claro que pueden ver el mercado laboral de forma más negativa, pues son ellos quienes se han enfrentado a la dificultad de poder acceder en muchos casos a trabajos que no son los deseados, pero por necesidades se deben tomar, esto aun siendo profesionales, pues el tema laboral presenta dificultades para gran parte de los jóvenes y es por la falta de oportunidades y la falta de experiencia, además de no contar con relaciones sociales para hacer inmersión al mercado laboral. Es claro además para los 
jóvenes que los esfuerzos ya no garantizan el ingreso al trabajo, no es sinónimo de generar mejores condiciones de vida (27).

Este grupo etario requiere de mayor atención y de programas que estén enfocados en ellos y sus problemáticas, en la mejora de condiciones para ellos para lograr a construir mejores perspectivas frente a las realidades existentes. Hay inequidades existentes y esto se refleja en las condiciones socioeconómicas y problemas que se deben enfrentar de forma diferente. Existe una gran diferencia entre jóvenes y adultos más allá de la experiencia, pues los primeros están saliendo a adquirir sus primeras responsabilidades, habilidades y capacidades, mientras que los segundo ya tienen la experiencia, las habilidades y capacidades.

\subsection{Trabajo decente en Colombia}

Desde varios años atrás, el empleo viene cambiando, los niveles de desempleo en una constante situación de desconocimiento sobre lo que pasará y los jóvenes enfrentándose a distintas condiciones, afectándolos en mayor grado que a otros grupos etarios.

La OIT, como se mencionó al inicio de este trabajo tiene como labor trabajar por el Programa de Trabajo Decente, siendo su objetivo "promocionar los derechos sociales y laborales, del empleo, de la protección social y el diálogo social a escala internaciones" (6).

Por lo anterior la OIT solicitó a los países que crearan políticas sobre el concepto de trabajo decente lo que significaba según JOVENES, EMPLEO Y TRABAJO DECENTE, promover condiciones básicas para el desarrollo, dando a las personas un mínimo de garantías para llevar una vida digna.

Para la OIT el trabajo decente según la reunión No. 87 de 1999 se da mediante 4 objetivos estratégicos categorizados así:

1. Oportunidades de empleo e ingresos.

2. Protección y seguridad social.

3. Principios y derechos fundamentales en el trabajo y normas laborales internacional.

4. Diálogo social y tripartismo. 
Los anteriores aspectos se han ido olvidando en la construcción de políticas que van dirigidas a la empleabilidad, en especial la empleabilidad de los jóvenes que tantos problemas tiene para lograr el acceso a la fuerza laboral formal y que además carecen de derechos, pues no son regulados y garantizados, están a disposición de quiénes los contraten.

Ahora bien, según el mismo documento JÓVENES, EMPLEO Y TRABAJO DECENTE, en el contexto colombiano el trabajo decente tiene que ver con lo que aspiran los seres humanos en lo que respecta al campo laboral en su vida con las mejores condiciones teniendo en cuenta la remuneración justa, trabajo productivo, seguridad en su lugar de trabajo y la protección social para el individuo, como para su familia (71).

Lo anterior destacado en la Constitución Política de Colombia en los artículos 25 que refiere al derecho al trabajo y el artículo 53 que contiene los principios dentro de los cuales se encuentran la igualdad de oportunidades, remuneración vital y móvil, estabilidad en el empleo, irrenunciabilidad a los beneficios mínimos, primacía de la realidad sobre formalidades establecidas por los sujetos de las relaciones laborales garantía a la seguridad social, la capacitación, el adiestramiento y el descanso necesario, entre otras.

Se conoce según artículo El mercado laboral de los jóvenes y las jóvenes de Colombia: realidades y respuestas políticas actuales que los instrumentos de las políticas que se han creado en Colombia y que inciden en los mercados laborales no han sido suficientes para mitigar el efecto negativo existente en el campo laboral y de empleabilidad, además de ser necesario generar nuevas políticas o reevaluar las existentes para mejorar la situación que enfrenta el país, pero desde la experiencia propia del país y acogiendo lineamientos necesarios internacionales para evaluar los efectos (72).

Para finalizar, si se sabe y se conoce lo que existe en la Constitución y lo que se pide para generar trabajo decente, ¿por qué se permite la elaboración de políticas dirigidas y enfocadas a dar beneficios a las empresas que generen empleabilidad o a crear empresas si se tiene claro que no es el objetivo de todos y no todos cuentan con las capacidades para hacer y competir en mercados laborales tan difíciles y disimiles como son los de Colombia? Además que como dice el artículo el tema de dinamismo y empuje como solución a la desocupación se desconoce y que para los jóvenes además esta no puede ser la mejor solución, para que pueda quizás funcionar los jóvenes deben tener mayor 
apoyo político, mayor apoyo además del sector financiero y mayor facilidad de acceso para competir (72).

\subsection{Caracterización del empleo y los jóvenes en Colombia}

\section{Informalidad en el país}

La informalidad en Colombia, según el DANE en lo que respecta a 13 ciudades la información para el año 2010 era de 51,5 mientras que para el año 2016 se encontraba en 47,7 mostrando tendencia a disminuir con el pasar de los años.

En lo que refiere a las 23 ciudades y áreas metropolitanas la informalidad representó para el año 2010 52,7 y para el año 2016 fue de 48,8.

Si se revisa la variación de las dos proporciones de ciudades mostradas, muestra que bajaron aproximadamente 4 puntos porcentuales, lo que representa una variación positiva, pero no satisfactoria pues siguen siendo cifras muy elevadas para presentar la informalidad del país, la esperanza de conseguir un trabajo digno, decente y formal es grande y esta problemática necesita una solución más allá de los programas de empleabilidad que se están presentando en el país (73).

Gráfica2. Proporción de población ocupada informal Total 13 y 23 ciudades y áreas metropolitanas Trimestre julio - septiembre (2010-2016)

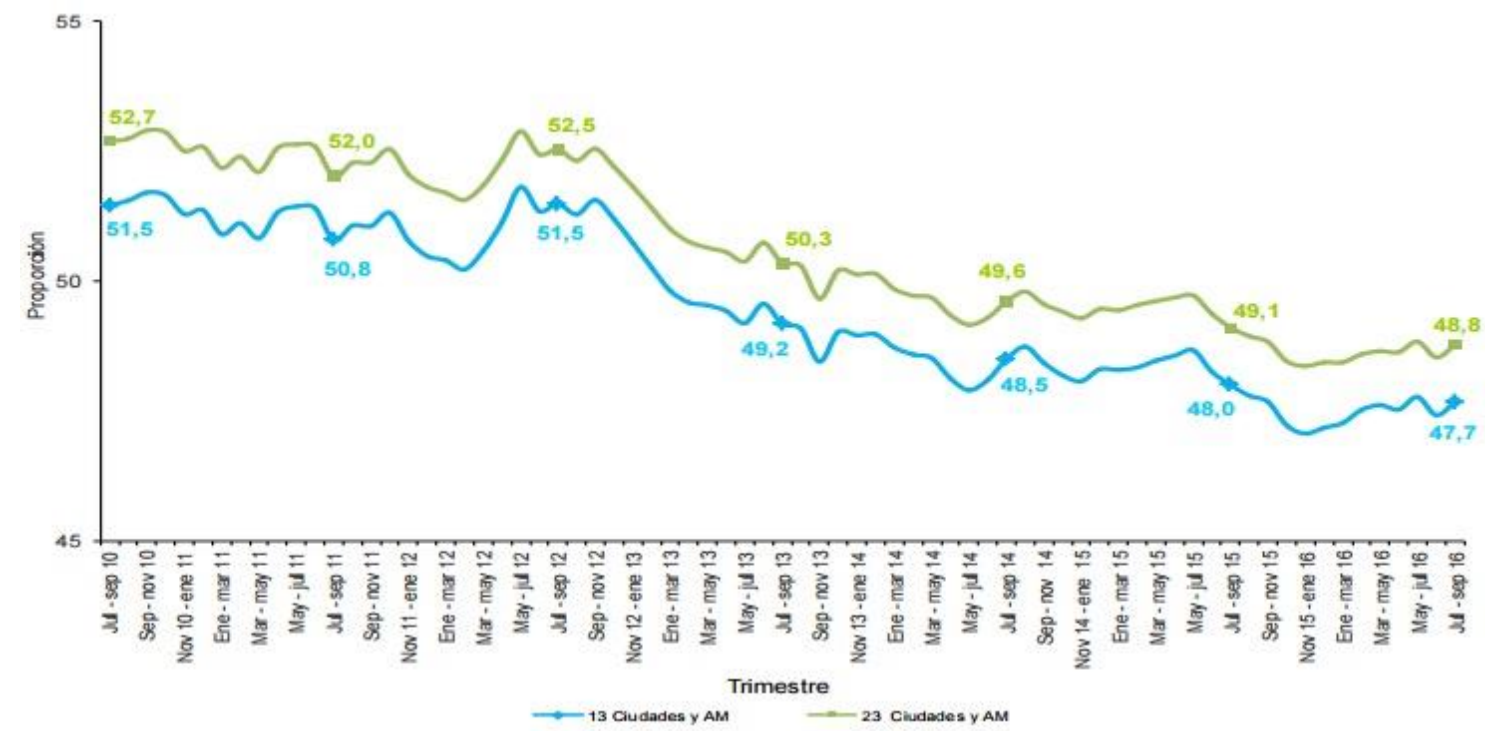

FUENTE: DANE - GEIH. Tomado de:

http://www.dane.gov.co/files/investigaciones/boletines/ech/ech_informalidad/bol_ech _informalidad_jul_sep16.pdf 


\section{Informalidad por ciudades en Colombia}

Como se mostró en la gráfica anterior, la informalidad en el país tiene cifras muy elevadas, si se revisa por ciudades, en el período que comprende julio - septiembre de 2016 podemos ver como Cúcuta de Norte de Santander tiene la mayor informalidad, mientras que Manizales la menor.

Es importante ver el rango donde se encuentra la ciudad de Bogotá $(42,2)$, que aunque es una de las ciudades donde existe menos informalidad, siguen siendo elevadas las cifras donde la población espera conseguir un trabajo decente y digno.

Lo que se sabe es que la informalidad ha venido en aumento y esto no es conveniente para la economía del país y tampoco para el problema laboral que enfrentan los jóvenes (73).

Gráfica 3. Proporción de la población ocupada informal según ciudad 23 ciudades y áreas metropolitanas Trimestre julio - septiembre 2016

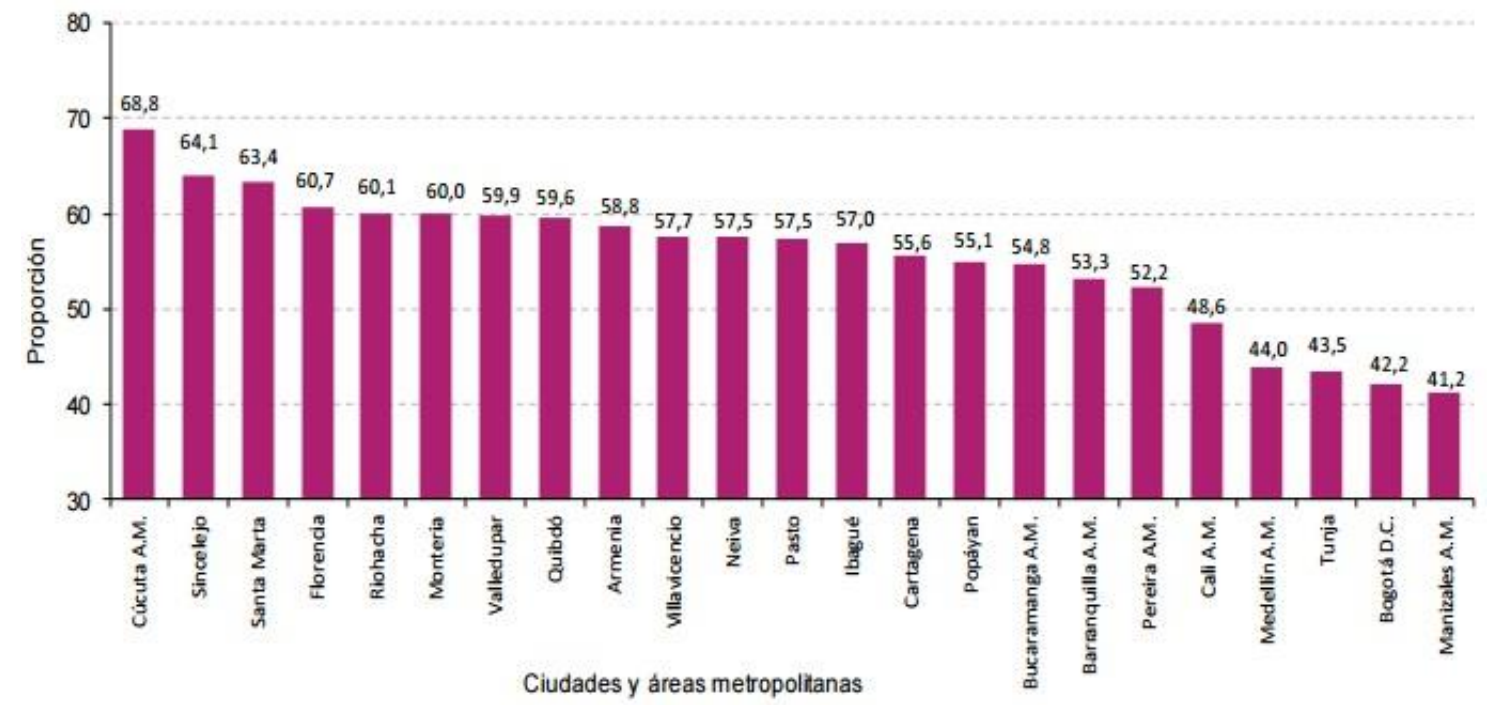

FUENTE: DANE - GEIH. Tomado de:

http://www.dane.gov.co/files/investigaciones/boletines/ech/ech_informalidad/bol_ech _informalidad_jul_sep16.pdf

\section{Mercado laboral desde 2007 hasta 2016}

La tasa de desempleo en Colombia se registró para septiembre del año 2007 en 10,8\%, dos años después para septiembre aumentó el desempleo ubicándose en 12.2\%, aunque 
ha disminuido el porcentaje, ubicándose para el 2016 en septiembre en 8.5\%, el desempleo cada vez es más notorio, y no cabe duda de que el mismo afecta de manera particular a los jóvenes, quiénes no tienen experiencia, no quieren ser contratados por empresas, no todos tienen las mismas relaciones sociales y no existe equidad, sino grandes brechas de inequidad en este grupo etario que tiene grandes diferencias tanto económicas, como sociales y culturales (74).

Gráfica 4. Tasa de desempleo Septiembre (2007 - 2016)

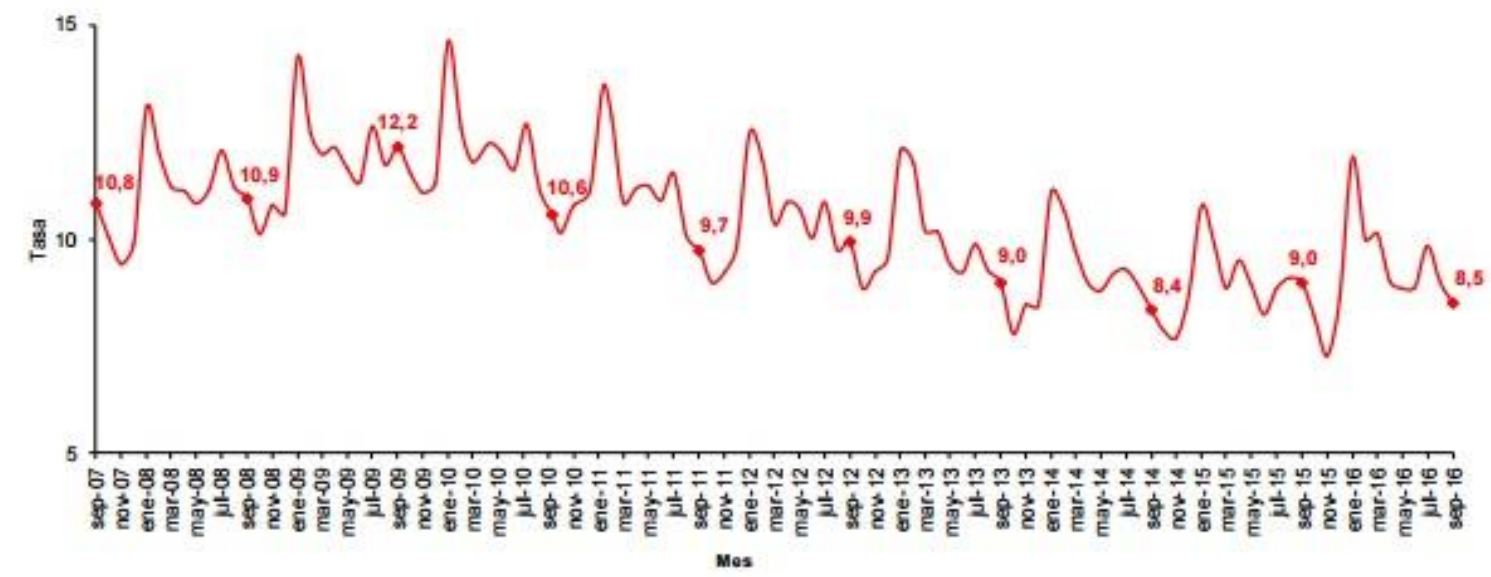

Fuente: DANE - GEIH. Tomado de:

http://www.dane.gov.co/files/investigaciones/boletines/ech/ech/bol_empleo_sep_16.p

$\underline{\mathrm{df}}$

\section{Tasa global de participación a nivel nacional}

Al revisar cómo se encontraba la tasa de participación para septiembre de cada año se ha notado la tendencia de aumento, mientras que en los últimos 3 años se ha mantenido en un rango muy similar. Esta medida que toma la población activa y la población en edad de trabajar es bastante grande si se relaciona con el desempleo y la informalidad, todas las personas esperan poder conseguir un trabajo que les permita cubrir todas las necesidades y mejorar sus vidas mediante el mismo. Para lograrlo deben acceder a trabajos decentes y dignos como se repite constantemente en este trabajo (74). 


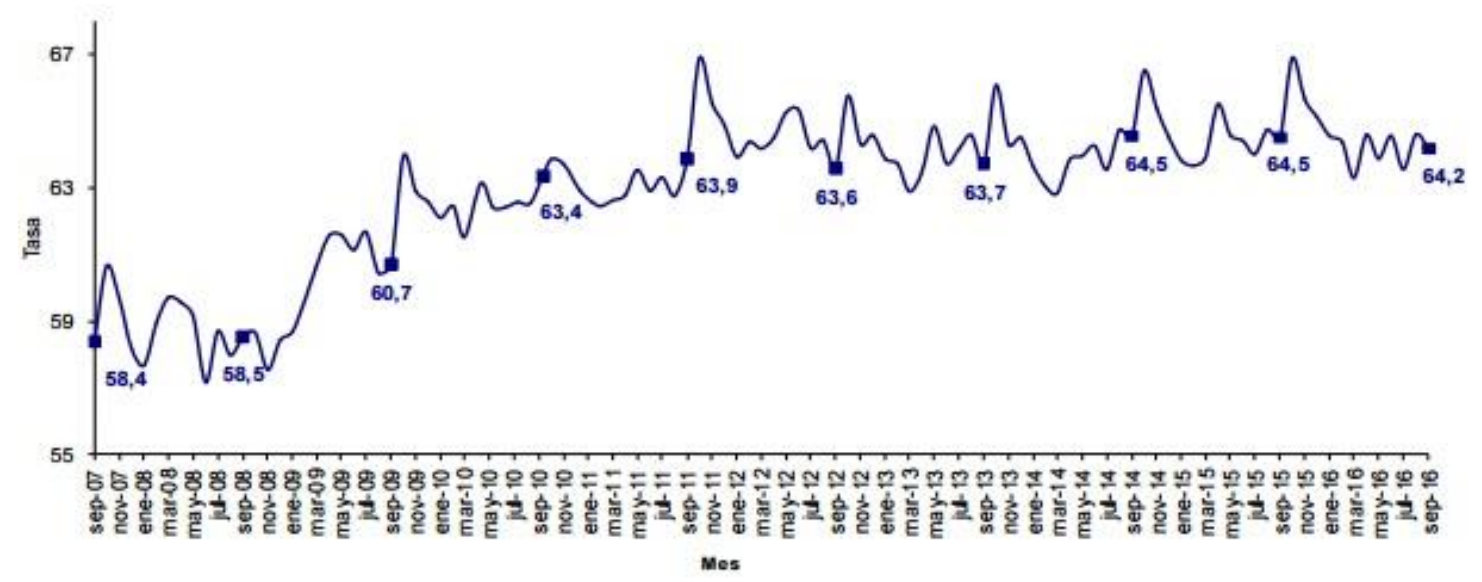

Fuente: DANE - GEIH

Tomado de:

http://www.dane.gov.co/files/investigaciones/boletines/ech/ech/bol_empleo_sep_16.p $\underline{\mathrm{df}}$

\section{Comportamiento del mercado de la juventud en Colombia (14 a 28 años)}

En el territorio nacional, es muy importante hablar sobre lo que pasa sobre las problemáticas y una de ellas es el comportamiento del mercado de la juventud, pues este tiene un comportamiento diferente al de otros rangos poblacionales y la dificultad de acceder a estos mercados es cada vez más dura. Ya no importa en muchos casos el nivel de educación, porque ya el tener un grado superior no garantiza que se pueda hacer inmersión inmediata al mercado laboral.

La siguiente gráfica muestra el comportamiento del desempleo por años y sexo, donde además se logra diferenciar la brecha de género existente, donde además de ver que el desempleo para los jóvenes tiene un aumento en el último año, las mujeres son las más desempleadas.

Estas cifras se dan luego de que se implementara el programa de empleabilidad realizado por el Ministerio de Trabajo “40.000 primeros nuevos empleos”, donde se esperaría las cifras mejorarán con esta propuesta que además iba de la mano con la Ley de Primer Empleo, entonces aquí se vería si la propuesta estaría funcionando como se pretendía (74). 
Gráfica 6. Tasa de desempleo de los jóvenes de 14 a 28 años según sexo Trimestre móvil junio - agosto (2015 - 2016) Total nacional y total 13 ciudades y áreas metropolitanas

\begin{tabular}{lcccc}
\hline \multirow{2}{*}{ Población jóven 14 - 28 años } & \multicolumn{2}{c}{ Total Nacional } & \multicolumn{2}{c}{ Total 13 ciudades y áreas metropolitanas } \\
\cline { 2 - 5 } & Jun - ago 2015 & Jun - ago 2016 & Jun - ago 2015 & Jun - ago 2016 \\
\hline Total & 15,4 & 15,9 & 16,1 & 16,9 \\
Hombres & 11,4 & 12,5 & 12,7 & 14,1 \\
Mujeres & 20,9 & 20,5 & 20,2 & 20,0 \\
\hline
\end{tabular}

Fuente: DANE - Gran Encuesta Integrada de Hogares (GEIH). Tomado de:

http://www.dane.gov.co/files/investigaciones/boletines/ech/juventud/Bol_eje_juventud jun_ago16.pdf

Tasa global de participación, de ocupación y de desempleo de jóvenes (14 a 28 años) por género

La situación del país es compleja en tema laboral, más cuando se refiere al tema de los jóvenes quiénes son quiénes se enfrentan a la situación que se vive en el país. La siguiente gráfica muestra en primer lugar la participación de los jóvenes la cual representa un total nacional de 57,7, la de ocupación 48,6 y el desempleo de los jóvenes 15,9 .

La afectación para jóvenes es amplía y para la mujer en especial representa un alto grado.

La forma en que es medido el empleo en Colombia muestra cifras muy generales que no logran dejar entrevisto casos específicos, pues en muchos casos la ocupación puede tomarse así la persona haya estado ocupada una vez al mes, un mes, dos meses, etc., al momento del estudio, ¿qué pasa con los que tienen continuas transitoriedades de trabajo, que no encuentran un trabajo luego de haber tenido su primera oportunidad laboral? Las políticas y programas de apoyo en el desempleo juvenil, deberían tener en cuenta estas problemáticas que afectan tanto este rango de población, teniendo en cuenta sus diferencias y como se puede ver el rango de las mujeres, es necesario ofrecer mayores oportunidades y beneficios para las mujeres que tienen mayores problemas (74). 
Gráfica 7. Tasa global de participación, de ocupación y de desempleo de los jóvenes de 14 a 28 años según sexo Trimestre móvil junio - agosto 2016 Total

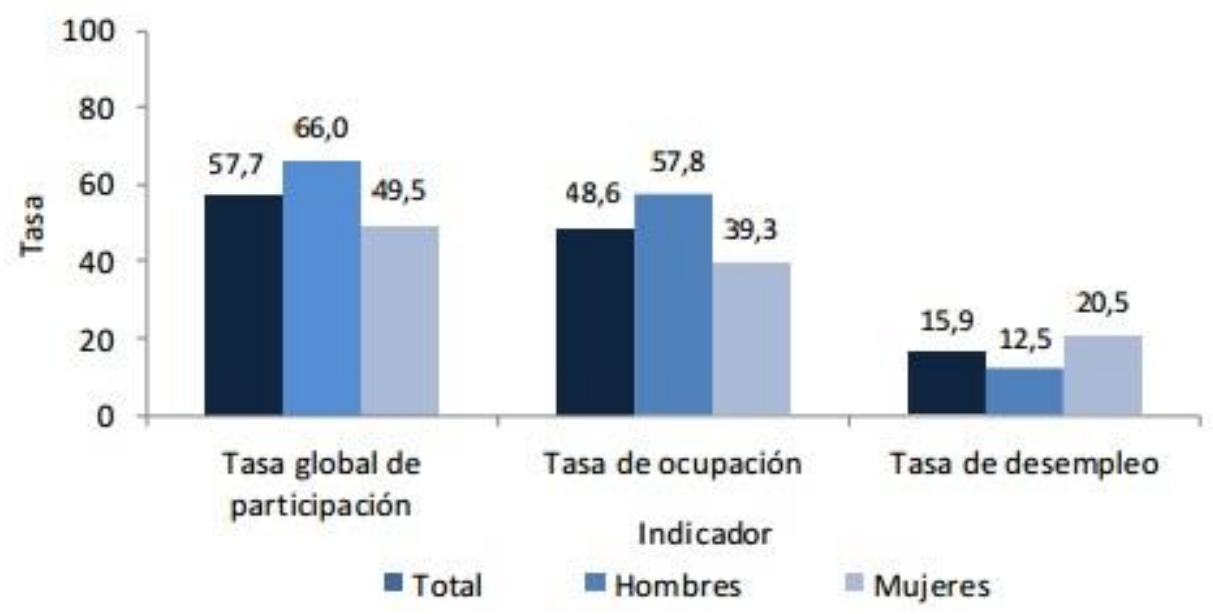

Fuente: DANE - GEIH. Tomado de:

http://www.dane.gov.co/files/investigaciones/boletines/ech/juventud/Bol_eje_juventud jun_ago16.pdf

\section{Nivel académico alcanzado de los jóvenes, padres y madres}

De acuerdo a la Encuesta de Transición de la Escuela al Trabajo y datos del año 2015, la población joven ha logrado tener más estudios académicos que sus padres y esto puede ser por las facilidades de acceso que ahora existen para el ingreso a la educación, además porque los esfuerzos de los padres son mayores para que sus hijos logren el acceso a la educación superior, viendo sin duda alguna esto como la forma de poder salir adelante y mejorar sus condiciones sociales y económicas.

Los jóvenes de ingresos bajos o medios reconocen que para este momento la educación es importante para obtener satisfacer sus necesidades. Sin duda alguna es un logro importante para los seres humanos, sin embargo, esta no garantiza el ingreso a todos los jóvenes, en muchos casos al no conseguir empleo los jóvenes pueden sentirse decepcionados de sus logros, pues existen pocas oportunidades de empleo, además de las pocas oportunidades que se les quieren brindar por la falta de experiencia (75). 
Gráfica 8. Distribución porcentual de la población de 14 a 29 años de edad según nivel educativo alcanzado de los jóvenes, sus padres y madres Total 13 ciudades 2015

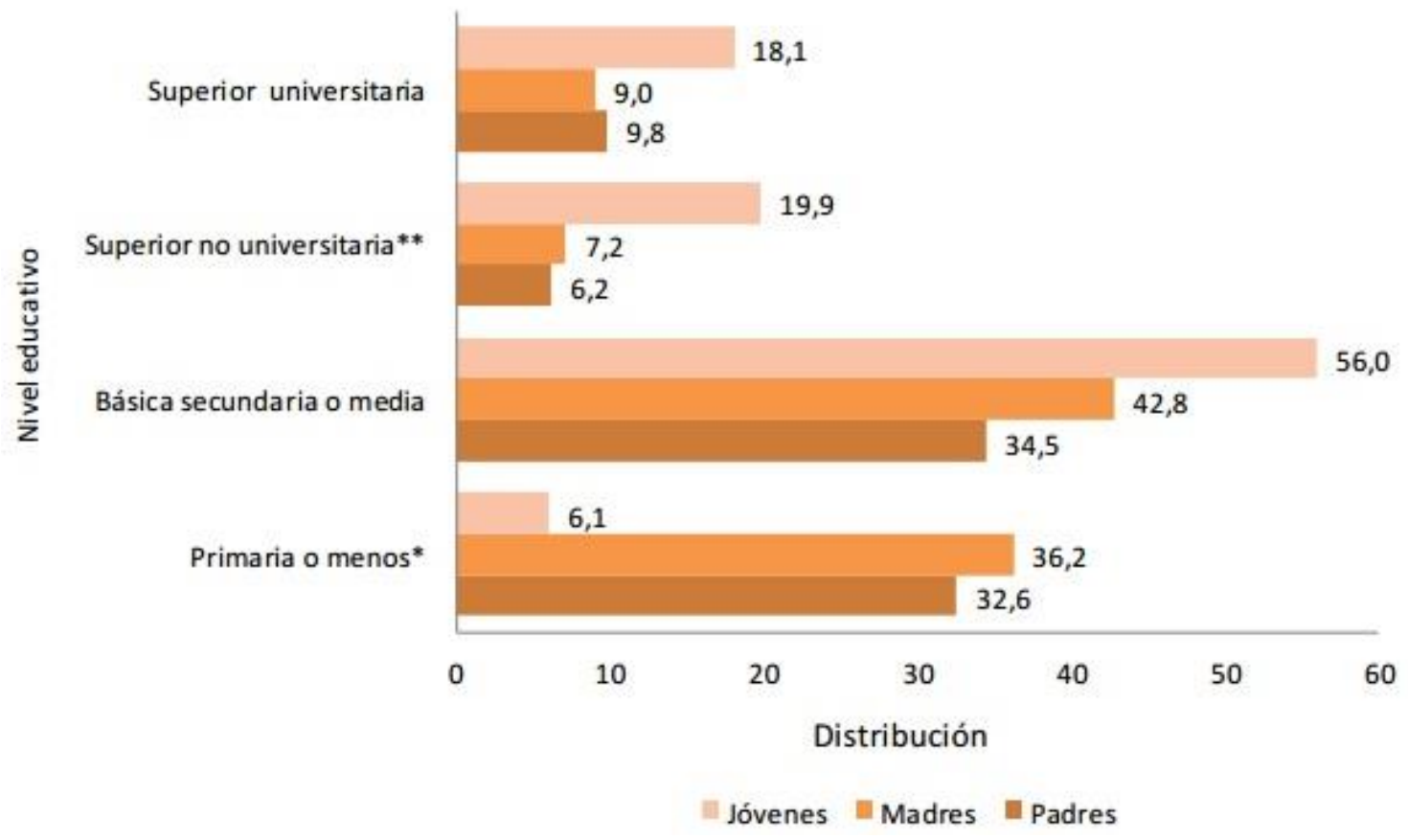

Fuente: DANE - Encuesta de Transición de la Escuela al Trabajo 2015. Tomado de: http://www.dane.gov.co/files/investigaciones/boletines/etet/Bol-tecnico-ETET2015.pdf

\section{Jóvenes y sus perspectivas frente al campo laboral}

Como se puede apreciar en la siguiente gráfica los jóvenes universitarios y técnicos tienen la mayor expectativa de ingreso al mercado laboral y esto se debe a que el tener un título en el país es tan importante tanto para las personas como para quiénes se encuentran interesados. Aunque no cabe duda que los sectores de prestación de servicios como los outsoursing que se encuentran creciendo en el país, no ven como requisito los grados superiores pero sus salarios tampoco corresponden a salarios buenos y buenos beneficios de horarios para los trabajadores.

Sin duda alguna, los jóvenes se enfrentan a la competencia laboral y a las dificultades de la misma, se quiere además que los esfuerzos económicos y de habilidades y capacidades en el aprendizaje sean valorados. En este punto se requiere que las políticas dirijan sus miradas a solventar las necesidades de los jóvenes quienes requieren obtener mejores oportunidades en el ingreso al mercado laboral, donde además estos trabajos 
sean decentes y representen seguridad en estabilidad y protección tanto de su salud como de sus derechos (75).

Gráfica 9. Distribución porcentual de la población de 14 a 29 años de edad según expectativa de ocupación en el futuro Total 13 ciudades 2013 y 2015

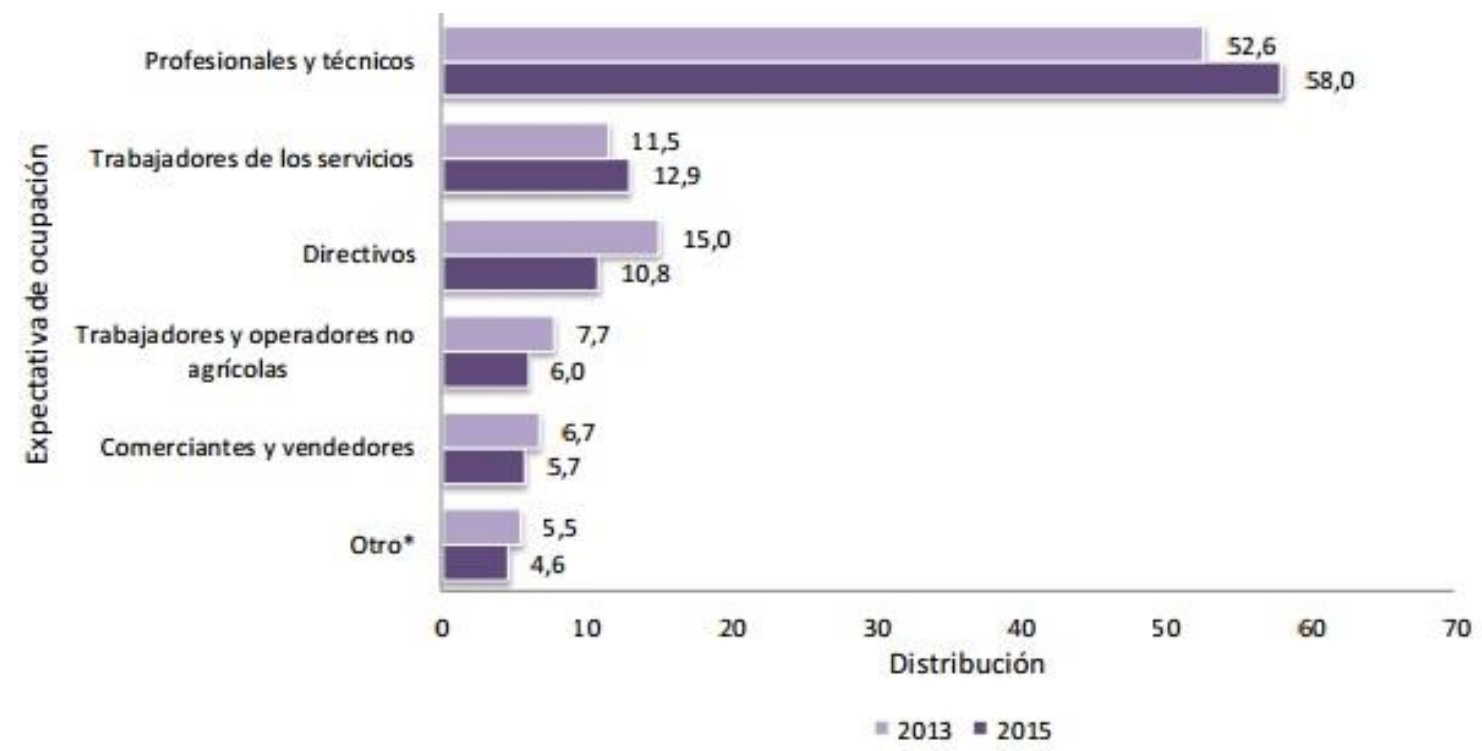

Fuente: DANE - Encuesta de Transición de la Escuela al Trabajo 2015. Tomado de: http://www.dane.gov.co/files/investigaciones/boletines/etet/Bol-tecnico-ETET2015.pdf

\section{Población joven ocupada independiente}

En muchas ocasiones y por falta de oportunidades laborales, las personas como medio de subsistencia comienzan a buscar opciones que les permitan solventar diversas necesidades que deben enfrentar en la vida.

La siguiente gráfica muestra que es de gran importancia la independencia con 31,3\% para el año 2015, sin embargo, no muy lejos se ubica el no encontrar trabajo por búsqueda de un salario que se encuentra en $29,4 \%$. El no encontrar trabajo es lo que lleva a muchos al rebusque y a la independencia, además es una razón por la que el sector informal ha crecido pues muchas personas se someten a cualquier tipo de trabajo con el fin de poder obtener recurso económico. Este sector además es más asequible 
para quienes no tienen experiencia y no cuentan con niveles de educación requeridos en trabajos formales (75).

Gráfica 10. Distribución porcentual de la población ocupada independiente de 14 a 29 años de edad según razones para trabajar como independiente Total 13 ciudades 2013 y 2015

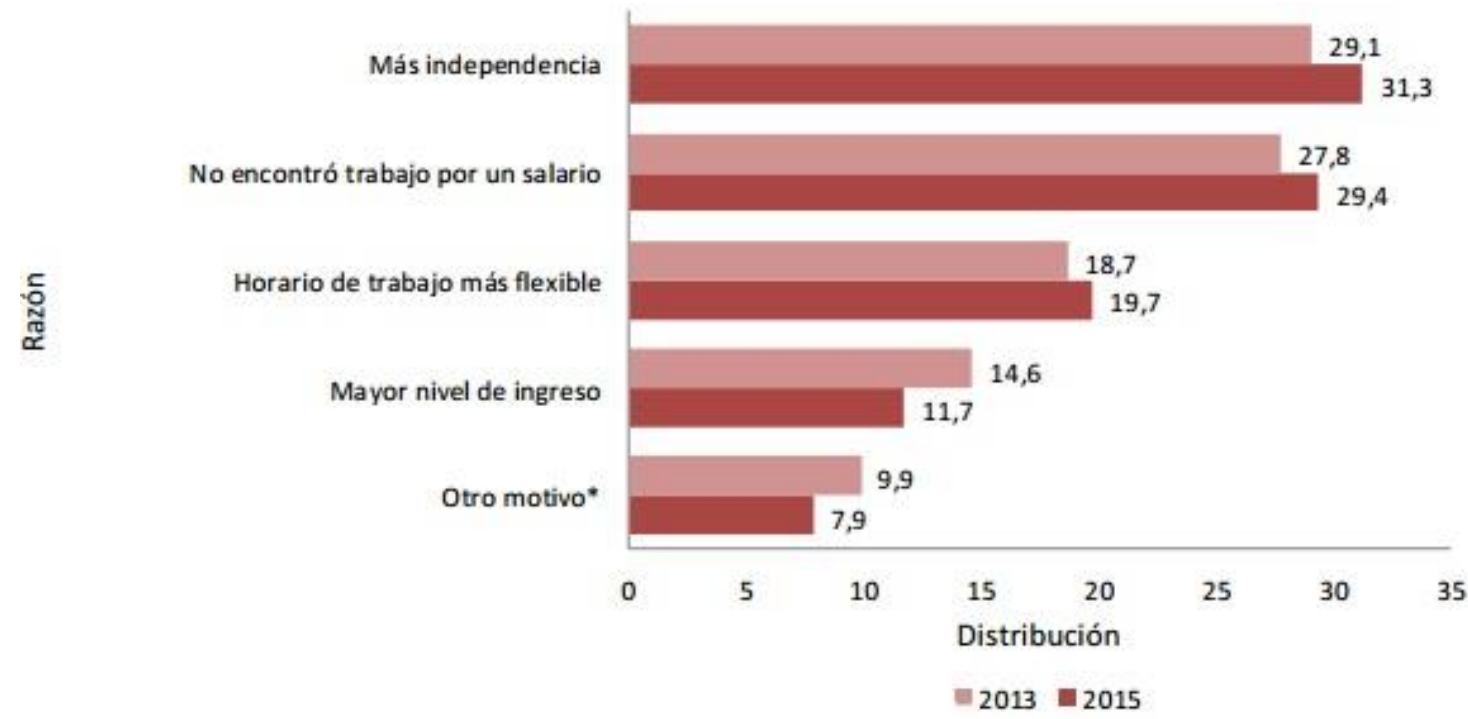

Fuente: DANE - Encuesta de Transición de la Escuela al Trabajo 2015. Tomado de: http://www.dane.gov.co/files/investigaciones/boletines/etet/Bol-tecnico-ETET2015.pdf

\section{Jóvenes ocupados y con seguridad social}

Obtener seguridad social es tan importante en cualquier sociedad porque es mediante esta que los seres humanos logramos obtener protección ante posibles riesgo económicos como consecuencia de una enfermedad de alto costo, de algún tipo de riesgo de trabajo, de quedar desempleado o para tener una vejez digna.

En Colombia los jóvenes entre 14 y 29 años de edad que contaban con seguridad social completa, se encontraban para el año 2013 con 39,7\% y para el año 2015 con 44,6\%, mientras que en la incompleta era de 60,3\% y en el año 2015 estaba en 55,4\%. Es de gran importancia además mencionar que es de notarse que estas cifras son demasiado 
elevadas, pues el porcentaje de afiliación de seguridad social debería tener mayores cifras con el fin de prevenir riesgos económicos para sociedad.

Si bien la incompleta ha bajado y la completa no tiene un buen porcentaje, es necesario poder promocionar la seguridad social y prevenir sobre los posibles riesgos que puede sufrir el ser humano. En este trabajo y según lo que se encontró en los jóvenes es que no ven la importancia sobre la seguridad social, porque simplemente no se ha realizado educación frente a este tema tan importante.

Es necesario que los jóvenes reconozcan la importancia de estar asegurado ante todos los riesgos y que además sepan sobre los costos de no estar asegurados tanto para su economía como para la de sus familias (75).

\section{Gráfica 11. Distribución porcentual de la población de 14 a 29 años de edad ocupada según seguridad social Total 13 ciudades 2013 y 2015}

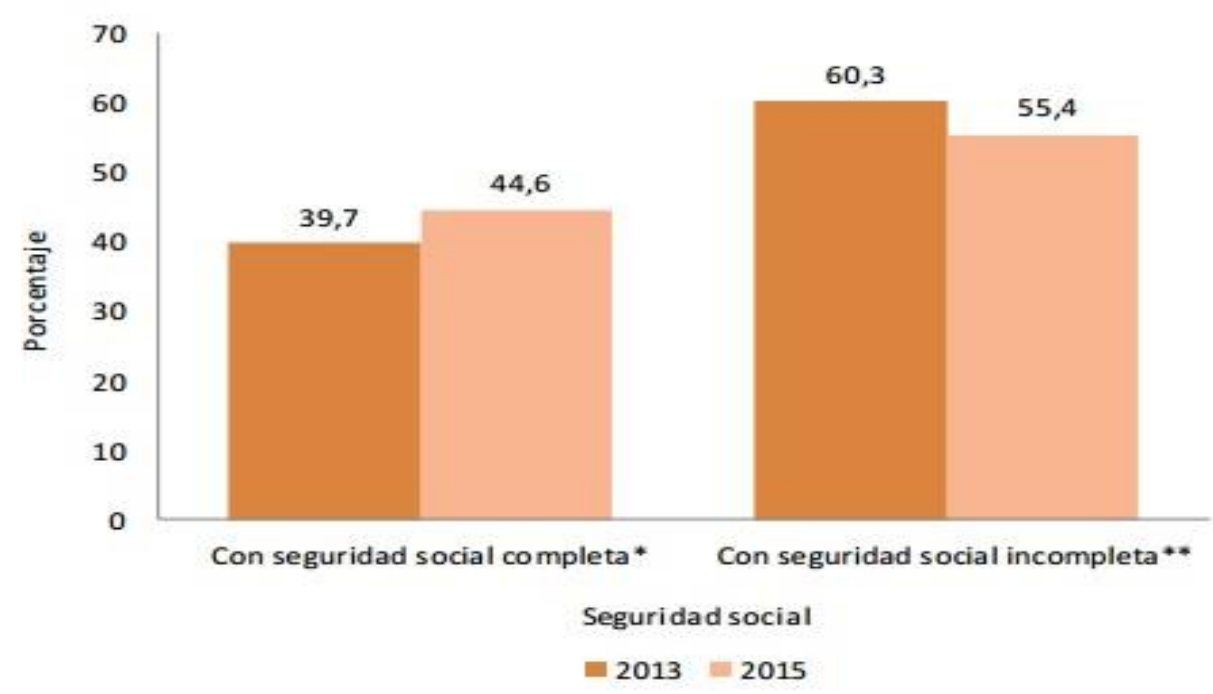

Fuente: DANE - Encuesta de Transición de la Escuela al Trabajo 2015. Tomado de: http://www.dane.gov.co/files/investigaciones/boletines/etet/Bol-tecnico-ETET2015.pdf

\section{Los jóvenes desocupados en Colombia}

El tema de desocupados en Colombia tiene una elevada importancia, en cuanto a que los cambios de modalidades de contratación han permitido a los empleadores medir el 
empleo de la personas o contratar por servicios en tiempos que ellos mismos determinan, es aquí como los derechos de los trabajadores se demuestra que han quedado en manos de los empleadores, dando prioridad a sus necesidades, más que a la estabilidad y necesidad que las personas están buscando (en este caso: los jóvenes).

Esta gráfica muestra las condiciones por las que atraviesan los jóvenes. El encontrar trabajo en el país es cada vez más difícil y se necesita se aborde este tema ya sea desde donde se ofrecen los empleos o desde la capacitación de los jóvenes para lograr la inmersión.

Los jóvenes duran de uno a tres meses en conseguir empleo en un porcentaje de $26,1 \%$, lo que es muy elevado, al igual que de tres o menos de seis meses que es un porcentaje de $25,7 \%$, siendo estos tiempos demasiados largo para personas que se encuentran en edad de trabajar, que cuentan con todas las capacidades para hacerlo, pero que se les limita por diversos aspectos como lo son falta de experiencia, niveles de educación, entre otros.

El conseguir empleo no debería ser tan difícil para una población que tiene grandes expectativas frente a la participación en el mercado laboral, en muchas ocasiones las expectativas son más grandes de lo que se espera, pero es que es obvio cuando se tienen las energías para comenzar a creer que se pueden lograr tantas cosas en la vida y que se logran por medio de ingresos económicos, sin los mismos, lo único que se espera de los jóvenes es indisposición y un alto grado de desinterés por el ingreso a estos mercados laborales (75). 
Gráfica 12. Distribución porcentual de la población desocupada de 14 a 29 años de edad según tiempo de búsqueda de empleo Total 13 ciudades 2013 y 2015

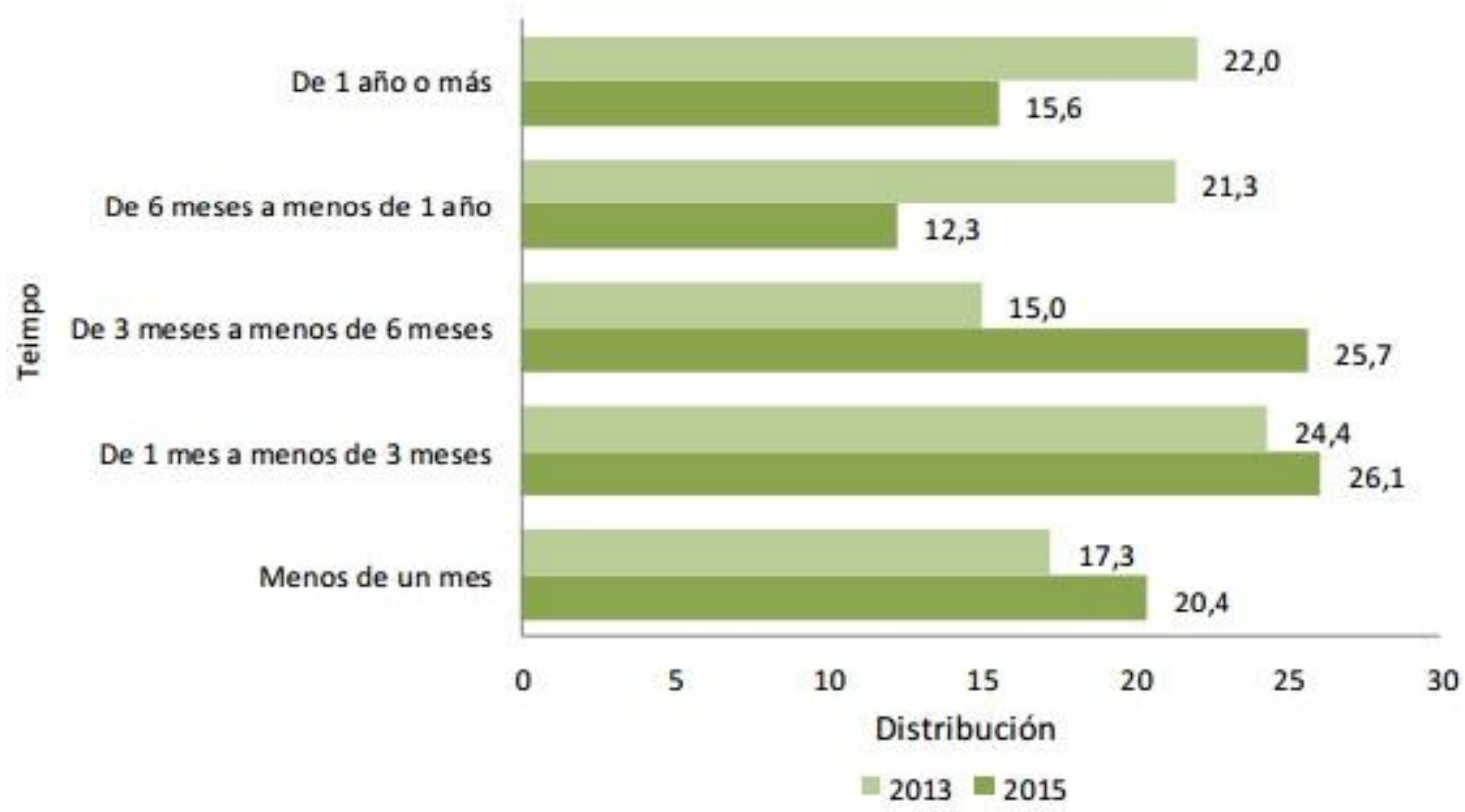

Fuente: DANE - Encuesta de Transición de la Escuela al Trabajo 2015. Tomado de: http://www.dane.gov.co/files/investigaciones/boletines/etet/Bol-tecnico-ETET2015.pdf

\section{Razones para no encontrar empleo inmediato según los jóvenes (14 - 29 años)}

Existen razones por las cuales el acceder al mercado laboral es tan difícil, aunque se reconoce cuáles son las principales razones en vez de disminuir, han ido aumentando y esto se refleja en la siguiente gráfica.

La mayor razón por la que no se logra acceder al mercado laboral es el no tener experiencia laboral la cual para el año 2013 era de 34,3\% y para el año 2015 se encontraba en 40,8\% un aumento significativo. Además este tema es cuestionable en cuanto a que hay muchas expectativas de los jóvenes para realizar inmersión al mercado laboral, pero los empleadores son demasiados exigentes en sus términos de tiempos de experiencia para la contratación cosa imposible para jóvenes que apenas están enfrentándose al ingreso del mercado laboral para adquirir esa experiencia que tanto exige el mercado laboral. 
Otras de las razones por las que se cree se obstaculiza el ingreso al mercado laboral es que los requisitos del trabajo son mayores que la educación/formación recibida, aunque las cifras han variado siendo en el 2013 un porcentaje de 21,3\% y para el 2015 encontrándose en $16,8 \%$ y esto porque existe más preocupación por capacitar para el trabajo, un ejemplo claro es el SENA, sin embargo, existen falencias en la relación entre las instituciones educativas y el trabajo, esto porque primero hay desconocimiento de las ofertas laborales, segundo porque no hay interés por las instituciones educativas por capacitar para emplear, sino simplemente su interés es capacitar y según lo establezcan, las oficina de empleo de las universidades son limitadas y en muchas ocasiones invisibles.

Y sin duda alguna concuerdo con que las oportunidades de trabajo no son suficientes en el 2013 el porcentaje era de 15,3 y para el año 2015 era de 14,3\%, pues es más la población en edad para trabajar, que lo existe en oportunidades de empleo. Sin embargo, crear empresa no es la solución a la problemática que hoy existe (75).

Gráfica 13. Distribución porcentual de la población desocupada de 14 a 29 años de edad según principal obstáculo para encontrar un trabajo Total 13 ciudades 2013 y 2015

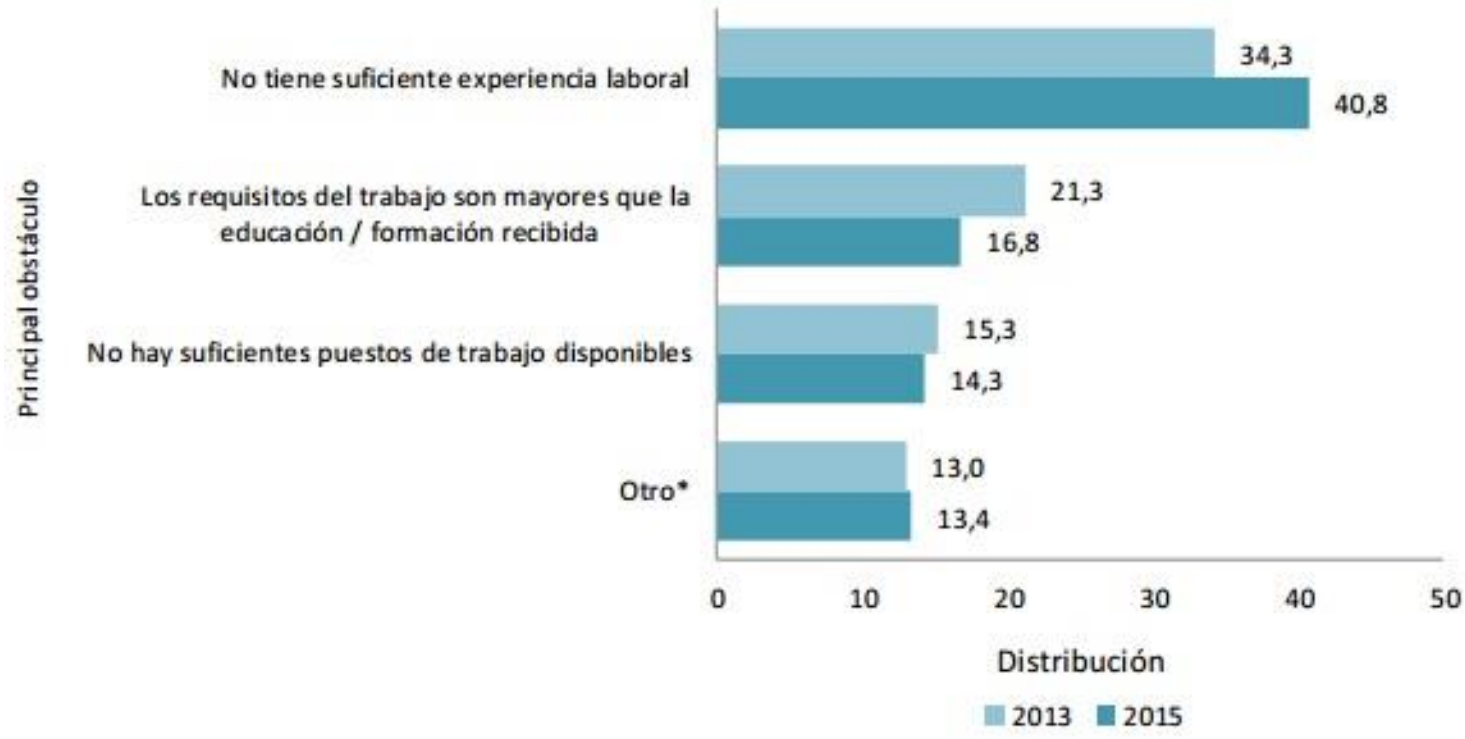

Fuente: DANE - Encuesta de Transición de la Escuela al Trabajo 2015. Tomado de: http://www.dane.gov.co/files/investigaciones/boletines/etet/Bol-tecnico-ETET- 
Las anteriores cifras demuestran la situación que viven los jóvenes en Colombia y que el panorama no se muestra en su mayoría positivo para ellos. Las expectativas sin duda alguna son mayores, pero solo quiénes deben enfrentarse a esta problemática saben lo difícil que es hacer inmersión al mercado laboral y se preocupan sobre este panorama.

A quiénes las necesidades se hacen visibles saben lo importante que es acceder de una manera pronta al mercado laboral.

Es necesario desde estos puntos expuestos replantear la necesidad de políticas que estén dirigidas a la población específica según sus necesidades, también específicas. Es tan importante que se tengan en cuenta con el fin de comenzar a brindar soluciones y mejoras concretas, teniendo en cuenta todos los ámbitos.

El grupo etario de la juventud debe ser analizado primero por necesidades, segundo por edades que no tengan un rango tan grande cómo es de 14 a 28-29 años de edad y tercero por sus niveles educativos, de tal forma que se logren ver las necesidades y las propuestas logren abordar todo tipo de problemáticas que enfrente este grupo etario.

Además de esto se hace necesario trabajar por la población productiva y que es productiva activa, pues se estará trabajando por mejor contribución y no por mayor población subsidiada que llevará a un desenlace de un desarrollo económicamente inactivo. Es necesario combatir y luchar por las desigualdades porque tendremos un sistema que no funcionará que nos llevará a hacer un mal uso de los recursos que solo se encaminarán a favorecer y apoyar aquellas poblaciones que se encuentran en necesidades, esto por Cecchini y Martínez. (33) 


\section{CAPÍTULO 3. JÓVENES EN BOGOTÁ Y CONDICIONES LABORALES}

Bogotá, la capital de Colombia, se compone de una población que expresa la diversidad demográfica del territorio colombiano, Después de muchas migraciones en el pasado, la situación no ha variado y son múltiples las razones que les permiten a las personas de las regiones plantearse la idea de salir de sus lugares natales para habitar en la capital. Las oportunidades son una de ellas. Los jóvenes al terminar su bachillerato están eligiendo Bogotá para seguir sus estudios y en muchas ocasiones para conseguir mejores oportunidades laborales, tratando de insertarse al mercado laboral formal/informal. Aunque no solo se hace para mejorar sus condiciones económicas, pues en muchas ocasiones las personas en distintos lugares del territorio colombiano se ven forzadas a abandonar sus lugares de origen por el conflicto armado multipolar.

Las condiciones son aún más exigentes para esta población que se encuentra acostumbrada al campo y a vivir de manera distinta a lo que representa vivir en la urbe. El espacio geográfico es mucho más complejo que lo que representa el campo, en lo que tiene que ver con infraestructura y población.

La migración es entendida por el DANE como: "La migración, tanto interna como internacional es uno de los tres componentes demográficos que determinan el volumen, estructura y distribución de la población en un territorio" (76). Esta población crece cada vez más y las condiciones se vuelven cada vez más difíciles para muchos. El acceso al mercado laboral es restringido para la demanda existente dentro del país.

Las necesidades obligan a la supervivencia del ser humano por medio de un ingreso económico que le permita solventar sus necesidades y ello se vuelve más difícil ante el cierre de oportunidades laborales. Por lo general, la población comienza a trabajar de manera independiente sean jóvenes o adultos en diversas actividades como negocios pequeños en sus hogares, vendedores ambulantes. En algunas ocasiones logran desde su experiencia construir pequeñas empresas, que les permiten generar ingresos para cubrir necesidades, acción que no solo enfrentan adultos, sino también jóvenes que no han podido integrar al mercado laboral estable o simplemente no ha conseguido una oportunidad. 
Para esta población joven que ha decidido crear empresa y desean que su empresa crezca, la Ley 1429 de 2010: Formalización y Generación de Empleo, se centra en ofrecerles incentivos para creación y contratación de personal y esto se apoya en un programa de empleabilidad ya antes mencionado, el cual es ofrecido por el Ministerio de Trabajo. Esto generaría un gran cambio para las empresas que demuestren un desarrollo económico, sin embargo, cabe resaltar que las mismas pueden quebrar.

Gráfica 14. Tabla Beneficios 1429 de 2010. "Ley de Primer Empleo

\begin{tabular}{|c|c|}
\hline $\begin{array}{r}\text { LEY } 142 \\
\text { "LEY DE PRI }\end{array}$ & R EMPLEO” \\
\hline BENEFICIOS EMPRESAS & BENEFICIOS JOVENES \\
\hline $\begin{array}{l}\text { - Podrán tomar los aportes parafiscales } \\
\text { correspondientes a los nuevos empleos } \\
\text { (progresividad dependiendo el tiempo que } \\
\text { lleve la empresa desarrollando su actividad } \\
\text { económica principal). } \\
\text { - No pagara el costo de la matricula mercantil } \\
\text { durante el primer año, en los dos siguientes } \\
\text { años pagaran el } 50 \% \text { y } 75 \% \text { de la tarifa } \\
\text { establecida. } \\
\text { No pagaran impuestos de renta en sus primeros } \\
\text { años de operación. En los siguientes tres años } \\
\text { lo pagarán de manera progresiva, } 25 \%, 50 \% \text { y } \\
75 \% \text { de la tarifa general establecida, } \\
\text { respectivamente. }\end{array}$ & $\begin{array}{l}\text { - Más trabajos. } \\
\text { - Contrataciones con seguridad social (no } \\
\text { menor, ni mayor a } 6 \text { meses). } \\
\text { - Obtener experiencia. }\end{array}$ \\
\hline
\end{tabular}

Información tomada de: BENEFICIOS DE LA LEY FORMALIZACIÓN Y GENERACIÓN DE EMPLEO (LEY 1429 de 2010) "Ley de Primer Empleo" Ministerio de Trabajo. Guía Beneficios. Descargar en: http://www.mintrabajo.gov.co/empleo/abece-ley-de-primerempleo.html 
La Ley ofrece además contrataciones para jóvenes que se encuentren buscando empleo y que no sean mayores de 28 años de edad. También ofrece a las empresas bajar costos y un límite de contratación; pero las garantías de los jóvenes quedan excluidas de la misma ley al no referirse a ellos, la empleabilidad de los jóvenes no se destaca, la individualización de sus derechos se hace más visibles, lo que si se destaca es el emprendimiento, un emprendimiento que propone la individualización de los riesgos, riesgos donde la protección social no tiene cabida, no mientras no se propongan nuevas propuestas acertadas a esta problemática y estas nuevas ideas y formas de contratación.

La ley y los programas propuestos parecen no ofrecerles mejores oportunidades y una estabilidad que permita a los mismos poder competir posteriormente con esta experiencia. Recordemos que en Colombia los empleadores exigen experiencia de un año en adelante, o hasta dos. Además, no son leyes que sean universales, son leyes que se están focalizando, por tanto no es una ley de enfoque de derechos que tenga en cuenta a todas las personas garantes de derechos y que el Estado garantice su análisis, su funcionamiento, su transparencia, participación de diferentes entes para su construcción y una inversión social eficaz. Realizar inmersión al mercado laboral sin duda alguna es difícil para los más pobres o con más necesidades que para otros y en esto tiene que ver también con los dos tipos de sectores (formal e informal), sin embargo, no quiere decir que otros sectores no se enfrenten a esta problemática y se ajusta muy bien a las diversidad de clases sociales y a la que se enfatiza este trabajo; las personas de estrato 3 y 4, clase media o población sandwich, no son una población a la que se direccionen las políticas públicas generadas, es por esto que se necesitan nuevas estrategias que tengan en cuenta todas las poblaciones con sus diferencias y que apunten a las diferentes necesidades, sin que estas se enfrenten a riesgos que posiblemente traigan más gasto, al requerir subsidios sin ser necesariamente pobres.

Las capacidades además de generar empresas y empleos no son para todos, tema que no se tiene en cuenta. Estas nuevas políticas y programas están dirigidos a poblaciones específicas y que tienen recursos y ganas de crear, existe mucha población, si no es su mayoría que no tienen como propósito de vida generar empresa y creer en el emprendimiento propuesto por este gobierno, sino que su ideal está en poder hacer inmersión en el mercado laboral en condiciones dignas y justas. 
De lo anterior, es preciso mencionar que la ley discrimina a una población que tuvo acceso al trabajo pero que no volvió a conseguir, situación de muchos jóvenes profesionales o a punto de graduarse en el país. No hay una norma destinada a todas las poblaciones, sin discriminación alguna, y esto se hace necesario. Además de no considerar las diferencias que existen en este grupo poblacional, la capacidad de generar empresa no es para todos, no todos piensan enfrentarse a más riesgos de los que probablemente ya se estén enfrentando como deudas, denota un trabajo constante por las inequidades, más que por la eliminación de la pobreza y de inequidades.

La dinámica de contratación en Colombia es más rotativa y transitoria que en años anteriores, y los bogotanos sufren de este tipo de contratación. Se puede decir que esto funciona así debido a:

El desconocimiento de los jóvenes sobre el mercado de trabajo y los puestos disponibles haría que aceptaran aun desconociendo si ofrece las características buscadas. A su vez la forma en que el empleador aprende si el joven es el trabajador adecuado para el puesto sería contratándolo y evaluando su desempeño. Ambos procesos de aprendizaje explicarían que los comienzos de la inserción en el mercado laboral se caracterizaran por corta permanencia en el puesto, alta rotación entre puestos y elevado flujo hacia el desempleo (77).

La población joven en Colombia y en especial en grandes ciudades como Bogotá que es su capital, sufre una grave crisis a la hora de acceder al empleo, puesto que las condiciones de formalidad son mínimas para esta población, además de no ser dignas, ni equitativas.

De acuerdo a la revista Dinero el empleo informal representó para el trimestre comprendido entre noviembre de 2015 y enero de 2016 el 47,1\% y el formal el 52,9\%, cifras muy parejas que reflejan la situación del país en cuanto a oportunidades laborales (78). Estas oportunidades tienen diversas formas de presentarse en las diferentes regiones del país, sin embargo, se conoce y es claro que la capital es la que más recibe todo tipo de población, pues ofrece más oportunidades para los jóvenes tanto en el sector formal como en el informal, permitiendo así una migración a todos los niveles, lo que genera una competitividad cada vez más alta.

Es posible decir que existe una brecha grande en lo que refiere a empleos por género. 
La tasa de desempleo para la población joven fue de 18,0\%, en el primer trimestre de 2015 fue de 16,2\%. Para los hombres jóvenes se ubicó en 13,5\% y para las mujeres jóvenes fue de 23,8\% (79).

Por otro lado, cabe mencionar que el DANE demuestra con cifras que Bogotá es una de las ciudades que tiene las tasas de desempleo más bajas con 8,5\% (80). No obstante, aunque estas tasas se muestren satisfactorias es de gran importancia mencionar que existen trabajos formales e informales y que el trabajo informal puede cuestionarse sobre estas cifras, pues no es lo mismo estar empleado de una forma legal y digna.

Las oportunidades en Bogotá son competitivas y muy escasas, los jóvenes al ser una población activa, que se encuentra con todas las capacidades suficientes para absorber conocimientos y entregar buenos servicios, se encuentra en una constante búsqueda de mejores oportunidades laborales

Según proyecciones de población joven 14-28 años, en Bogotá hay 1.945.346, jóvenes, siendo 959.403 mujeres y 985.943 hombres (28) y según la publicación trimestral de la Dirección de Equidad y Políticas Poblacionales ROSTROS Y RASTROS. Razones para construir ciudad del año 2014, las pirámides poblacionales demuestran que la población joven es más grande en comparación con otras edades, excepto por el rango de edad de 30 a 35 años de edad que supera la edad joven a partir de 2013 y 2014, el crecimiento es dado por el género femenino principalmente (81).

La problemática de esta población, es preciso sea tenida en cuenta al igual que sus esfuerzos por querer mejorar la calidad de vida. Las políticas deben cambiar sus fines, prometiéndoles mejores oportunidades y no más necesidades de las que ya se puedan tener.

Gráfica 15. Población por rangos de edad y sexo en porcentajes sobre total población ciudad 


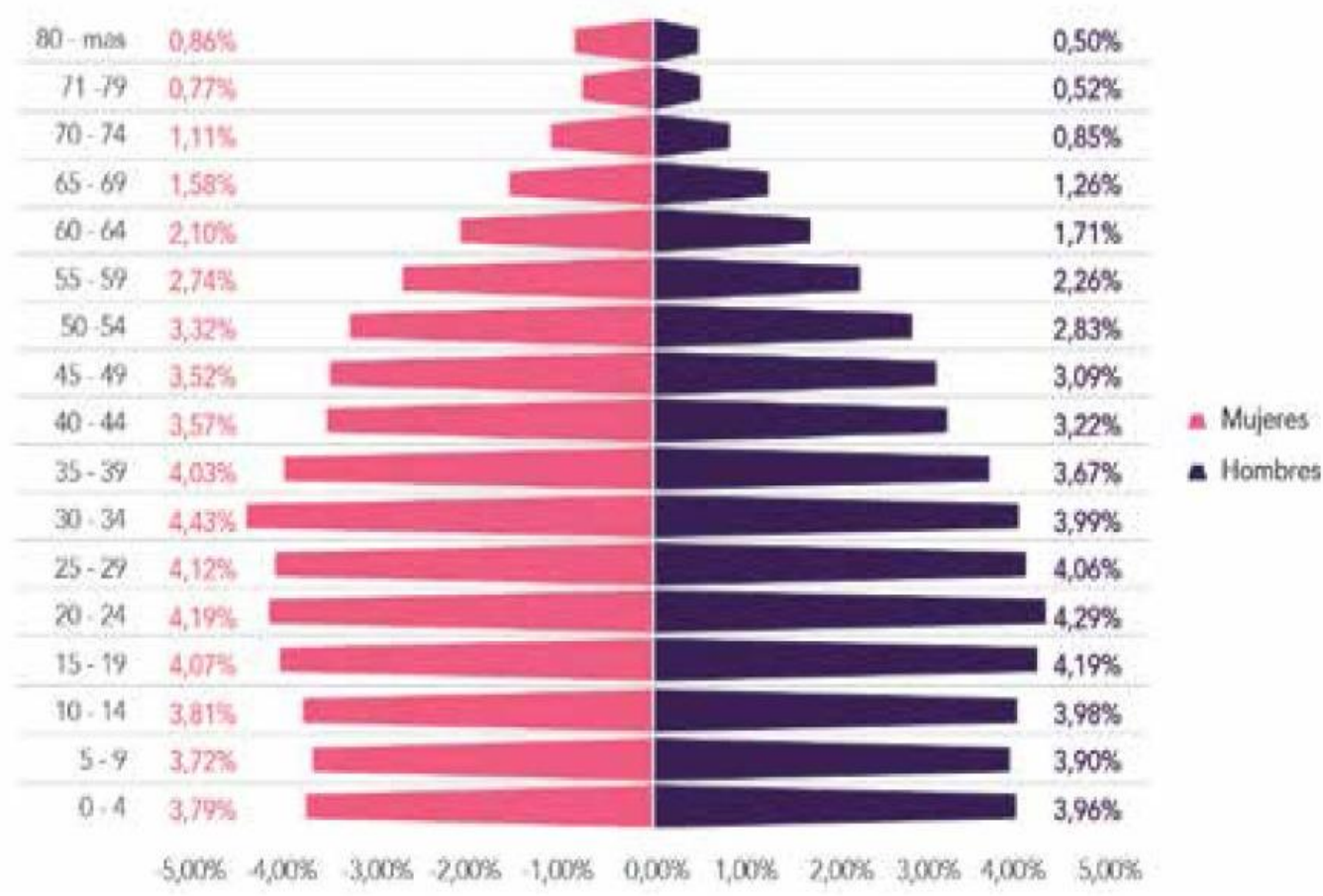

Fuente: Proyecciones poblacionales DANE. Procesamiento dirección de Estudios Macro, SDP Tomado de: Fuente: TRANSCURRIR VITAL V. JÓVENES EN BOGOTÁ. Rostros y Rastros Publicación trimestral de la Dirección de Equidad y Políticas Poblacionales. Año 2. 6. 2014. Secretaría Distrital de Planeación.

De acuerdo a este crecimiento existente, se puede decir que la población joven se está enfrentando a un mercado laboral competitivo, que requiere de capacitación y que es de difícil acceso por la misma competencia y magnitud poblacional en el caso de los jóvenes.

Los jóvenes en la ciudad de Bogotá se enfrentan a la competencia laboral, que cada día es más estrecha. Solo quiénes han tenido necesidades o por interés propio han buscado ofertas laborales, podrán tener clara cuál es la problemática que no solo enfrenta la ciudad, sino el país entero. Muchas veces esta población no le da importancia al empleo hasta que debe enfrentarse al mundo laboral. Las garantías que se les ofrece allí cada día son menores:

La problemática juvenil se refiere a la materialización de sus derechos estipulados en la Política Pública de Juventud (Decreto 482 de 2006), ya que esta población no cuenta con las condiciones suficientes para poder satisfacer sus necesidades en lo que a sus derechos se refiere, la visión que tiene la 
ciudadanía en cuanto a los jóvenes, principalmente a la ocupación de su tiempo y cómo influye en su desarrollo personal; la deserción escolar hace que los jóvenes salgan al mercado laboral a temprana edad, dejando a un lado sus estudios, las transformaciones de los roles (jóvenes con mayor independencia, menor número de hijos), entre otros elementos vitales para su desarrollo (82).

La Política Pública de Juventud para Bogotá D.C. 2006 - 2016, refiere en el artículo 3 a principios, dimensiones y propósitos que permitirían que los jóvenes tengan una mejor y mayor participación en la sociedad. Entre los cuales para este trabajo se destacan: la universalidad buscando igualdad de oportunidades para aquellos que se encuentran enfrentados a alguna vulnerabilidad, equidad de géneros buscando las mismas oportunidades para ejercer sus derechos, participación para la toma de decisiones, la difusión de información que permita a los jóvenes tener una apropiación y conocimiento sobre contenidos de jóvenes, el Estado y la sociedad. (83).

La población joven de la ciudad crece progresivamente, con diferentes necesidades según su edad, su entorno socioeconómico y condiciones sociales. Es decir, no es homogénea en su composición y alternativas, lo cual hace más compleja su atención (82).

Gráfica 16. Población total de 15 a 29 años en Bogotá 2010 - 2014

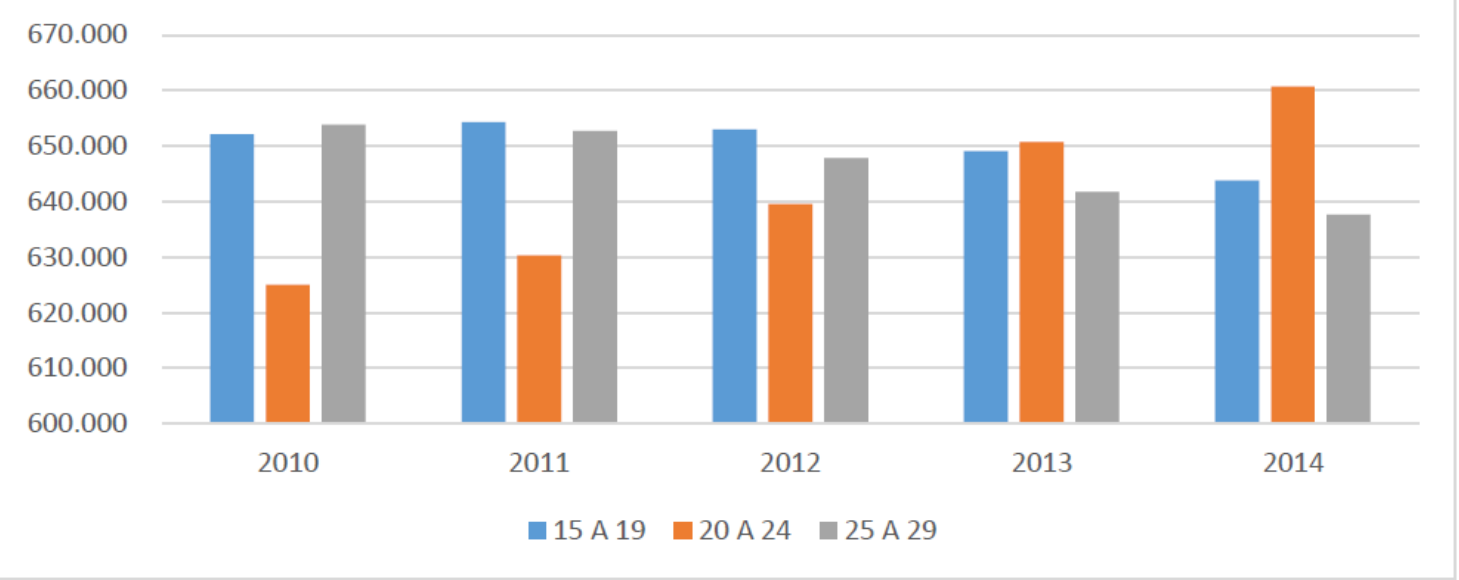

Fuente proyecciones poblacionales DANE. Procesamiento Dirección de Estudios macro. SDP Fuente: TRANSCURRIR VITAL V. JÓVENES EN BOGOTÁ. Rostros y Rastros Publicación trimestral de la Dirección de Equidad y Políticas Poblacionales. Año 2. 6. 2014. Secretaría Distrital de Planeación. Tomada de: Diagnóstico Sectorial 2015. Octubre 2015. Secretaría de Integración Social. 
Es de resaltar cómo la población joven de Bogotá, de 20 a 24 años de edad, ha tenido un crecimiento durante los años, como muestra la Gráfica 3. En cuanto a las otras edades, la gráfica muestra que van disminuyendo, sin embargo la población general sigue creciendo en la ciudad. La edad de trabajar es la más alta y las tasas de desempleo son elevadas.

Es importante mencionar que no todas las personas cuentan con las mismas necesidades laborales, no es lo mismo decir que una persona que se encuentra en quintil 1 , tenga la necesidad que puede tener una persona quintil 6 y tampoco es lo mismo en Bogotá salir de universidad pública, que de una universidad privada, aunque en Colombia la Universidad Nacional siendo pública es una de las más apetecidas.

Por su lado el ingreso a la educación superior según informe del año 2015 del Ministerio de Trabajo tiene mayor incidencia en ciudades como Bogotá con participación del 48,5\%, Santander con 40,3\%, Quindío 43,7\% entre otras. La población que ingresa a la educación superior inmediatamente sale del colegio se representa así: de instituciones públicas el 29,9\%, que además ingresan a instituciones educativas de nivel superior públicas, mientras que quiénes salen de instituciones privadas representan el 49,6\% y hacen ingreso a instituciones de nivel superior privadas (84).

En lo que refiere a la ubicación de la población joven en Bogotá, su distribución se encuentra así:

En contexto general, la distribución de la población total bogotana se encuentra concentrada en las localidades de Suba (1.120.342) y Kennedy (1.019.949), con cifras que superan el millón de habitantes, Engativá cercana a los 800.000, Ciudad Bolívar por encima de los 700.000, Bosa más de 500.000 y Usaquén y San Cristóbal por encima de los 400.000. En este sentido se puede deducir que la mayoría de la población bogotana se localiza hacia el margen sur occidental y parte del sur oriental de la ciudad y hacia el norte (82).

Según estas cifras, ¿sería posible aplicar la Ley 1429 de 2010? Si observamos atentamente a la población joven en su gran mayoría se encuentra en sectores que no pasan de estrato tres, lo cual es una desventaja a la hora de crear empresa; muchas de estas personas o no cuentan con los recursos o simplemente no quieren crear empresa. 
Además de lo anterior cabe mencionar los esfuerzos que en muchos casos la población de estrato 1 y 2 debe hacer para poder acceder a la educación, y que diferentes a los que problablemente deban hacer estratos 5 y 6 en Bogotá, lo que introduce una gran inequidad en el campos de las oportunidades de estudio. Valdría la pena tener en cuenta que estratos 3 y 4 al no ser pobre, ni rico no esta siendo tenido en cuenta, por tanto las políticas y estrategias asumen que pueden solventar sus necesiades y no es así, se necesitan política universales que tengan en cuenta los derechos tanton económicos, como sociales y hasta culturas para construir una sociedad con bienestar, donde todos hagan parte, conozcan y se conviertan en garantes de sus propios derechos.

Con relación al desempleo en la ciudad, en el primer trimestre del año 2016 sigue teniendo tasas altas siendo de 16,8\%. En los últimos años, según el Observatorio de Desarrollo Económico, las cifras son más altas que los cuatro años anteriores, aunque no es la ciudad con más desempleo (85). 


\section{Gráfica 17. Desempleo juvenil en Bogotá y Colombia (\%) Trimestre móvil noviembre - enero (2008-2016)}

\section{Desempleo juvenil en Bogotá y Colombia (\%) Trimestre móvil noviembre- enero (2008-2016)}
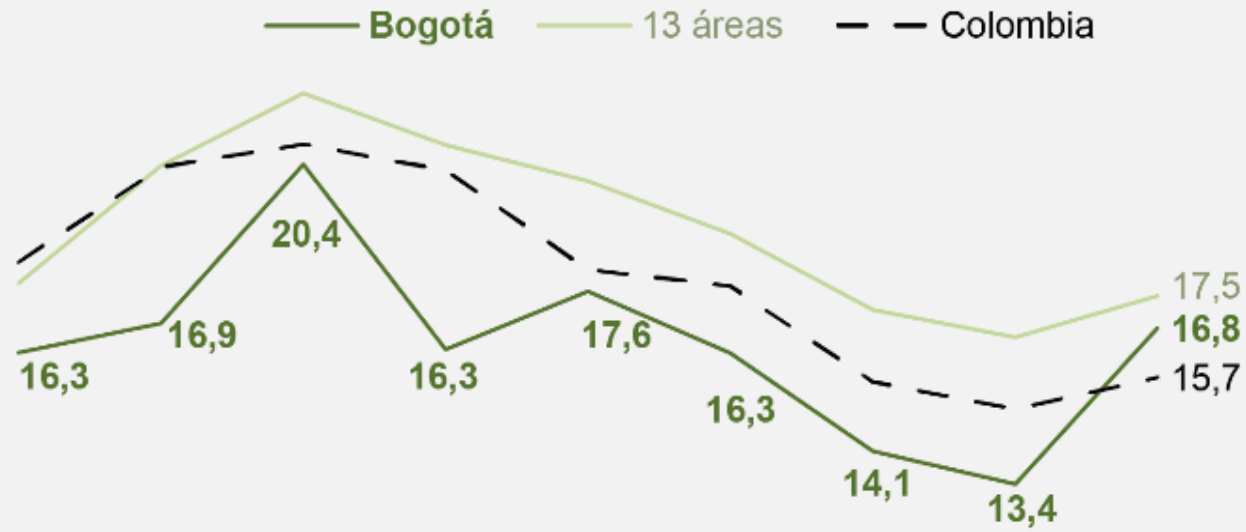

\begin{tabular}{lllllllll|}
2008 & 2009 & 2010 & 2011 & 2012 & 2013 & 2014 & 2015 & 2016
\end{tabular}

Fuente: Dane. Gran Encuesta Integrada de Hogares -GEIH.

Fuente: Dane Gran Encuesta Integrada de Hogares.

Tomado de: Observatorio de Desarrollo Económico. Secretaría de Desarrollo Económico.

La población joven se caracteriza por una participación activa y en crecimiento en comparación con años anteriores en la educación profesional, sin embargo, es claro que existe deserción escolar y se debe entre otras, a factores económicos. En muchas ocasiones se debe elegir entre seguir estudiando o trabajar para poder comer. En otros casos también se sabe que la deserción se origina en la toma de decisiones equivocas del programa educativo o poco gusto por la educación. Finalmente en algunos casos la deserción se produce porque se logra una inserción laboral que interrumpe jornadas de estudio o queda el gusto por el ingreso económico, entre otros factores, problemas que de los sistemas políticos para esta población, pero que no han mostrado solución, porque estas políticas públicas son creadas por gobiernos, nuevas propuestas de gobiernos que desvían el alcance o las mejoras para un desarrollo social y económico.

Las cifras sobre el mercado laboral para esta población preocupan y es necesario que exista relación sobre lo que se hace en el gobierno (Estado, la educación (instituciones), 
las empresas o empleadores y la población joven, se debe agregar además que esta población es tan importante como cualquier otra y que necesita que se le ofrezcan garantías y para el ámbito laboral se le declaren derechos, pues es una población que aún sigue siendo maltratada por considerarse sin experiencia frente a diversos ámbitos.

Se necesitan políticas nuevas que permitan recoger todas las experiencias y todas las necesidades de las personas en este ámbito, sin exclusiones como se están viendo y sin olvidar que el ser humano requiere de protecciones que por sí solo en muchas ocasiones no se puede dar. 


\section{CAPÍTULO 4. PERCEPCIONES DE LOS JÓVENES}

\subsection{Recolección de datos}

Para la recolección de datos se trabajó técnicas de observación y entrevistas semi estructuradas. Ver formato entrevista en anexos 1 y 2.

El formato aplicado en las entrevistas se encuentra compuesto por:

1. Consentimiento informado mediante el cual se expresa el fin con el que será utilizada la entrevista y la aprobación del entrevistado.

2. Datos del entrevistado, campo informativo que permitiría conocer más acerca de los entrevistados. (Género, Universidad, Colegio/bachillerato, grupo étnico, entidad donde labora (si labora).

3. El proceso del sujeto del entrevistado en el que se hace acercamiento a dos temas de interés: procesos educativos y laborales (si la persona los ha tenido).

4. Políticas y leyes de empleo para jóvenes. Este apartado permitiría saber si hay interés y conocimientos en el área laboral por parte de los jóvenes.

Es necesario precisar que las grabaciones de las entrevistas realizadas tienen corta duración, pues los entrevistados no mostraban interés sobre un tema que pese a ser considerado como problemática mundial, no parece preocuparlos demasiado. 


\section{Caracterización de los sujetos participantes}

\section{Gráfica 18. Tabla de caracterización sujetos participantes egresados}

\begin{tabular}{|c|c|c|c|c|c|c|c|c|c|c|c|c|}
\hline \multirow{2}{*}{$\begin{array}{c}\text { ENTREVISTADOS/E } \\
\text { GRESADOS } \\
\end{array}$} & \multirow{2}{*}{ GÉNERO } & \multirow{2}{*}{ EDAD } & \multirow{2}{*}{ PROCEDENCIA } & \multirow{2}{*}{\begin{tabular}{|l|} 
GRUPO \\
ÉTNICO \\
\end{tabular}} & \multicolumn{2}{|c|}{ COLEGIO BACHILLERATO } & \multicolumn{3}{|c|}{ UNIVERSIDAD } & \multirow{2}{*}{ CARRERA } & \multicolumn{2}{|r|}{ TRABAJA } \\
\hline & & & & & $\begin{array}{l}\text { PÚBLICO } \\
\end{array}$ & PRIVADO & PÚBLICA & PRIVADA & \begin{tabular}{|l|} 
EXTRANJERA \\
\end{tabular} & & SIINd & EMPRESA \\
\hline ENTREVISTADO 1 & MUJER & 23 & $\begin{array}{r}\text { LA VEGA, } \\
\text { CUNDINAMAR } \\
\mathrm{CA}\end{array}$ & No & & $x$ & & $\begin{array}{r}\text { FUNDACIÓN } \\
\text { UNIVERSITARI } \\
\text { A DEL ÁREA } \\
\text { ANDINA }\end{array}$ & & ENFERMERÍA & $x$ & $\begin{array}{l}\text { CLÍNICA SAN } \\
\text { RAFAEL- SECTOR } \\
\text { SALUD }\end{array}$ \\
\hline ENTREVISTADO 2 & HOMBRE & 25 & BOGOTÁ & no & & $x$ & & $\begin{array}{r}\text { PONTIFICA } \\
\text { UNIVERSIDAD } \\
\text { JAVERIANA }\end{array}$ & & SOCIOLOGÍA & $x$ & \\
\hline ENTREVISTADO 3 & MUJER & 23 & BOGOTÁ & No & & $x$ & & $\begin{array}{r}\text { PONTIFICA } \\
\text { UNIVERSIDAD } \\
\text { JAVERIANA }\end{array}$ & & ARQUITECTURA & $x$ & $\begin{array}{c}\text { TEMPORAL- } \\
\text { ARCADIA } \\
\text { ARQUITECTURA - } \\
\text { SECTOR DISEÑO - } \\
\text { CONSTRUCCIÓN }\end{array}$ \\
\hline ENTREVISTADO 4 & MUJER & 27 & $\begin{array}{l}\text { IBAGUÉ, } \\
\text { TOLIMA }\end{array}$ & No & $x$ & & & & \begin{tabular}{|r|} 
GRACELAND \\
UNIVERSITY, \\
USA
\end{tabular} & PSICOLOGÍA & $x$ & \\
\hline
\end{tabular}

Gráfica 19. Tabla de caracterización sujetos participantes estudiantes

\begin{tabular}{|c|c|c|c|c|c|c|c|c|c|c|c|c|}
\hline \multirow{2}{*}{$\begin{array}{l}\text { ENTREVISTADOS/E } \\
\text { STUDIANTES }\end{array}$} & \multirow{2}{*}{ GÉNERO } & \multirow{2}{*}{ EDAD } & \multirow{2}{*}{ PROCEDENCIA } & \multirow{2}{*}{$\begin{array}{l}\text { GRUPO } \\
\text { ÉTNICO } \\
\end{array}$} & \multicolumn{2}{|c|}{ COLEGIO BACHILLERATO } & \multicolumn{3}{|c|}{ UNIVERSIDAD } & \multirow{2}{*}{ CARRERA } & \multicolumn{2}{|r|}{ TRABAJA } \\
\hline & & & & & PÚBLICO & PRIVADO & PÚBLICA & PRIVADA & EXTRANJERA & & SI NO & EMPRESA \\
\hline ENTREVISTADO 5 & MUJER & 25 & $\begin{array}{r}\text { ISTMINA, } \\
\text { CHOCÓ }\end{array}$ & AFRO & & $x$ & $\begin{array}{r}\text { UNIVERSIDAD } \\
\text { DISTRITALY } \\
\text { ESAP }\end{array}$ & & & $\begin{array}{r}\text { INGIENERÍA } \\
\text { CATASTRALY } \\
\text { GEODESÍA Y } \\
\text { ADMINISTRACIÓN } \\
\text { PÚBLICA } \\
\end{array}$ & $x$ & \\
\hline ENTREVISTADO 6 & HOMBRE & 19 & BOGOTÁ & No & $x$ & & & $\begin{array}{r}\text { UNIVERSIDAD } \\
\text { DE LA SALLE }\end{array}$ & & $\begin{array}{l}\text { NEGOCIOSY } \\
\text { RELACIONES }\end{array}$ & $x$ & \\
\hline ENTREVISTADO 7 & HOMBRE & 20 & BOGOTÁ & No & & VALIDÓ & & $\begin{array}{r}\text { UNIVERSIDAD } \\
\text { CENTRAL } \\
\end{array}$ & & CINE & $x$ & \\
\hline ENTREVISTADO 8 & MUJER & 22 & BOGOTÁ & NO & & $x$ & & $\begin{array}{r}\text { UNIVERSIDAD } \\
\text { KONRAD } \\
\text { LORENZ }\end{array}$ & & PSICOLOGÍA & $x$ & $\begin{array}{r}\text { UNIVERSIDAD DE } \\
\text { CUNDINAMARCA- } \\
\text { ÁREA SOCIAL }\end{array}$ \\
\hline ENTREVISTADO 9 & MUJER & 20 & BOGOTÁ & No & & $x$ & & $\begin{array}{r}\text { UNIVERSIDAD } \\
\text { DE LA SALLE }\end{array}$ & & $\begin{array}{l}\text { NEGOCIOS Y } \\
\text { RELACIONES }\end{array}$ & $x$ & \\
\hline ENTREVISTADO 10 & MUJER & 21 & BOGOTÁ & No & & $x$ & & $\begin{array}{r}\text { UNIVERSIDAD } \\
\text { DE LA SALLE }\end{array}$ & & $\begin{array}{l}\text { NEGOCIOS Y } \\
\text { RELACIONES }\end{array}$ & $x$ & \\
\hline ENTREVISTADO 11 & HOMBRE & 24 & BOGOTÁ & No & $x$ & & & $\begin{array}{l}\text { UNIVERSIDAD } \\
\text { COOPERATIVA } \\
\text { DE COLOMBIA }\end{array}$ & & $\begin{array}{r}\text { COMERCIO } \\
\text { INTERNACIONAL }\end{array}$ & $x$ & $\begin{array}{r}\text { TRANSPORTES } \\
\text { HUMADEA - } \\
\text { SECTOR } \\
\text { COMERCIO }\end{array}$ \\
\hline
\end{tabular}

\subsection{Análisis de entrevistas realizadas}




\section{Procesos de los sujetos entrevistados en el ámbito educativo}

De acuerdo a la pregunta número uno de la entrevista realizada todos coincidieron en que a la hora de tomar la decisión para elegir la carrera universitaria, influyó completamente el gusto personal. También influyeron factores adicionales como el trabajo y las relaciones personales. Para personas como el entrevistado número 11, influyó el área donde se encontraba laborando en el momento de iniciar la carrera.

La entrevistada número 9 afirmó: “influyó que tengo un amigo que estudió relaciones internacionales y me comentó al respecto y me apasioné, cuando fui a las universidades me gustó mucho que se tratará de política y demás".

Como se puede observar en este grupo de personas, no se refieren a mecanismos de capacitación en la vida escolar dirigidos a preparar a los jóvenes en la toma de decisiones informadas sobre la elección de las carreras profesionales. De hecho en la educación superior existen muchas desigualdades como lo dicen Bourieu y Passeron (86), en Los herederos: los estudiantes y la cultura, además de algo clave que también menciona es que la elección de las carreras son más limitadas cuando quién se dispone a estudiar, pertenece a un medio más desfavorecido. Es raro ver que personas con mejores recursos se limiten a elegir carreras o universidades, pues cuentan con los medios necesarios para su acceso, el limitarse ya es cuestión de una posición social/familiar que es otro aspecto. Hay una gran desigualdad enmarcada en el sistema educativo superior, donde quiénes se favorecen son quiénes cuentan con los recursos y sin duda alguna excluye a la clase menos favorecida.

De acuerdo a si existía o existe preocupación por cómo se iba a conseguir empleo mientras se estudiaba, de los 4 egresados, 2 mencionaron haber tenido preocupación por cómo iban a conseguir empleo.

La entrevistada número 1 argumentó: “Sí, por la oferta y la demanda que hay alrededor del área de la salud, por conseguir un buen empleo, estabilidad económica y cambiar mi forma de vida". Por otro lado, la entrevistada número 4, quien realizó sus estudios en el exterior, menciona cómo el hecho de no haber conseguido empleo la hizo retornar a su país natal; sin embargo, menciona las trabas que se tienen en el país al momento de convalidar la carrera realizada fuera del país, lo que involucra tiempo de espera para poder conseguir empleo. 
Los entrevistados número 2 y 3 egresados de la Universidad Javeriana coincidieron en argumentar que no tuvieron preocupación por cómo iban a conseguir empleo. La respuesta del entrevistado número 3 fue: "No, la verdad no he tenido preocupación de conseguir empleo".

Los 7 entrevistados aun estudiantes respondieron "SI" a la preocupación por cómo iban a conseguir empleo. Solo el entrevistado numero 7 ve como ventaja el conseguir "recursos propios".

La entrevistada numero 8 respondió: "sí, siempre me preocupó por que normalmente en Colombia los universitarios recién egresados es muy difícil que consigan empleo”.

Mientras que la entrevistada número 9 respondió: "Bueno sí. Me ha preocupado, aunque pues en realidad no he hecho mucho como por comenzar ahorita a tener experiencia laboral. Me ha preocupado porque hay mucha competencia pues en el mercado laboral".

La entrevistada número 10 por su lado hace referencia a lo que viven muchas personas no solo en Bogotá sino en todo el país, dijo: "Sí, yo creo que ahorita se ven muchos casos de, pues sales de la universidad y duras 2 o muchos años esperando a conseguir un trabajo donde te paguen bien y pues muy difícil conseguirlo".

De esto se puede concluir que los estudiantes que acceden a universidades de mayor prestigio y que provienen de un estrato socioeconómico alto, manifiestan menor preocupación por el ámbito laboral. Quiénes ya se han enfrentado a la necesidad de conseguir empleo conocen la preocupación y otros no demuestran interés.

Se le preguntó a los entrevistados si la universidad en el momento de elegirla le informó o lo capacitó sobre el mercado laborar para la profesión elegida, a lo que los entrevistados respondieron en su mayoría que las universidades si les informaron sobre la salida al mercado laboral. Adicional a esto agregaron que las universidades les brindaron información sobre Campos donde podrían desarrollarse y les advirtieron sobre demasiadas personas ingresando al campo profesional elegido. De este último se puede decir que de acuerdo a lo investigado en este trabajo el ingreso de muchas personas en un mismo campo representa enfrentarse a una competencia en el mercado laborar e incluso a un desempleo en su área por escases de oportunidades. 
Es de gran importancia reconocer por parte de las universidades y del Estado los esfuerzos de tiempo y económicos que hacen las personas para el ingreso a la universidad, por esto se les preguntó a los entrevistados si las universidades por medio de oficina ayuda a los estudiantes/egresados a conseguir empleo, a lo que responden en su mayoría que las universidades si tiene un área específica que manejan este tema, unos pocos expresaron que existe desinterés o desconocimiento sobre esto, pues dicen no saber, no estar informados o que la universidad no tiene ni siquiera prácticas para su profesión (una persona).

Aun conociendo que la universidad si tiene oficina, la información entregada a los estudiantes y divulgación sobre el tema no es la apropiada para algunos casos, pues como menciona el entrevistado número 6: "He escuchado como en la universidad un departamento sobre orientaciones o seguimientos al egresado pero pues la verdad no tengo bien entendiendo el tema, no estoy bien informado".

El entrevistado numero 2 por su lado dijo: "Sí, la universidad tiene como su campo específico en el cual pues la ayuda a uno a conseguir empleo, pero pues son muy pocas las veces o muy selectivas las personas que entran en este tipo de convenios y ofertas laborales". Esto demuestra las falencias y el poco interés de las universidades por preparar a los egresados para la salida al campo laborar.

Es importante reconocer los intereses que tienen los egresados profesionales luego de este proceso educativo por lo cual se hizo importante preguntarles sobre los mismos, recibiendo respuestas como:

- "Buscar trabajo para adquirir experiencia laboral”. (Entrevistada número 1).

- "Intereses guiados a lo laborar. Conseguir buen trabajo". (Entrevistada número 4).

- Seguir estudiando fue el interés solo para 2 egresados.

- El interés de viajar solo lo tuvo un egresado de la Universidad Javeriana que no muestra interés por conseguir empleo. "Si se da bien, sino pues también". (Entrevistado número 2).

En cuanto a los estudiantes se les preguntó sobre lo que creen que va pasar cuando se gradúen, pues es preciso conocer si tienen intereses en el campo laboral y si es un tema que les preocupa frente al panorama existente en la ciudad. A lo que responden en su 
mayoría, conseguir empleo, o para el caso de los 2 estudiantes que se encuentran empleados en que las situaciones son:

- Mantener su empleo. (Entrevistado número 8).

- conseguir un mejor empleo pues de estudiante no recibe buenas remuneraciones. (Entrevistado número 9).

De los 11 entrevistados, 5 quieren seguir estudiando poniendo en relación factores para realizar estos estudios como:

- Seguir estudiando pero para hacerlo debe tener un empleo. (Entrevistado número 7).

- "Seguir estudiando porque en realidad creo que con un pregrado pues nos quedamos cortos". (Entrevistado número 10).

Este último factor es notorio en el acceso al mercado laboral ya que las exigencias cada vez son mayores para quienes se postulan a nuevas oportunidades laborales.

Es importante resaltar lo que mencionaron los entrevistados números 5 y 9 quienes hacen referencia a la realidad laboral en la ciudad:

- $\quad$ "Pienso que puede ser un poco duro el choque con la realidad, una cosa es estar en las aulas y en la parte académica y otra enfrentarse en lo que es todo los avatares que tiene el campo laborar, los compañeros, los sueldos, los tiempos". (Entrevistada número 5).

- “Una de mis preocupaciones más grandes para cuando me gradué va a ser como ya lo dije pues el campo laborar, porque hay mucha competencia no solo en mi universidad sino en todas las universidades de Bogotá y eso me preocupa”. (Entrevistada número 9).

Temas que sin duda alguna no son preocupaciones infundadas, sino producto de realidades que existen en el campo laboral, en especial respecto a la fuerte competencia en Bogotá para los jóvenes profesionales o finalizando su proceso de formación profesional.

Es necesario conocer el proceso que viven los jóvenes profesionales y de últimos semestres de carreras profesionales en sus tránsitos académicos, por lo que se preguntó sobre los estos, desde que salió del colegio a la fecha con su profesión. Esta pregunta 
tuvo respuestas diversas por parte de los jóvenes, donde muy pocos mencionaron la importancia o preocupación por el campo laboral.

La egresada número 1 demostró encontrarse muy segura sobre la profesión elegida, siempre estuvo relacionada con el empleo, pues trabajó mientras estudió. El egresado número 2 por su lado menciona cómo en el colegio no se ven condiciones de necesidades económicas, mientras que en la universidad si son visibles, lo que hace importante pensar en la obligación de trabajar y suplir las mismas.

La egresada y estudiante número 3 por su lado mencionó cómo el cambio del colegio a la universidad le fue complicado, además de replantearse sobre la elección de su carrera profesional en el proceso. En el ámbito laborar no demostró interés, pues está cursando una segunda carrera profesional.

Mientras que la egresada número 4 esperaba que la transición a la universidad iba a ser mejor, menciona no tener experiencia laboral y no haber tenido su primer empleo, sin embargo dice haber tenido una agradable experiencia en el ámbito educativo por las enseñanzas constantes. También menciona haber pasado por la etapa de preguntarse sobre la elección de su carrera y cree que la mayoría pasan por este momento. Es importante mencionar lo que dijo referente a la salida de la universidad: "obviamente ya después de que uno sale de la universidad empiezan los pensamientos: ¿Qué hare con mi vida?, ¿Qué voy a hacer?, ¿Dónde conseguir trabajo? Y pues no se me ha facilitado como pensé y pues es ahí donde se me vienen todos los pensamientos negros de saber qué pasará con lo que voy a realizar a futuro".

De acuerdo a lo anterior se puede determinar que las oportunidades en la ciudad son escasas y que el desempleo afecta a muchas personas. Los esfuerzos de capital humano están siendo desaprovechados pues hay pocas ofertas laborales. Es aquí donde muchos pueden crear empresa y generar empleo, pero ¿Quiénes están dispuestos a lo anterior?, ¿Quién tiene los recursos y habilidades? o ¿Quiénes quieren hacerlo? Es de tener en cuenta que el capital humano está siendo desaprovechado en su mejor etapa, pues es la edad de trabajar y de generar nuevos cambios a través de sus conocimientos, los cuales pueden ir desarrollando por medio de la experiencia. No se puede seguir ofreciendo salarios sin condiciones dignas, sometimiento a trabajos informales o con salarios muy bajos, que lleven al joven a sentirse sin utilidad en su campo elegido, el cual requirió de esfuerzos como tiempo y dinero. 
La estudiante entrevistada número 5 dijo que el cambio de colegio a la universidad fue un choque sorpresivo al comienzo. Habla de cómo la entrada a la universidad "genera más responsabilidades", responsabilidad que también es mencionada por el entrevistado número 11. Los estudiantes entrevistados número 6, 7, 8, 9 y 10 dicen estar a gusto con la elección de su carrera profesional, pero no mencionan nada relacionado con el campo laboral.

De acuerdo a lo que esperan los jóvenes estudiantes al culminar sus estudios, se les preguntó sobre cómo imaginan el proceso luego de salir como profesional, a lo que respondieron:

- Conseguir empleo con buena remuneración. (Entrevistado número 6).

- Crear y explorar aun sabiendo lo difícil que es "conseguir los recursos, sustentar los proyectos, hacerlos viables". Entrevistado número 7).

- Construir proyectos en el ámbito social, desde su lugar de trabajo y cambiar posiblemente de empleo. (Entrevistado número 8).

- Conseguir empleo, pero no tiene experiencia por lo que considera le ofrecerán salarios bajos, lo que además no le permitiría seguir avanzando en su vida estudiantil o laborar. (Entrevistado número 9).

- El cambio a universidad a trabajo va a ser muy difícil. Buscar empleos donde obtenga remuneraciones merecidas lo considera muy complejo, además de considerar que con un pregrado ya no es suficiente para ser valorado. (ya no solo exigen pregrado). Sin experiencia es muy complicado ingresar al mercado laboral. Con el título considera obtener más oportunidades en mejores empleos, con mejores remuneraciones. (Entrevistado número 10).

\section{Procesos de los sujetos entrevistados en el ámbito laboral}

La manera en que los jóvenes profesionales o de últimos semestres de carreras profesionales (entrevistados entre estrato 3 y 4) perciben el ámbito laboral es importante, pues indica el interés que tienen sobre el campo y si el conocimiento sobre la situación actual de la situación laboral del país, de acuerdo a las experiencias que han tenido en su vida. 
Con el fin de saber cuáles son los tipos de contratos que les ofrecen a los jóvenes en el momento de la entrevista, se les preguntó a quienes laboraban, cuál es el tipo de contrato que tiene cada uno, a lo que respondieron:

- Egresados:

La egresada número 1 tiene un contrato a término fijo mientras que la egresada número 3 cuenta con un contrato por prestación de servicios establecido de manera verbal.

- Estudiantes

La entrevistada número 9 cuenta con contrato a término fijo, mientras que el entrevistado número 11 dice tener un contrato a término indefinido.

En este punto se puede precisar que quienes trabajan, se encuentran en sectores formales, sin embargo, son solo 4 personas de 11 que se encuentran vinculadas laboralmente.

Para algunos entrevistados (estudiantes) se realizó la pregunta acerca de si estaba pensando en buscar empleo y donde los buscaría. Las respuestas fueron:

El entrevistado número 6 dijo no estar interesado en el momento, sin embargo, mencionó que buscaría en organismos internacionales o empresas que se dediquen a la importación y exportación. Los otros entrevistados a los que se les realizaron la pregunta, si se encuentran interesados en conseguir empleo o cambiar si ya lo tienen.

El entrevistado número 7 reconoce que no sabe dónde buscaría, pero que le gustaría en tiendas independientes y creativas. Los entrevistados número 5, 7 y 8 si buscarían empleo. El entrevistado número 9 está interesado en buscar empleo pero no en su campo de estudio por ahora, busca empleo vacacional. Los entrevistados número 7 y 10 no saben dónde buscar empleo. La entrevistada número 10 considera que por falta de experiencia solo podría conseguir empleo en tiendas de ropa. El entrevistado número 7 dice interesarse por tiendas independientes y creativas. El entrevistado número 11 que se encuentra laborando, está buscando otro empleo, su interés es adquirir nuevos conocimientos. 
La búsqueda de empleo en la ciudad puede parecer en muchas ocasiones incierta si se trata de buenos empleos. Por buenos empleos se entiende tener condiciones dignas, obtener todas las prestaciones legales, salarios acordes y garantías claras.

Otra pregunta que se realizó a los entrevistados fue si trabajaron mientras se encontraban estudiando. De los 11 entrevistados 4 no trabajaron mientras se encontraban estudiando o mientras estudian, uno de ellos menciona no tener necesidad de laborar pues sus padres suplen todas las necesidades.

Mientras que 7 personas respondieron "si”, en la que la mayoría respondieron hacerlo por gusto y necesidad, siendo solo 2 quiénes expresaron la necesidad de adquirir experiencia y de seguir progresando.

La entrevistada número 9 está interesada en la búsqueda de empleo vacacional, la estudiante número 10 considera que por falta de experiencia solo podría conseguir empleo en tiendas de ropa y el entrevistado número 11 que se encuentra laborando dice estar buscando empleo y su interés va ligado a adquirir nuevos conocimientos.

Los sectores que mencionaron para la búsqueda fueron $\mathrm{ONG}^{\prime} \mathrm{S}$, secretarias, ministerios, tiendas de ropa, call centers. Los medios, reconocidos fueron las convocatorias (1 persona).

De lo anterior, es preciso mencionar que los jóvenes profesionales o estudiantes de últimos semestres de carreras profesionales al reconocer que no tienen experiencia, pueden deducir qué tipo de empleos son ofertados en la ciudad y a cuáles pueden acceder, en muchas ocasiones estos empleos son informales y con mínimas garantías. Sin duda alguna se sabe que la experiencia es un factor clave para el acceso al mercado laboral, sin embargo, no se logra satisfacer, pues las exigencias son demasiado elevadas para recién egresados.

Aunque la intención de las preguntas anteriores era explorar de manera indirecta las percepciones, se incluyó una pregunta directa sobre este tema, a lo que respondieron:

- El área de la salud requiere mucho tiempo, pero hay gusto por la experiencia laboral que se adquiere.

- El trabajo se da por relaciones sociales. (rosca y palanca fueron mencionados por dos personas) 
- El empleo es un medio de aprendizaje.

- El empleo es un medio de subsistencia.

- Es difícil de conseguir por la falta de experiencia.

- Existe discriminación de jóvenes (no todas las empresas) por la falta de experiencia.

- Es una actividad por medio de la cual las personas logran beneficiarse económicamente. En Colombia hay mucho desempleo, sin empleos fijos.

Los anteriores referentes o ideas reflejan la manera como los jóvenes entrevistados perciben la realidad laboral en Bogotá, de acuerdo a las experiencias que se ha enfrentado los jóvenes en sus saberes sobre el campo laboral. Por otro lado, es necesario saber si para quiénes se encontraban laborando consideraban que los salarios obedecían a las tablas de clasificación laboral.

De los 11 entrevistados 4 se encuentran laborando y dicen:

- "Si obedecen a las tablas de clasificación laboral, pues tiene todas las prestaciones laborales y legales que yo debo tener como trabajador". (Entrevistado número 1).

- “Sí. las prestaciones son fundamentales". (Entrevistado número 3).

- Si obedece. Sin embargo considera que en la mayoría de los trabajos no se paga lo que se debería pagar a las personas por su trabajo. (Entrevistado número 8).

- Por ser estudiantes de últimos semestres o profesionales recién egresados, la remuneración es baja y muchas veces por conseguir el primer empleo les toca someterse a salarios mínimos o por debajo del mínimo. (Entrevistado número 11).

La pregunta también fue realizada a 2 estudiantes con el fin de conocer el punto de vista de cada uno, a lo que respondieron:

- "Hay salarios malos y buenos. Un mínimo es precario para un habitante de Bogotá”. (Entrevistado número 2).

- Considera que los salarios no son equitativos. "La mayoría ofrecen es un salario mínimo". (Entrevistado número 5).

Para reconocer las realidades que hay en la ciudad sobre lo que ofertan laboralmente, se preguntó a los entrevistados si las ofertas laborales en Bogotá son adecuados para los 
recién egresados. De los 11 entrevistados solo una persona contestó que dependía del campo educativo elegido y de las exigencias del mercado. Los otros 10 entrevistados coincidieron en decir que las ofertas no son adecuadas y los factores que hacen que sean inadecuadas serían:

- Falta de experiencia (exigen experiencia a recién egresados).

- Migración a la ciudad capital (genera competencias). Entrevistado número 2

- Diversidad de universidades, carreras, cantidad de personas que salen al mercado laboral a competir. (alta demanda, pocas ofertas).

- Pocas oportunidades y de difícil acceso. ("se necesita de palanca para el ingreso", entrevistado número 10)

Bajos salarios ofrecidos para los recién egresados. ("salarios no corresponden a los 5 años invertidos", entrevistado número 10).

De acuerdo a las dos preguntas anteriores es de reconocer que los estudiantes y recién egresados deben someterse en muchas ocasiones a trabajos poco dignos con el fin de insertarse al mercado laboral, recibiendo salarios mínimos, que en la ciudad representan una capacidad adquisitiva demasiado baja en relación con el costo de vida. Aunque en ocasiones pueden recibir todas las prestaciones, el salario no supliría, ni correspondería a los costos que significa estudiar y vivir.

En muchas ocasiones y como ya se ha mencionado antes, deben someterse al sector informal que es el que brinda oportunidades laborales sin experiencia. Los estudiantes entonces, consideran algunas veces que sus esfuerzos no valieron la pena al tener que someterse a cualquier oportunidad laboral, así no tenga relación con su campo de estudio, con el fin de poder generar ingresos y cubrir necesidades.

De lo anterior es preciso mencionar que la realidad que se vive en el campo laboral para los jóvenes de últimos semestres y carreras profesionales tienen falencias que deben trabajarse desde un punto distinto al de crear empresas. Se hace necesario replantearse si se deben generar exigencias tanto en sectores públicos/privados para mitigar estas problemáticas a las que los jóvenes se enfrentan a diario.

\section{Conocimientos de los jóvenes sobre políticas y leyes de empleo en Colombia.}


Cada joven y cada persona en el mundo tienen necesidades diferentes, sin embargo, los jóvenes profesionales y de últimos semestres en su mayoría tienen intereses muy relacionados como tener vida social, estudiar y conseguir un buen empleo, sin embargo, ¿qué tan importante es este último campo para los jóvenes? Por lo anterior se preguntó a los jóvenes objeto de este trabajo si conocen las políticas públicas diseñadas para el empleo que hay en Colombia, a lo que 10 de ellos respondieron no conocerlas y solo quien estudia Derecho (entrevistada número 3) menciona conocer algunos referentes como la ley 1429 de 2010, Código Sustantivo del Trabajo y ley 100 de 1993.

Quiénes mencionaron no conocer la normatividad, dieron motivos como:

- Falta de información o divulgación sobre las mismas.

- Falta de interés.

Sin duda alguna es la falta de interés la más significativa, pues la información aunque no es divulgada con un tiempo que permita recordación, es necesario que los jóvenes y personas se interesen por lo que el gobierno plantea, logrando en este caso una activa participación en las políticas públicas.

Es necesario resaltar que los medios tienen gran influencia sobre las personas, lo que permitiría que con mayor divulgación se pudiese despertar mayor interés sobre el campo laboral para los jóvenes.

En cuanto a la Ley 1429 de 2010 se hace necesario saber si las personas tienen conocimiento sobre la misma, por lo que se les preguntó a los entrevistados si la conocían y cuál era su opinión sobre ella. La respuesta de 9 de los entrevistados (3 egresados - 6 estudiantes) fue NO conocerla, mientras que 2 de los entrevistados (1 egresada/estudiante -1 estudiante) respondieron SI.

La entrevistada número 3 (egresada/estudiante) hizo referencia a lo que trata la ley. Beneficios para las empresas si realizan contrataciones y personas que buscan empleo: jóvenes, desplazados por conflicto armado y mujeres mayores de 40 años que no han laborado durante el último año.

La entrevista número 8 por su lado señaló conocerla como "ley de primer empleo" y expresó que la misma fue creada para impulsar a que los jóvenes lograran conseguir empleo y experiencia laboral. De lo anterior indicó que los programas de esta ley no 
ofrecen buenos salarios, los trabajos no son buenos y que la ley está enfocada en ofrecer beneficios a las empresas, más que a los jóvenes.

De acuerdo a esto, es preciso decir que es notorio el desinterés que existe por parte de los jóvenes entrevistados sobre temas que los involucran aun conociendo la situación de empleo que vive Bogotá. Es de destacar que quizás por sus diferentes experiencias y necesidades tienen perspectivas desiguales sobre el campo laboral.

La situación socioeconómica puede ser un factor representativo que complica o facilita la situación actual de cada persona. En el caso de la situación de nuestro país, muchos jóvenes profesionales y de últimos semestres de carreras profesionales, que cuentan con recursos más limitados tienen obligaciones y necesidades distintas que determinan el nivel de dificultad para afrontar problemáticas diarias. No es lo mismo tener la capacidad de cubrir todas tus necesidades gracias a una economía estable, que cuando se necesita una estabilidad económica para sostener tus obligaciones académicas, familiares, alimenticias, ocias y personales.

No es lo mismo la situación para la entrevistada número 3, quien estudia en la Pontificia Universidad Javeriana (universidad de prestigio en la ciudad) y no tiene ninguna necesidad más que terminar su segunda carrera, que para la entrevistada número 8 que estudia psicología, le gusta el área social, se encuentra adquiriendo experiencia laboral en su campo de estudio y además tiene una responsabilidad, ser madre.

La idea sobre la ley, se puede percibir de acuerdo a las necesidades existentes y experiencias que tienen frente al tema laboral visto desde cualquier ámbito (familiar, educativo, político).

Para los entrevistados que no conocían nada sobre la ley se les leyó el fragmento del objeto de la misma con el fin de generar interés y conocer la interpretación que pueden tener sobre esta de acuerdo a sus experiencias. Además de poder obtener información relevante para agregar a este trabajo.

Se obtuvieron respuestas como:

- Aunque las leyes se ven bonitas en papel, las realidades son otras. 
- No existen instituciones fuertes que realicen programas para brindar acompañamiento a personas que quieran formar su propia empresa o para lograr un desarrollo pleno.

- ley importante en la generación de empleo.

- Se deberían incluir: parte académica y otras semillas de las universidades con un espacio laboral fijo.

- Interesante la ley, pues aporta a los recién egresados y estudiantes de últimos semestre a lograr el acceso a los mercados y reciban buenas remuneraciones.

- Reconocimiento en que es una ley para creación o formalización de empresa, sobre esto realizaron comentarios como:

- Ayudar a empresas beneficiándolos con la formalización y la contratación de nuevos empleados.

- Al impulsar y fomentar el trabajo a través de la formalización suena bonito, pero hacerlo no funciona tanto.

- Revisión sobre quienes quieren crear empresas, porque no todo el mundo tiene la condición económica para crearlas.

- La creación de empresas es muy difícil.

○ Competir con otras empresas sin experiencia es complejo.

Según la información brindada, se reconoce en lo anterior que la ley está creada en beneficio de las empresas y nuevos emprendedores. También se reconoce el interés que hay por la generación de empleos y no existe inquietud sobre qué garantías ofrecerá a los nuevos empleados beneficiados.

También es interesante ver cómo una persona reconoce la debilidad de las instituciones del Estado y la regulación de los programas creados.

Incluir la academia en el diseño e implementación de las políticas, sin duda alguna es importante, también realizar cambios que permitan mitigar problemas laborales de jóvenes que hacen esfuerzos por capacitarse.

Y aunque se menciona lo interesante que es generar empleo y dar oportunidades a recién egresados y personas de últimos semestres, hay que preguntarse bajo qué garantías se ofrecen estas oportunidades y dónde se encuentran estipulados sus derechos. Por otra parte es preciso preguntarse si existe una regulación de los salarios y continuidad en 
estos empleos que les permita a los jóvenes sentirse útiles ante la sociedad reconociéndoles sus esfuerzos durante la academia. (Físicos-económicos-tiempo).

Otra pregunta que se realizó con el fin de revisar si entendían o reconocían temas laborales, se relacionó con lo que entendían por formalización en el campo del empleo, donde se considera importante realizar una revisión sobre aspectos a los que se verán enfrentados en el momento de conseguir un empleo.

De lo anterior "se refleja" que en su mayoría las personas jóvenes reconocen que es la formalización en el campo del empleo, sin embargo, 3 personas no tienen conocimiento sobre el mismo, siendo una de estas personas empleada con contrato indefinido.

El tema de reconocer las cesantías y legalización de contratos (derechos de los trabajadores) es tan importante y preventivo para el desarrollo de sociedades que se debería realizar enseñanza desde el nivel educativo conveniente, con el fin de que las personas tomen consciencia y entiendan los riesgos que pueden traer no solo personales sino económicos a todo el país, lo que referiría a la protección social que deben tener las personas.

En cuanto los programas de emprendimiento que se trabajan en el país y que son propios de las políticas de empleo se hizo relevante saber cuál es la idea, referente, etc., sobre el "primer empleo". Pese a que hay una sola pregunta de percepciones, las demás responden y van en función de las mismas (percepciones). Si bien como su nombre lo indica, las personas entrevistadas dicen que es el primer trabajo que consigue cualquier persona. Entrevistados agregan además, que no importa el sector, si es formal o informal.

Solo 3 personas de las entrevistadas saben que el primer empleo es el más difícil de conseguir, 2 de estas personas refieren que esto pasa por la falta de experiencia y 1 de estas dice que el primer empleo "es donde está centrado al tema de prestaciones y de formalizar casi el resto de tu vida laboral".

Vale la pena mencionar que el "primer empleo" sin duda alguna es el más difícil de conseguir por la falta de experiencia de los jóvenes en el ámbito laboral; lo que no se reconoce es que se desaprovechan los conocimientos debido a las exigencias de contratación inalcanzables para los recién egresados, situación que puede generar desempleo elevado en este grupo poblacional. 
Se les preguntó si en las políticas o en las leyes se refleja lo que establece la constitución política de Colombia igual al trabajo digno como un derecho, a lo que respondieron:

En su mayoría los entrevistados respondieron que no, quiénes respondieron algo distinto argumentaron las realidades que hacen que las mismas no se establezcan, como es el caso de la entrevistada número 3 quien dijo: "en efecto si claro, las leyes tienen que estar todas acordes a la Constitución o sino serian inconstitucionales y deben prever todo tipo de garantías que las Constitución manda, sin embargo, la realidad puede ser un poco complicada o la ley puede ser para enmarcar".

Los otros entrevistados mencionaron factores por los cuales no se refleja el trabajo digno en las políticas o las leyes como:

- No hay claridad sobre los derechos de las personas.

- Hay explotación laboral, incumplimientos en pagos, no reconocimiento a las horas extras.

- Hay trabajos precarios.

- Las leyes están beneficiando muchos más a las empresas, se están enfocando más en la empresarial que en las propias contrataciones a las personas.

- Hay informalidad.

- Las políticas no garantizan lo que está en la constitución, muchas de ellas están en contravía y no permiten ese desarrollo del trabajo digno.

- Hay altas tasas de desempleo.

- No hay condiciones justas en los trabajos.

- Las políticas y las leyes son para favorecer a las empresas, la economía, el estado y no se enfocan en las personas.

- No todas las personas tienen un trabajo digno.

- No hay buenas oportunidades.

- No se aplica para las personas que están en desempleo.

Es de apreciar que son factores significativos frente a las realidades que se viven y a la que los jóvenes se ven enfrentados, ya sea por experiencias propias o experiencias de familiares o conocidos. Sin duda alguna las leyes y políticas en muchos casos no van acordes a lo que estipula la Constitución Política de Colombia y los programas no muestran relación certera con la ley de la que emanan. 
De acuerdo a las experiencias vividas de los entrevistados se les preguntó cómo perciben la equidad laboral, a lo que en su mayoría respondieron que sin duda alguna la edad define una inequidad existente pues se cree que los jóvenes no cuentan con la experiencia para ingresar a laborar. Un factor mencionado por varios entrevistados es el género del cual dijeron:

- No hay equidad por ser mujer, algunos trabajos son dirigidos solo a hombres. Hay envidias y machismo. Mujeres tienen menos oportunidades.

Otros factores que influyen según los entrevistados son la discriminación e incluso la pertenencia a algún grupo étnico, las orientaciones sexuales diversas, o tener tatuajes.

Una persona mencionó además que en Colombia y en el mundo existe segregación o clasificación de las personas para ocupar un puesto, refiriéndose al físico del ser humano.

Por lo anterior, se puede decir que una de las cosas que se constata con lo que dicen los entrevistados es que la edad y la experiencia son dos características que influyen mucho en la contratación. Hay una contradicción entre la exigencia de gran experiencia y la edad, se desecha del mercado laboral a los adultos mayores que cuentan con más experiencia, pero al mismo tiempo se limita el acceso a los jóvenes por falta de experiencia.

El género sin duda alguna es un factor de alta relevancia pues aún se creen que algunos puestos solo pueden ser ocupados por hombres y que las mujeres deben dedicarse a otro tipo de actividades como el hogar. Las mujeres han demostrado que tienen las capacidades para participar en campos laborales y competir en los mismos, sin embargo, aún se evidencias cifras donde el desempleo es más alto para este género.

Es notorio cómo el aspecto físico importa, en muchos casos hay racismo y la diversidad de género es burlada, acciones que no reflejan de ningún modo una equidad en la sociedad.

Para finalizar con el cuestionario se le preguntó a los entrevistados cómo interpretan que la ley 1429 de 2010 se refiera más al emprendimiento empresarial que al primer empleo, a lo que respondieron: 
- Si habla de primer empleo pensaría sobre los derechos que tienen las personas, las maneras de conseguir el primer empleo y las condiciones en las que va a trabajar. (Entrevistado número 1).

- "Lo veo más como no a querer emplearse directamente apenas salga de la universidad, sino, más como a la creación de una empresa que también sirva para impulsar a otras personas que estén buscando empleo". (Entrevistado número 3).

- El crecimiento empresarial es bueno pero donde están las garantías del buscador de empleo. (Entrevistada número 4).

- "Lo llevo más a la parte del mercado. No tanto en garantizar esa formalización, sino en la parte de producción para el país”. (Entrevistado número 5).

- Estaría mal porque debería hablar del primer empleo y lo que hace es incentivar el emprendimiento empresarial (creación de empresa). (Entrevistados 6 y 7).

- Es de destacar lo que menciona el entrevistado número 7, pues describe la posible realidad sobre la ley, hace un acercamiento: El primer empleo no es lo que funciona ahí, “El primer empleo es tal vez un artículo necesario para motivar esta ley, yo creo. Yo creo que si tú pones una ley donde dices pues vamos a seguir generando empresas sin darles empleo, no va a pasar. Tal vez el primero sea una muletilla".

Con esta ley tal vez haya crecido un poco el primer empleo, pero no se sabe si lo necesario.

- La entrevistada número 8 dice que hay enfoque porque las empresas se lucren, no hay interés en los jóvenes y su experiencia.

- No existe conexión entre ambas. Primer empleo debería enfocarse a las personas. Por otro lado el emprendimiento empresarial no todos tienen las condiciones económicas para crear empresa. (Entrevistada número 9).

- Es errónea. Se debe lograr que el primer empleo sea más flexible y fácil de conseguir. Cuando se habla de emprendimiento empresarial es como limitaciones es más difícil salir y crear empresa sin experiencia. (Entrevistada número 10).

- Tener primer empleo a través de la generación de la creación de su propia empresa y ser más independientes en el ámbito laboral. 
Esto lleva a pensar que no es posible que el primer empleo como se conoce la ley tenga que estar relacionado con la creación y formalización de empresas.

Se necesita regulación por parte del Estado para que se garanticen los derechos de las personas y que cuando se hable de primer empleo se reconozca que el mismo va dirigido al ser humano, no a otra cosa.

Por lo que es necesario mencionar que no es posible que cuando se busque ley de primer empleo, haya una conexión inmediata con la ley 1429 de 2010 que va dirigida a pequeñas y medianas empresas ofreciéndoles beneficios en formalización y contratación y a las creación de empresas.

Existe una problemática en relación con lo que propone el gobierno sobre la ley y el primer empleo. Sus enfoques no recaen sobre el futuro empleado reconociendo sus derechos y deberes dando garantías establecidas para su contratación, garantías como un trabajo formal y digno, no permitiendo que se sometan a malos tratos y acosos laborales por su condición de novato en el mercado laboral.

\subsection{Discusión}

Conforme a los datos arrojados en las entrevistas realizadas a los estudiantes y egresados de carreras profesionales se obtuvo información relevante y que concuerda con lo planteado en el primer y segundo capítulo del presente estudio.

En primer lugar, cabe resaltar que la mayoría de los jóvenes profesionales y que se encuentran a punto de finalizar su proceso de formación profesional presentan desconocimiento de las leyes y políticas que les compete. En las preguntas de la entrevista referentes a sus estudios no mencionaban en su mayoría interés por oportunidades laborales. Se reconoce que los jóvenes tienen conocimientos sobre la situación que emerge el campo laboral y un factor problemático es "la experiencia", sin embargo queda el vacío sobre su interés por la problemática.

Los empleos de alto nivel en Colombia exigen diversos requisitos de experiencia y formación académica que por lo general es imposible alcanzar para los recién egresados o estudiantes de últimos semestres que se encuentren interesados en el acceso al mercado laboral. 
Así mismo, por no tener experiencia o por encontrarse estudiando y no ser profesional, se les ofrece salarios mínimos que no corresponden, ni recompensan los esfuerzos académicos, económicos y de tiempos, pero a los cuales deben someterse con el fin de lograr acceso al mercado laboral y poder obtener la elevada exigencia de experiencia de la actualidad que exige el mercado, sometiéndose también a condiciones paupérrimas de escasas garantías sobre los derechos de esta población.

En Argentina, por ejemplo, como se menciona en Juventud y Trabajo en la Argentina: diagnóstico y visión de los actores, se identifican problemáticas que son muy similares a las de Colombia, sin contar que sus contextos son distintos, por lo que no se podría accionar de la misma forma para resolverlos. Entre estos se identifican cuatro cuestiones básicas como la permanencia de elevadas tasas de desocupación entre los jóvenes, débil incremento de la participación juvenil en el mercado del trabajo, el fenómeno de la precariedad laboral que afecta directamente a la población joven y la segmentación de itinerarios laborales referentes al ambiente educativo segmentado que se encarga de condicionar el tránsito de la vida educativa al mundo laboral. "Los problemas de mayor incidencia en la situación laboral de los jóvenes de Argentina y también de Latinoamérica genera consecuencias negativas tanto ara los integrantes de la población afectada como para el desarrollo económico y social de los países" (87).

La OIT (51) señala que se les deben ofrecer a los jóvenes mejores oportunidades tanto educativas como de formación, con el fin de que los mismos puedan desarrollar competencias que les permita acceder a trabajos dignos, pero además menciona algo importante y es que se debe garantizar la igualdad de condiciones, lo que de cierto modo como se visualizó en las entrevistas no es reconocido, pues los jóvenes no son tenidos en cuenta por su falta de experiencia, se tienen diferencias de género, por diversidades sexuales, por enfermedades y por raza, lo que no permite que todos logren un acceso a la productividad o que ingresen a trabajos de buenas condiciones y salarios dignos y representativos.

A los jóvenes se les están ofreciendo trabajos en el sector informal, el cual según el DANE (16) está teniendo mayor concentración y participación de la población joven. También se reconoce por los sujetos entrevistados que es en el sector informal donde podrían conseguir empleo y no porque sea el sector que más agrade, sino porque es el sector que más brinda oportunidades cuando no se cuenta con experiencia laboral. 
Como se dio a conocer en el análisis realizado, las políticas están siendo creadas en beneficio de las empresas, lo que permitiría indagar sobre los intereses que busca el Estado que se reflejan más hacia el crecimiento económico, que a mitigar la problemática del empleo juvenil en Colombia y los factores que implican el tema de contratación de acuerdo a los derechos que tienen como ser humanos. Y si es de la población objeto de las políticas, se puede destacar que las mismas están enfocadas en ciertas poblaciones, olvidando que la construcción de estas, se necesitan de tal manera que acojan toda necesidades, pero que además, no solo necesitamos mejorar la economía, sino que necesitan estrategias que permitan acoger modelos de desarrollo que tenga en cuenta diversos aspectos como lo son culturales, productivos, entre otros,

Un factor que cabe destacar de acuerdo a lo encontrado, es que la situación de empleo para los jóvenes universitarios es compleja, tanto que los jóvenes y todas las personas pueden someterse a transiciones laborales en cualquier momento, desde el empleo al desempleo con duraciones diversas de acuerdo a su situación y procesos de empleabilidad como lo menciona la CEPAL (77) En las dos formas de conseguir empleo. Sin embargo, es una situación que los sujetos jóvenes en su mayoría no tienen en cuenta y más aún cuando no se han enfrentado a la búsqueda de empleo porque sus necesidades no lo ameritan, tema contrario para quienes ya se han enfrentado a las búsquedas y que de alguna forma tienen necesidades. Los jóvenes tampoco reconocen en su mayoría que el primer empleo es el más difícil de conseguir y fue evidente en el proceso de información entregada por los mismos.

La precariedad laboral no es tenida en cuenta y no es regulada ni siquiera por el Estado, aun sabiendo que "El mercado laboral ofrece a los jóvenes sobre todo a los jóvenes pobres oportunidades de un alto nivel de explotación, maltrato y bajos salarios" (87).

Igualmente, es importante señalar que la población joven se está enfrentando a un mercado laboral competitivo, el cual exige cada vez más un mayor grado de capacitación. Las competencias en el país han crecido por las facilidades de acceso a la educación técnica, tecnológica y superior, entre las cuales se encuentra el financiamiento. Cabe resaltar que en Colombia y en los demás países en desarrollo como menciona el Banco Mundial (50) el segmento poblacional juvenil es muy grande, factor clave también para la generación de competencias. 
Si los jóvenes profesionales y de últimos semestres de carreras profesionales reconocen que el primer empleo es por medio del cual se benefician económicamente y reciben aprendizaje, que es difícil de conseguir por la falta de experiencia, pero además, saben que se accede a él por rosca o palanca, ¿por qué quienes manejan los temas laborales no tienen mejor incidencia y mayor actuación frente las problemáticas que refieren a el incumplimiento de los derechos de los jóvenes y las formas de contratación que se les está ofreciendo?

No es posible que existan aun inequidades y que se esté afectando una población activa como los jóvenes, negándoles su acceso al mercado laboral (género, edad, raza, enfermedades, condición sexual), y en muchas ocasiones desconociendo los esfuerzos que han hecho para su formación. Se necesita una valoración distinta de los jóvenes en el mundo laboral para aprovechar sus conocimientos y dar cumplimiento a sus derechos dentro de la sociedad, pero además, se debe educar a la población sobre el vivir en unión con los otros, compartir solidaridades, reconocer debilidades económicas de unos y no perturbar en los apoyos sociales para hacer efectivas y eficaces las inversiones sociales, pues si el Estado garantiza y regula estas últimas, "asegura la riqueza de un país" (31).

Se sabe que es necesario formalizar las empresas, pero también se sabe y se tiene claro que formalizarlas y hacer que generen empleo, no es lo mismo que garantizar el Primer Empleo. El Estado debe regular de una manera más clara las condiciones para obtener las primeras oportunidades de empleo y permitir que las personas reciban condiciones, contrataciones y salarios justos y dignos. No es posible que se sigan contratando por ser mano de obra barata y presten servicios como objetos inertes.

Las expectativas frente al mercado laboral que tienen los jóvenes, no pueden ligarse a la creación de empresa, porque crear empresa no es lo que quieren todos los jóvenes y no todos tiene la capacidad económica para tomar el riesgo de exponerse a posibles deudas futuras.

El no tener las experiencias también puede ser contraproducente. "La falta de saberes específicos, en un campo que demanda competencias muy técnicas, es frecuentemente reemplazada por voluntarismo o por visiones idealizadas que redundan en la promoción de actividades independientes y de dudosa eficacia" (87). Sin embargo, no hace falta indagar a esta población, para reconocer que no cuenta con experiencia ni siquiera para asumir sus riesgos y que por eso la protección social se crea para prevenir sobre 
eventualidades y garantizar que pueda la persona asumir riesgos y sea garante de derechos que están establecidos en la Constitución Política de Colombia como lo es el Derecho al Trabajo.

De acuerdo a la experiencia de Uruguay con la ley, cabe resaltar que la industria tiene un interés particular sobre la misma y no precisamente se basa en la contratación de nuevo personal. Puntualmente en el artículo: Acerca de la Ley de Empleo Juvenil, del Periódico El País de Montevideo, en el que además refieren al interés de la industria sobre esta ley:

¿Por qué contratan trabajadores las empresas? No lo hacen porque lo deseen, de la misma manera que no compran insumos porque quieran comprar insumos. Lo hacen porque buscan obtener beneficios a partir de la producción y venta de bienes y servicios cuya producción necesita maquinaria, vehículos, insumos, energía y mano de obra. Por eso en economía se dice que la demanda de trabajo es una demanda "derivada": se deriva de la búsqueda de las empresas por alcanzar sus objetivos fundamentales (88).

No se puede aceptar que las personas se sigan viendo como objetos que prestan servicios y reciben un beneficio por la prestación de este servicio. Las personas son sujetos de derechos que deben ser respetados, pero que además deben ser reconocidos ante cualquier circunstancia, por tanto no pueden en este caso estar directamente enfocados solo al beneficio de los empresarios. Se debe tener reconocimiento de garantías para la persona a emplear y que pueda prestar de forma correcta sus servicios.

\section{¿Qué papel cumplen los medios en la divulgación de las iniciativas para generar empleo adelantadas por el Ministerio de Trabajo?}

La propaganda que se le hizo a través de los medios de comunicación al programa inició en el año 2015 en el primer semestre, no fue todo el semestre y tampoco continuó. En ella se nombraban el programa del Ministerio de Trabajo "40.000 mil primeros empleos es talento, no palanca" para las personas objeto de la ley conocida como primer empleo.

A través de esta propaganda que se le hizo al programa, se evidencia el interés en los beneficios que recibirán las empresas que contraten personas, sin embargo, las personas de la sociedad de derecho no aparecen, si bien deben existir para la ley, pero no es a las 
personas que se emplearán a quién va dirigida la propuesta. De nuevo los derechos de los trabajadores quedan por fuera.

Esta propaganda menciona que se quiere acercar la academia con la industria, pero más adelante sale algo importante y es que la persona que egresa de la universidad no está formada para el trabajo, entonces, ¿si esto se sabe y es publicado por el Ministerio de Trabajo por qué no se comienza a hacer una articulación que conlleve a efectos positivos? Los potenciales juveniles sin duda alguna se están desaprovechando y dependen de las oportunidades que se brinden para que las personas puedan conseguir empleo.

Sin duda alguna un resultado de esta problemática son las nuevas contrataciones que se están generando, que permiten jugar con el tránsito laboral de las personas, algunos contando con la mala suerte de quedar desempleado y no poder volverse a vincular o vincularse en áreas que no tienen nada que ver con sus campos de estudio ${ }^{1}$.

La OIT se ha encargado de reforzar todos los programas que involucran el campo de empleo juvenil en América Latina, porque sus problemáticas son amplías y el interés por las mismas se ha venido dando desde los setentas y aplicando políticas en los noventas. "Actualmente para contrarrestar la creciente informalización de los trabajos, la OIT hace hincapié en la necesidad de impulsar políticas laborales que fomenten la generación de empleo decente" (89) buscando mejores condiciones para el trabajador en remuneración y equilibrio entre flexibilidad y seguridad.

Los beneficios sin duda alguna son para las empresas, porque para los jóvenes no se menciona más que la posibilidad de obtener experiencia, pero las condiciones, derechos,

1 Al revisar los artículos informativos del Ministerio de trabajo $(105,106,107,108,109,110,111,112)$, permiten ver que todos hablan en beneficio de la ley, como si fuese la mejor propuesta, una propuesta sin contenidos para corregir, sin mencionar sobre las cifras de desempleo y las inequidades por género existentes que menciona el Observatorio de Desarrollo Económico (54) por ejemplo. Uno de los artículos dice: la Ley de Formalización y Generación de Empleo "Ley de Primer empleo": "Demostró ser un excelente instrumento para mejorar la situación laboral del país, con beneficios para cerca de 45.000 empresas y 400.000 jóvenes". 
garantías de su primer empleo no se encuentran claras, ni establecidas. "Demostró ser un excelente instrumento para mejorar la situación laboral del país, con beneficios para cerca de 45.000 empresas y 400.000 jóvenes" (90).

Además, los documentos relacionan los beneficios de las empresas. Este programa propuesto por el Ministerio, si bien debería estar relacionado con el Primer Empleo, ello no ocurre. Se excluyen las garantías, beneficios y derechos de los trabajadores que están en la búsqueda de Primer Empleo.

Lo que no mencionan es que las pequeñas empresas andan en alarma por el exceso de deudas. Existen presiones de pago, hay endeudamiento sobre el endeudamiento que supera la capacidad de pago y están yendo por el camino de endeudamiento con fuentes informales como lo son los "gota a gota" (91). Algunas de estas empresas pueden estar vinculadas con el dichoso beneficio que brindaba el gobierno para la contratación, al crear y querer formalizar o debido a esta alerta se pueden estar perdiendo trabajos y aumentando el desempleo. Pero no es de interés mencionar la problemática, porque para el Ministerio todo está marchando de maravilla con la nueva ley.

Estoy de acuerdo con lo mencionado en el artículo de la Universidad del Rosario Ley de primer empleo tiene deficiencias en la promoción del empleo juvenil:

Las medidas contempladas en la norma para crear pequeñas empresas a través de la excepción de la matrícula mercantil, los estímulos para la normalización de la situación militar y la excepción en el pago de los aportes a las cajas de compensación, son paños de agua tibia que no contribuyen eficazmente a la reducción del desempleo juvenil, explicó Iván Daniel Jaramillo, investigador del Observatorio Laboral (92).

Cabe destacar que hacen falta medidas para mitigar los efectos negativos que tiene sobre la sociedad el desempleo, el mismo no se va a arreglar con la creación de empresas, aportes de cajas de compensación o regulaciones sobre la libreta militar; de manera estructural deben crearse bases que se dediquen solo al eje laboral juvenil, involucrando ajustes al aparato productivo del país. Es necesario plantear nuevas estrategias enfocadas a esta población. 
Aunque estas nuevas políticas y programas van dirigidos a ofrecer a los jóvenes la búsqueda de experiencia mediante los empleos o la creación de empresas con facilidades de acceso a impuestos tributarios, se ha demostrado que las políticas no han surtido efectos positivos y se sabe si es necesario incluirlas y basarlas en el contexto del diálogo social, sin generar incentivos no adecuados con posibles efectos de desplazamiento o el cambiar un trabajador por otro e incluso evitar tratos discriminatorios hacia los jóvenes (68).

Caso que permite ver que no ha sido funcional este tipo de políticas públicas y programas, que ya se habían implementado antes y que además no son funcionales para Colombia porque sencillamente las situaciones sociales, económicas y culturales no son las mismas, no se comparten las mismas experiencias entre todos los países de América Latina, algunas tienen similitudes, pero se trata de contextos históricos distintos, donde las diferencias son amplías y más si se trata de economía y empleabilidad.

Ahora bien, la experiencia de México (93) con la Política no se aleja de lo que vive Colombia frente a la Ley 1429 de 2010; en especial sobre si tiene algo de bueno este tipo de políticas y programas, pues se puede decir que cumplen en el marco jurídico con el concepto de universalidad desde el enfoque de derechos, igual que en México, garantiza igualdad para todos en oportunidades y en la creación de empresas, pero la focalización no protege a la población vulnerada, la población joven con dificultades para acceder a buenos empleos y que se han capacitado y no hay nada que se enfoque sobre sus garantías. La protección de los jóvenes es necesaria y debe ser completa. No se debe vender con otro tipo de ideas que favorecen solo ciertos sectores y tampoco se puede comparar con algo que no involucre a todos, las garantías deben ser claras y explicitas en las políticas que deben además estar dirigidas a este público objeto y solo a ellos. 


\section{CAPÍTULO 5. CONCLUSIONES}

\subsection{Hallazgos}

El mundo sufre la problemática del desempleo juvenil, es clave reconocer que cada día los países sufren crisis económicas y que son pocos los que se encuentran desarrollados y estables, en comparación con lo que sufre la región latinoamericana. Los sectores económicos al debilitarse, logran deteriorar las oportunidades laborales y afectar en el tema de empleabilidad, de este modo es importante generar políticas que se adecuen a 
las problemáticas económicas, pero que sean independientes a las generadas por y para las personas en el campo laboral.

Es de reconocer que a nivel mundial la población se encuentra en crecimiento y que por tanto se deben generar propuestas que estabilicen esta población para su desarrollo tanto educativo, como laboral. Se debe regular las ofertas laborales que se están proponiendo para los mismos. La educación y las garantías laborales merecen mayor atención, los jóvenes se encuentran en un riesgo que afecta a la sociedad en cuanto a que se deberían destinar más recursos para solventar las necesidades de esta población.

Es pertinente revisar las ofertas laborales y sus requisitos, donde exigen título, experiencia de alto grado, incluso, otro idioma, pero solo brindan salarios mínimos o incluso inferiores a los salarios mínimos legales vigentes, que no alcanzan ni para compensar los procesos educativos y los costos que estos generan, como recompensa del sacrificio. Comenzar por este tipo de ofertas y restringir esas exigencias podría ser un paso importante para comenzar a cambiar, no solo la educación y conocimientos de los jóvenes para competir en los mercados laborales, sino también las ofertas y las empresas/instituciones.

Sin duda alguna existe una gran problemática con los jóvenes estudiantes y egresados de carreras profesionales, estos como en el resto de los países del mundo, encuentran restringidas las oportunidades de estudio y trabajo, y, en general, ellas tienen mayor acceso para quienes cuentan con mejores condiciones económicas.

El problema del desempleo juvenil, es sin duda un tema que debe ser de interés para toda la población de una sociedad sin importar que papel desempeñe dentro de la misma, no se puede permitir que los derechos laborales de las personas, estén desapareciendo, que además el Estado a través de las políticas se estén quitando responsabilidades y las descargué sobre sectores que no le interesa proteger estos derechos.

Cada vez se hace más notorio la falta de garantías para sobrevivir en la sociedad, tanto así que la población misma debe encargarse de solventar sus necesidades y protegerse sobre posibles riesgos, permitiendo así que el sector informal se fortalezca y que la base de cotización pierda su eje y traiga mayores costos para el país, que deban apoyarse mediante otros recursos que se destinaban antes para otras situaciones. 
La población sola no puede encargarse de su protección, el Estado debe prestar apoyo, mediante derechos ya estipulados, no se puede permitir que las nuevas formas de contratación sigan afectando tanto el campo del empleo y las acciones se hacen pertinentes con la participación en creación de nuevas políticas con apoyo del Estado.

Las políticas deben reconocer mejor esta situación y deben replantearse para ayudar a solventar esta problemática, involucrando a los jóvenes, a sectores públicos y privado, y favoreciendo una coordinación conjunta con lo que refiere a los lineamientos de la administración pública sobre el empleo. Se deben plantear leyes, políticas, programas que cobijen a todas las personas y no que solo beneficie a los sectores, los mismo sectores que siempre se ven beneficiados.

Es transcendental reconocer que existen diferentes necesidades en la población joven profesional y de últimos semestre, que requieren de la formulación y gestión de políticas y proyectos que abarquen dichas problemáticas relacionadas con el acceso al empleo. Estas no deben ir enfocadas solamente a la creación de empresa, pues no todos cuentan con los recursos económicos para hacerlo y existirán otros que no querrán crearlas, tampoco necesitan esas mismas políticas vistas desde lo que favorece a las pequeñas y medianas empresas, porque en nada se refiere a lo que dan a conocer como "Ley de Primer Empleo".

Se sabe además que existe una participación fuerte de jóvenes en el ingreso a las universidades que requieren seguimiento por parte del Estado para ofrecerle garantías y empleos regulados y dignos a los futuros egresados, aspirantes a conseguir su primer empleo, de tal forma que sean reconocidos sus esfuerzos y sientan que valió la pena el recorrido por el aprendizaje. Es necesario además para esto saber que no todos los jóvenes cuentan con un mismo entorno social y la misma suerte para acceder a empleos dignos en el país.

Los cambios notorios ocurridos en la sociedad y la población en aumento requiere prevenir futuros inconvenientes, que además puedan solucionarse con nuevos modelos, programas, políticas, leyes, que introduzcan la experiencia del país en general y no solo de las experiencias de otros países. En este sentido sería importante preguntarse ¿Cómo hacer una política en el empleo de los jóvenes que mire nuestras particularidades pero que tome también experiencias positivas de otros países? 
Este trabajo concluye, primero que las políticas creadas para solucionar la problemática de desempleo juvenil no son la adecuadas, pues el emprendimiento empresarial no es universal, las necesidades y gustos de las personas y en este caso de los jóvenes son diferentes, no todos quieren crear empresa, no todos tienen la capacidad económica para hacerlo, ni la capacidad de competitividad, además no todos tienen como proyecto de vida crear empresa, por ende la empleabilidad debe buscar salidas universales, que tengan en cuenta todas las condiciones de los jóvenes (edad, sexo, nivel educativo, estrato socioeconómico, experiencia, transito laboral, etc.).

En segundo lugar se sabe que los jóvenes no tienen conocimiento sobre los programas de emprendimiento y de empleo; y tampoco de las políticas, entonces se puede decir que el futuro de la Ley 1429 de 2010 y sus programas asociados necesitan reformas o ser derogadas, pues no es la solución a los problemas y esto ya se ha visto en experiencias de otros países como Chile. La ley y los programas sin duda alguna tendrán que ser removidas porque los cambios no contienen efectos positivos a la problemática y porque esta problemática en vez de mejorar, empeora.

No cabe duda que aunque hay nuevas modalidades en función del tema del empleo, se necesitarán nuevas ideas para abarcar estos problemas teniendo en cuenta los cambios que ha tenido el campo laboral en el mundo, no se pueden seguir generando estrategias solidarias con el sector económico, olvidando que existen personas activas con capacidades que necesitan hacer inmersión al mercado laboral.

\subsection{Experiencia con la técnica}

Sin duda alguna esta experiencia, permitió hacer un acercamiento y de gran interés para este trabajo, pues es a partir de las ideas y realidades concebidas por los jóvenes universitarios en Bogotá y que se encuentran finalizando su proceso de formación profesional que se pueden construir resultados y se puede abarcar la necesidad de construir nuevos campos investigativos que surgirán con este primer ejercicio de abordaje.

Con la técnica utilizada en este trabajo se permitió categorizar, sistematizar, jerarquizar, analizar e interpretar la construcción de conocimientos que se encuentran basados en la experiencia propia del ser humano. 
Con este trabajo de campo se permitió conocer el desinterés de los jóvenes entrevistados, desde el comienzo cuando se inicia preguntando sobre su proceso educativo, no mencionan en su mayoría que realizan estudios profesionales con el fin de poder realizar inmersión al mercado laboral. Aunque reconocen que hay una problemática en el tema laboral, sus prioridades no las abordan desde este punto.

Aunque el trabajo se realizó con un grupo pequeño de personas, hay un fuerte impacto para este trabajo, el desinterés, el desconocimiento y la falta de divulgación de los medios sobre las nuevas políticas y programas que se acerca a lo planteado en la hipótesis. Además del desconocimiento por algunos jóvenes, incluyendo los que se encuentran laborando sobre la formalidad e informalidad, temas cruciales en la vida y en el ingreso al mercado laboral.

Es fundamental el aprendizaje de este tema desde una edad temprana, con el fin de ir corrigiendo desde la sociedad el desconocimiento y sobre los problemas económicos que conlleva la informalidad para todo un país. Los jóvenes muestran desconocimientos sobre lo que refiere el primer empleo en su mayoría, lo que además genera más interés aun porque esto sea una enseñanza para su crecimiento y enfrentamiento a una vida laboral

Las personas entrevistadas para este trabajo tienen un nivel socioeconómico entre tres y cuatro, lo que permitió ver desde un punto equitativo y analizar las diferencias que además se reflejan en el caso de dos jóvenes que se encuentran en nivel cuatro y estudiaron en universidad prestigiosa como lo es la Javeriana, sus necesidades y expectativas por el ingreso al mercado laboral no son su prioridad. Además pasa también con quiénes no han tenido que enfrentarse a la dificultad de salir a conseguir empleo, solo quiénes se han enfrentado al mismo saben de qué se trata y hablan de las problemáticas desde su experiencia.

Se hizo notorio como las universidades no tienen una iniciativa significativa para la vinculación de los jóvenes al mercado laboral, no tiene programas fuertes en las mismas instituciones y no son tan distinguidas, pues no tienen una repercusión para los jóvenes, ni un centro de ayuda principal que tengan en cuenta los estudiantes para conseguir empleo. 
Otro aspecto de relevancia que se encontró es la experiencia laboral. Los jóvenes reconocen que sin esta no pueden acceder a trabajos dignos o no pueden vincularse. Sin duda alguna, esto desde el punto de vista de los empleadores, las exigencias para poder contratar son elevadas $\mathrm{y}$ en muchos casos las contrataciones se hacen por intermediaciones. Algunos jóvenes dicen que conseguir empleo en el país, un buen empleo requiere de "palanca" y relaciones sociales, tema que concuerda además con lo investigado en este trabajo.

Las competencias del mercado laboral son demasiado elevadas, existen demasiadas exigencias de experiencia y hay una discriminación de jóvenes profesionales recién egresados que no la poseen y se encuentran en calidad de aspirantes, las oportunidades en el país son escasas y los esfuerzos de quiénes acceden a la educación superior no está siendo captada, pues los requerimientos cada vez son más altos.

Las expectativas de los jóvenes profesionales y de últimos semestre frente al empleo son grandes y lo demuestran integrándose a la educación con el fin de poder conseguir empleos dignos y remuneraciones justas. Se necesitan definir los derechos y garantías claras para los jóvenes que se van a emplear, dirigidas además especialmente a este campo, las personas entrevistadas reconocen que hay explotación laboral, existen trabajos precarios, hay informalidad (para quiénes tienen conocimiento sobre este concepto), no hay condiciones justas en los empleos, el desempleo es elevado, las oportunidades que se ofrecen no son buenas, entre otras, que además se encontraron en el proceso de construcción del inicio de este documento. Las problemáticas son reconocidas por los jóvenes a través de su experiencia.

Se reconoció en este proceso que se necesita hacer involucración de instituciones educativas y espacios laborales fijos con el fin de mitigar estas problemáticas. El crear empresa no es para todos y no todos quieren crearlas es mencionado también.

Para finalizar es importante dar referencia al análisis Desempleo juvenil en Colombia donde encontraron recomendaciones que se adecuan a lo planteado en este trabajo y sus resultados, contemplando en sus argumentos las políticas de empleo juvenil en Colombia y la situación de empleo y desempleo. Entre estas, se encontraron las que están directamente relacionadas con este trabajo como lo son: 
- Las problemáticas que causan el desempleo juvenil están asociadas a las disfuncionalidades de la transición del sistema educativo al mundo laboral y a la desconexión entre aquellos.

- Las estadísticas de acceso a programas de educación superior demuestran la brecha en materia de calificación de los trabajadores, que limita el acceso al sistema formal de relaciones laborales.

- Para combatir el abandono de los procesos de formación es conveniente establecer políticas de intervención, así como identificar y estimular la inclusión en los programas de acuerdo con los criterios de calidad y pertinencia con la demanda de puestos de trabajo establecida por el servicio público de empleo.

- Es necesario establecer políticas de superación de la brecha por género, que muestran un desempleo juvenil masculino de 14,3\% frente a uno femenino de 23\%, causado por las asignaciones culturales de género y que en materia de desempleo juvenil se profundiza en función de la asignación de tareas de economía de cuidado, situación que incide en la empleabilidad de las jóvenes y demanda estrategias de corrección.

- La heterogeneidad del grupo poblacional de los jóvenes demanda también estrategias diferenciadas para corregir y eliminar barreras, mediante políticas de empleo enfocadas en cada subgrupo: nini, jóvenes sobrecalificados, sector rural, etcétera.

- Las garantías de primer empleo han mostrado ser ineficaces, fundamentalmente por propender a vínculos temporales y a centrar la estrategia en el impulso de políticas de promoción del emprendimiento para deslaboralizar la vinculación y trasladar la responsabilidad ocupacional al conjunto de trabajadores.

- El programa de subsidios a la demanda 40.000 primeros empleos debe reenfocarse, para que sea sostenible a largo plazo. Asimismo, es conveniente establecer estrategias que incentiven la vinculación laboral estable (94).

\subsection{Problemas de investigación que se abren para la Protección Social}


Como ya se mencionó antes la problemática de empleo se presenta a nivel mundial y esto es producto de diversos factores como las crisis de la economía, la alta tasa de población en edad para trabajar, el crecimiento de población capacitada, la falta de experiencia, la deserción escolar, la no articulación entre academia, la industria, la no regulación de contrataciones, el crecimiento del sector informal, y la dificultad del trabajo del Estado, donde ha intervenido en lo privado olvidándose de su rol principal que es lo público, construyendo políticas focalizadas, de gobierno y dejando políticas que son regresivas en cuanto a las inversiones que se realizan en el país (inversión social sigue en el mismo punto y hacia atrás en el campo laboral).

De acuerdo a lo anterior, el gobierno ha realizado estrategias con el fin de mitigar esta problemática. La ley conocida como "Primer Empleo" sería inconstitucional porque no hay relación entre el nombre difundido por el Ministerio y su contenido. Según la Constitución Política de Colombia en los artículos 158, 169 y 170 las leyes deben referirse a una misma materia, el título de las leyes debe corresponder al contenido y los mismos ciudadanos podrán convocar referendo para la derogatoria de la ley si incumple con lo anterior.

Esta ley está diseñada para beneficiar empresas y de algún modo buscar mejoría económica al país y por último esta ley no refiere a las personas que se encuentran en búsqueda de su primer acercamiento laboral, por tanto no podría ni siquiera llamarse o referirse al "Primer Empleo". Primer Empleo no es crear empresa y exponerse a sufrir más riesgos económicos, es más, muchos no quieren crear empresa. Quiénes quieren hacerlo, son una población muy pequeña.

Los modelos de políticas deben ser claros y referirse a un mismo tema. En Colombia se necesitan modelos que involucren la educación, la industria y el Estado, modelos que permitan dar a las personas nuevas formas de aprendizaje para competir según los requerimientos y exigencias de las empresas, el Estado es necesario para que regule las nuevas formas de contratación y obligue a dar garantías a los empleados, sin exclusiones, ni contratación por palancas, brindando igualdad y equidad a las personas.

Adicionalmente, estrategias que estén enfocados en las problemáticas, en este caso la de "Primer Empleo" con una divulgación prolongada con el fin de obtener reconocimiento y poder involucrarse en ella para beneficio propio y de la sociedad, para esto se debe contar participación activa de toda la sociedad; para el diseño de las mismas se debería 
convocar a un debate amplío nacional que permita la participación de sectores privados, mixtos, universidades, jóvenes y medios para la toma de decisiones frente al tema laboral de los jóvenes y las garantías para los mismos.

Es de gran importancia igualmente reconocer las falencias de las leyes y los programas que las rigen y hacerlo visible y público, de tal manera que se vayan corrigiendo y se permita la creación de propuestas y modelos efectivos y pertinentes para el país. No se pueden seguir copiando modelos implementados en otros países, pues las experiencias son distintas.

Se hace primordial propagar el interés sobre el tema laboral brindando bases y reconociendo que es necesario brindar enseñanza desde la finalización de la niñez o desde los inicios de la juventud, generando consciencia sobre lo que implica el desempleo a futuro y sobre la precariedad de los subsidios, lo que significa no tener aseguramiento de la salud y no tener una pensión para la vejez. No se puede seguir esperando a que los jóvenes deban enfrentarse a las problemáticas de conseguir un primer empleo sin que tengan conocimientos sobre la importancia de una protección social y lo que esto trae como consecuencia para todo el país en términos de bienestar y desarrollo.

El empleo según el informe de la CEPAL se puede conseguir de dos formas:

Primer lugar: puede ocurrir que un bajo flujo de personas ingrese al estado de desempleo y permanezca en esta situación un tiempo prolongado. En este caso, los desocupados constituyen un grupo de personas con dificultades para salir de esta situación.

Segundo lugar: El desempleo puede provenir de un elevado tránsito desde el empleo hacia el desempleo y desde allí al empleo nuevamente, esto es, caracterizarse por un ato flujo y corta duración. En este caso, continuamente ingresan al desempleo personas que encuentran rápidamente un empleo (77).

Es necesario que el gobierno y la sociedad en general acepten la repercusión que tiene la población joven y la necesidad de generar oportunidades para ellos, de tal forma que puedan asumir responsabilidades en el momento que adquieran el conocimiento y perfeccionen sus habilidades. Es necesario facilitar los servicios básicos de esta forma se estará superando la pobreza, ayudando un grupo etario que debe enfrentarse a 
necesidades, aprendiendo sin una experiencia previa en un mundo que no tiene oportunidades, la reducción de las desigualdades son el pilar de la construcción de la política social de protección con enfoque de derechos.

Por su parte, los modelos políticos, sociales y económicos tomados de otros países, que se aplican en Colombia, como lo es la propuesta de la Ley 1429 de 2010: Formalización y Generación de Empleo, abren el cuestionamiento: ¿estos modelos darían solución a la problemática existente? Teniendo en cuenta que Colombia se caracteriza por su diversidad cultural y cuenta con experiencias diferentes a los demás países de Latinoamérica y que se sabe no ha dado resultados efectivos, es preciso generar una nueva propuesta política, que vaya dirigida solo a jóvenes y que esté enfocada a las necesidades propias del país.

Es importante el desarrollo de un sistema educativo que pueda diferenciarse de los demás, una educación gratuita sin restricción de acceso, de alta calidad integrando tecnologías avanzadas para que quiénes culminen se conviertan en seres valiosos y requeridos no solo a nivel nacional, sino internacional, además de una participación de los sectores público-privado con el fin de poder resaltar la calidad de la demanda laboral joven frente a los empleadores (58).

Por último, tampoco se puede permitir que a lo único que los jóvenes puedan acceder en materia de empleos sea el sector informal, quedando desprotegidos, con condiciones no dignas y sin garantías de derechos. Es claro que hay que desarrollar esfuerzos estructurales, pero también otros coyunturales en donde la divulgación de información sobre las normas, leyes, políticas y programas resulta primordial para generar interés sobre temas de tanta importancia. Los medios juegan un papel importante en la sociedad y es de saber que es necesario reconocer siempre que así como existen mejoras en algunos temas, se necesita también el reconocimiento de las necesidades y problemáticas con el fin de mitigar y no enfrentar daños irreparables. La participación de todos los actores de la sociedad es de suma importancia para mejorar el bienestar de ella misma.

Desde la revisión y la investigación realizada en este trabajo, para la protección social se abren campos investigativos que involucran el tema abordado en este trabajo. 
- Estado deberá volver a reconocer sus responsabilidades y proteger a la población total del país y protegerla ante cualquier riesgo al que se enfrente.

- Regulación por parte del Estado de las contrataciones para los jóvenes.

- Eliminar y no permitir políticas individualistas, pues los jóvenes no están capacitados para enfrentar situaciones de riesgo y tampoco todos cuentan con las mismas oportunidades para hacerlo.

- Fortalecer y proteger los derechos laborales, no permitir que sigan desapareciendo en la sociedad y quitarse responsabilidades sobre los mismos.

- Trabajo conjunto de instituciones del Estado que permita ampliar y mejorar el campo laboral y las oportunidades laborales en el país.

- Políticas, leyes, programas enfocados en un campo específico, en este caso en los derechos y garantías de los jóvenes, que además se construyan desde el Estado y no por gobiernos, permitiendo así encontrar mejorar y trabajar en conjunto por las mismas.

- Trabajar por las problemáticas que tiene cada subgrupo, reconociendo sus desigualdades y sus necesidades (estudios recientes, pues se encuentra poca información y actualización sobre las poblaciones por ciudades, esto teniendo en cuenta que aun así hay muchas diversidades entre culturas del mismo país).

- Enseñanza a niños (en casi su fin de etapa) y jóvenes sobre la importancia del empleo, la precariedad de subsidios, el aseguramiento.

- Considerar que no toda la población es aspirante, que existen transiciones laborales en la población joven y que muchas se ocupan por horas, semanas, meses, sin tener una estabilidad, hay muchas personas que ya se emplearon por primera vez y no volvieron a integrarse al mercado laboral.

- Creación de un nuevo sistema educativo en el país gratuito y de alta calidad para competir en el MUNDO laboral.

- Abordar el campo de la informalidad para que este no continúe fortaleciéndose. 


\section{BIBLIOGRAFÍA}

1. Neffa J.[a]. Actividad, empleo y desempleo. Conceptos y definiciones. 4th ed. Buenos Aires: Ciudad Autonóma de Buenos Aires: Centro de Estudios e Investigaciones; 2014.

2. Rosanvallon P. El derecho al trabajo: Historia de un problema. In Rosanvallon P. La nueva cuestión social. Buenos Aires: Ediciones Manantial; 1995. p. 129 - 186.

3. Agudelo M. Transformaciones en el mundo del trabajo. In Giraldo C, editor. Política social contemporánea en América Latina. Entre el asistencialismo y el mercado. Bogotá: Desde abajo; 2013. p. 139 - 158. 
4. Jiménez G. La dotación de Capital Humano de America Latina y el Caribe. Revista CEPAL 86. 2005 Agosto;: p. 103-122.

5. Unidas N. Naciones Unidas. [Online].; s.f. [cited 2015 Octubre 3. Available from: http://www.un.org/en/development/desa/policy/wesp/wesp archive/2015wesp-eses.pdf.

6. Ministerio de Asuntos Exteriores y Cooperación - España. Organización Internacional del TRabajo (OIT). [Online].; s.f. [cited 2015 Octubre 3. Available from: http://www.exteriores.gob.es/RepresentacionesPermanentes/OficinadelasNacionesUn idas/es/quees2/Paginas/Organismos\%20Especializados/OIT.aspx.

7. Procuraduría General de la Nación. Trabajo digno y decente en Colombia. Seguimiento y control preventivo a las políticas públicas. Tomado de: http://www.procuraduria.gov.co/portal/media/file/Trabajo\%20digno\%20y\%20decente \%20en\%20Colombia_\%20Seguimiento\%20y\%20control\%20preventivo\%20a\%20las\%20 pol\%C3\%ADticas\%20p\%C3\%BAblicas(1).pdf.

8. Propiedad de la Secretaría General de la Alcaldía Mayor de Bogotá, D.C. Contitución Política de Colombia Bogotá: Gaceta Constitucional; 1991.

9. Propiedad de la Secretaría General de la Alcaldía Mayor de Bogotá, D.C. Código Sustantivo del Trabajo Bogotá; 1950.

10. Ministerio de la Protección Social, República de Colombia. Universidad del Tolima. [Online]. Bogotá; s.f. [cited 2015 Octubre 4 [Documento encontrado en búsqueda de google sobre mercado del trabajo]. Available from: http://www.ut.edu.co/administrativos/images/DOCUMENTOS\%20ADMINISTRATIVOS/ OBSERVATORIOS/Del Empleo y Recursos Humanos/Legislaci\%C3\%B3n laboral docu mentos/derecho al trabajo.pdf.

11. Maruani M. Revistas Científicas Computlenses. [Online].; s.f. [cited 2015 Octubre 3. Available from: http://revistas.ucm.es/index.php/POSO/article/viewFile/POSO0000230009A/24529.

12. Oficina Internacional de los Derechos Humanos Acción Colombia (OIDHACO). Oficina Internacional de los Derechos Humanos Acción Colombia (OIDHACO). [Online].; s.f. [cited 2015 Octubre 3. Available from: http://www.oidhaco.org/?art=1402\&lang=es.

13. Ministerio de Trabajo. Ministerio de Trabajo - Derechos Fundamentales. [Online].; s.f. [cited 2015 Octubre 3. Available from: http://mintrabajo.gov.co/derechosfundamentales/1347-derechos-fundamentales-del-trabajo-descripcion.html.

14. Organización Internacional del Trabajo. Organización Internacional del Trabajo Protección Social. [Online].; s.f. [cited 2015 Octubre 3. Available from: 
http://www.ilo.org/global/about-the-ilo/decent-work-agenda/social-protection/lang-es/index.htm.

15. Congreso de la República de Colombia. Ley Estatutaria 1622 de 2013 Bogotá; 2013.

16. El Heraldo. El Heraldo. [Online].; 2014 [cited 2015 Octubre 5 [Medio informático de comunicación (Periódico)]. Available from: http://www.elheraldo.co/economia/masjovenes-dejaron-de-buscar-trabajo-formal-en-colombia-163873.

17. Hernández S. R, Fernández C. C, Baptista L. P. METOdOLOGÍA DE LA INVESTIGACIÓN. Primera Edición ed. Naucalpan de Juárez, Edo. de México: MCGRAW-HILL. INTERAMERICANA DE MÉXICO, S.A. de C.V.; 1991.

18. MINISTERIO DE COMERCIO, INDUSTRIA Y TURISMO. Decreto número 0489. 2013 Marzo $14 .$.

19. CEPAL. Naciones Unidas. CEPAL. Naciones Unidas. Repository Economic Commission For Latin America and The Caribbean. [Online]. Santiago de Chile; 2006 [cited 20170605. Available from: http://repositorio.cepal.org/bitstream/handle/11362/6130/S0600897 es.pdf;jsessioni $\mathrm{d}=99886 \mathrm{EF9E4C553FDE70061 \text {C06BDA72D8?sequence } = 1 \text { . }}$.

20. Giddens A. La estructura de clases sociales avanzadas Madrid: Alianza Ed; 1979.

21. Giddens A. El capitalismo y la moderna teoría social Barcelona: Ed. Labor; 1997.

22. DEPARTAMENTO ADMINISTRATIVO NACIONAL DE ESTADÍSTICA - DANE. Reloj de Población. [Online].; 2005 [cited 2016 Marzo 31 [Revisada el día 31 de marzo de 2016 a las 11:50 am. Estos datos pueden variar al pasar el tiempo.]. Available from: http://www.dane.gov.co/reloj/reloj animado.php.

23. Muñoz OH. FACTORES DETERMINANTES DE LA PARTICIPACION LABORAL: ASPECTOS CONCEPTUALES. TENDENCIAS Revista de la Facultad de Ciencias Económicas y Administrativas. 2009 Primer Semestre;: p. 87-116.

24. DANE. PREGUNTAS FRECUENTES - EMPLEO. [Online].; n.d. Available from: http://www.dane.gov.co/files/faqs/faq ech.pdf.

25. Giraldo C. Capítulo 1. El origen de la protección social. In Giraldo C. ¿Protección o desprotección social? Bogotá: Ediciones desde abajo; 2007. p. 39 - 86.

26. Moya MA. IMPACTO DEL PROGRAMA “LEY DEL PRIMER EMPLEO” EN LA INCIDENCIA EN LA INFORMALIDAD Y EN EL SUBEMPLEO JUVENIL EN COLOMBIA. Suma de Negocios. 2013 Diciembre; 4(2): p. 97 - 111. 
27. Rojas G. CA. DILEMAS ACTUALES DE LA JUVENTUD FRENTE AL TRABAJO: Formas de inserción socio-laboral juvenil en Manizales (Colombia). Artículo. Cali: Universidad Icesi.

28. JUACO Sistema de Información en Juventud y Adolescencia en Colombia. JUACO. [Online].; s.f. [cited 2015 Octubre 3. Available from: http://obs.colombiajoven.gov.co/Observatorio/Observatorio.aspx?rpt=Buyel7PqAptVw 9lwUXO Fw==.

29. EL TIEMPO. [Online]. Available from: http://www.eltiempo.com/economia/sectores/cifras-de-empleo-informal-ydesempleo-juvenil-en-2015-en-colombia/16505802.

30. Dimas Hoyos D. Desempleo juvenil en Bogotá fue de $16,8 \%$. Observatorio de Desarrollo Economico. 2016 Apr.

31. Cecchini S. Protección social con enfoque de derechos para la América Latina del siglo XXI. Revista Opera 18. Universidad Externado de Colombia. 2016;: p. 11-33.

32. Comisión Económica para América Latina y el Caribe (CEPAL). Protección social inclusiva en América Latina: una mirada integral, un enfoque de derechos Cecchini S, Martínez R, editors. Santiago de Chile; 2011.

33. Comisión Económica para América Latina y el Caribe (CEPAL). Instrumentos de protección social. Caminos latinoamericanos hacia la universalización Cecchini S, Filgueira F, Martínez R, Rossel C, editors. Santiago de Chile; 2015.

34. Neffa Jea. Actividad, empleo y desempleo. Conceptos y definiciones. 4th ed. Buenos Aires: Ciudad Autonóma de Buenos Aires: Centro de Estudios e Investigaciones; 2014.

35. NU. CEPAL. CELADE. Juventud y bono demográfico en Iberoamerica. Segunda Edición ed. Madrid: CEPAL; 2012.

36. Schiffman LGyKLL. Comportamiento. 2005 Julio - Diciembre. Tomado de: http://www.unilibre.edu.co/CriterioLibre/images/revistas/17/art5.pdf.

37. Vargas M. LM. Sobre el concepto de percepción. aLTeRIDaDeS. 1994; 4(8): p. 47-53.

38. Mintrabajo. LOS BENEFICIOS. [Online]. Available from: http://www.mintrabajo.gov.co/empleo/abece-ley-de-primer-empleo.html.

39. Organización Internacional del Trabajo (OIT). Informalidad, calidad del empleo y segmentación laboral en Argentina. Documentos de Trabajo No. 2. Buenos Aires: Organización Internacional del Trabajo (OIT); 2013.

40. Organización Internacional del Trabajo (OIT). El trabajo decente y la economía informal. Sexto punto del orden del día. Conferencia Internacional del Trabajo 90.a reunión. 
Informe VI. Ginebra: Organización Internacional del Trabajo (OIT); 2002. Report No.: ISBN 92-2-312429-8.

41. Antunes R. La metamorfosis en el mundo de trabajo. Nómadas (Col). 2000;(12).

42. Chaplin C. Modern Times Estado Unidos; 1936.

43. Sotelo A. La reestructuración del mundo del trabajo, superexplotación y nuevos paradigmas de la organización del trabajo Ítaca: Escuela Nacional para Trabajadores, Morelia; 2003.

44. Organización Internacional de Trabajo - OIT. Organización Internacional de Trabajo - OIT. [Online].; 2015 [cited 2016 Marzo 10 [De Bismarck a Beveridge: seguridad social para todos]. Available from: http://www.ilo.org/global/publications/magazines-andjournals/world-of-work-magazine/articles/ilo-in-history/WCMS 122242/lang-es/index.htm.

45. Castel R. El ascenso de las incertidumbres. Trabajo, Protecciones, estatuto del individuo Buenos Aires: Fondo de Cultura ; 2010.

46. OIT. Tendencias Mundiales del Empleo Juvenil 2015. Organización Internacional del Trabaj; n.d.

47. Organización Internacional del Trabajo - OIT. Organización Internacional del Trabajo OIT. [Online].; 2015 [cited 2016 Marzo 10 [La crisis del empleo juvenil se atenúa, pero está lejos de terminar]. Available from: http://www.ilo.org/global/about-theilo/newsroom/news/WCMS 412427/lang--es/index.htm.

48. Banco Mundial (BM). Banco Mundial. [Online].; 2011 [cited 2016 Marzo 09 [La falta de empleo es ahora un problema mundial]. Available from: http://blogs.worldbank.org/voices/es/la-falta-de-empleo-es-ahora-un-problemamundial?cid=EXT WBBlogSocialShare D EXT.

49. Organizcación Internacional del Trabajo - OIT. Organizcación Internacional del Trabajo OIT. [Online]. [cited 2016 Marzo 10 [Empleo Juvenil]. Available from: http://www.ilo.org/wcmsp5/groups/public/--ed emp/documents/publication/wcms 141383.pdf.

50. Banco Mundial. Juventud. Reseña temática. [Online].; s.f. [cited 2016 Marzo 10. Available from: http://www.bancomundial.org/temas/iuventud/.

51. COMISIÓN ECONÓMICA PARA AMÉRICA LATINA Y EL CARIBE - CEPAL. TENDENCIAS RECIENTES DE LA INSERCIÓN DE LOS JÓVENES LATINOAMERICANOS EN EL MERCADO LABORAL. In Weller J, editor. LOS JÓVENES Y EL EMPLEO EN AMÉRICA LATINA. DESAFÍOS Y PERSPECTIVAS ANTE EL NUEVO ESCENARIO LABORAL. 2006th ed. Bogotá: Mayol Ediciones; 2006. p. 326. 
52. CEPAL. Educación y mercado de trabajo en América Latina frente a la globalización. Revista de la CEPAL. 2002 Agosto;(77): p. 123 - 141.

53. Pérez G, Romero M. JÓVENES: PRECARIEDAD E INSEGURIDAD SOCIAL. LA CUESTIÓN SOCIAL DE LOS JÓVENES. In ARG/04/034 SeeemdpP, editor. El Estado y la reconfiguración de la protección social: asuntos pendientes. Primera Edición ed. Buenos Aires: SIGLO XXI EDITORA IBEROAMERICANA, 2008., INSTITUTO TORCUATO DI TELLA; 2008. p. 377-410.

54. MercoPress. Venezuela en la antesala de hiperinflación, y 17\% de desempleo, según FMI. [Online].; 15 [cited 2016 Agosto. Available from: http://es.mercopress.com/2016/04/15/venezuela-en-la-antesala-de-hiperinflacion-y17-de-desempleo-segun-fmi.

55. Sistema Nacional de Información en Juventud y Adolescencia en Colombia JUACO. PROYECCIONES DE POBLACIÓN JÓVENES 14-28 AÑOS. [Online]. [cited 2016 Marzo 31 [La búsqueda la hice a la fecha y las cifras corresponden a lo que data el 2016 (Total Nacional)]. Available from: http://obs.colombiajoven.gov.co/Observatorio/Observatorio.aspx?rpt=Buyel7PqAptVw 9lwUXO Fw==.

56. MINISTERIO DE EDUCACIÓN. PERMANENCIA Y GRADUACIÓN: UNA APUESTA POR LA EQUIDAD EN EDUCACIÓN SUPERIOR. [Online].; 2015 [cited 2016 Marzo 04 [Tomado de: http://www.mineducacion.gov.co/1759/articles-350451_recurso_9.pdf]. Available from: http://www.mineducacion.gov.co/1759/articles-350451 recurso 9.pdf.

57. Jacinto C. Políticas públicas y perspectivas subjetivas en torno a la transición laboral de los jóvenes. In Novick M, Pérez Soto GC. EL ESTADO Y LA RECONFIGURACIÓN DE LA PROTECCIÓN SOCIAL. Primera ed. Buenos Aires: Buenos Aires : Instituto Di Tella : Siglo XXI, 2008.; 2008.

58. Naciones Unidas, Comisión económica para América Latina y el Caribe - CEPAL. JUVENTUD Y MERCADO LABORAL: Brechas y Barreras Charlin de Groote M, Weller Je, editors. Santiago de Chile: FLACSO, FacultadLatinoamericana de Ciencias Social; 2006.

59. Departamento Administrativo Nacional de Estadístic. DANE. [Online].; 2016 [http://www.dane.gov.co/index.php/estadisticas-por-tema/mercado-laboral/mercadolaboral-de-la-juventud].

60. Congreso de Colombia. Ley No.1429 de 2010, "Por la cual se expide la Ley de Formalización y Generación de Empleo". 2010. Tomado de: http://wsp.presidencia.gov.co/Normativa/Leyes/Documents/ley142929122010.pdf.

61. Departamento Nacional de Planeación - DNP. PLAN NACIONA DE DESARROLLO 2010 2014 "Prosperidad para todos" Resumen ejecutivo. s.f. Tomado de: 
https://colaboracion.dnp.gov.co/CDT/PND/Resumen\%20Ejecutivo\%20Ultima\%20Versi on.pdf.

62. Universidad Externado de Colombia. ¿La Ley 1429 de 2010 ha formalizado el empleo en Colombia? BOLETÍN DE OBSERVATORIO DEL MERCADO DE TRABAJO Y LA SEGURIDAD SOCIAL. 2012 Marzo;(13).

63. Departamento Nacional de Planeación - DNP. PLAN NACIONAL DE DESARROLLO 2014 2018. TODOS POR UN NUEVO PAÍS PAZ, EQUIDAD, EDUCACIÓN. s.f. Tomado de: https://colaboracion.dnp.gov.co/cdt/prensa/bases\%20plan\%20nacional\%20de\%20des arrollo\%202014-2018.pdf.

64. Cámara de Comercio de Bogotá. Todo sobre la Ley 1426 de 2010. [Online].; s.f. [cited 2016 Marzo 10. Available from: http://www.ccb.org.co/Inscripciones-yrenovaciones/Todo-sobre-la-Ley-1429-de-2010.

65. MINTRABAJO. TOdOS POR UN NUEVO PAÍS. PAZ, EQUIDAD, EDUCACIÓN. Ministerio de Trabajo. Eliminando la barrera de la inexperiencia en los jóvenes. [Online].; 2015 [cited 2015 Octubre 14. Available from: http://www.mintrabajo.gov.co/medios-mayo2015/4452-eliminando-la-barrera-de-la-inexperiencia-en-los-jovenes.html.

66. Oficina regional para América Latina y el Caribe. ¿QUÉ SABEMOS DE LOS PROGRAMAS Y POLÍTICAS DE PRIMER EMPLEO EN AMÉRICA LATINA?: OIT - Organización Internacional del Trabajo; 2015.

67. Naciones Unidas - Comisión Económica para América Latina y el Caribe - CEPAL. Magnitud y heterogeneidad: Políticas de fomento del empleo juvenil y las micro y pequeñas empresas. Estudio: Macroeconomía del desarrollo. Santiago de Chile: Naciones Unidas - Comisión Económica para América Latina y el Caribe - CEPAL, División de Desarrollo Económico; 2009. Report No.: ISBN 978-92-1-323363-4.

68. Organización Internacional del Trabajo (OIT). JUVENTUD E INFORMALIDAD. Primera ed. Lima; 2015.

69. Fernández P. Políticas y Programas de Apoyo a La Inserción Laboral de Los y Las Jóvenes en Chile. Charlin de Groote, M. y Jurgüen Weller ed. Santiago; 2006.

70. Rabbs S. V. empleo, ¿DE QUÉ HABLAMOS CUANDO HABLAMOS DE EMPLEABILIDAD JUVENIL? Estudio de caso de su significación y práctica en los programas de. 2005 Octubre..

71. Jiménez A. DP. JÓVENES, EMPLEO Y TRABAJO DECENTE. 2014. Universidad Nacional de Colombia. Maestría en Derecho del Trabajo y la Seguridad Social. 
72. Pedraza AAC. El mercado laboral de los jóvenes y las jóvenes de Colombia: realidades y respuestas políticas actuales. REVISTA LATINOAMÉRICANA DE CIENCIAS SOCIALES, NIÑEZ Y JUVENTUD. ; 6(2).

73. Departamento Nacional Adminisrtativo de Estadística - DANE. Medición del Empleo Informal y Seguridad Social. 10 de noviembre de 2016. Boletín técnico. Bogotá: DANE; 2016 Noviembre 10.

74. Departamento Administrativo Nacional de Estadística - DANE. PRINCIPALES INDICADORES DEL MERCADO LABORAL. 31 de octubre de 2016. Boletín técnico. Bogotá: DANE; 2016.

75. Departamento Administrativo Nacional de Estadística - DANE. Mercado laboral de la juventud (14 a 28 años). 10 de octubre de 2016. Boletín técnico. Bogotá: DANE; 2016.

76. Departamento Administrativo Nacional de Estadística - DANE. DEMOGRAFÍA Y POBLACIÓN - MOVILIDAD Y MIGRACIÓN. [Online].; s.f. [cited 2016 Abril 04. Available from: $\quad$ http://www.dane.gov.co/index.php/poblacion-y-demografia/movilidad-ymigracion.

77. Naciones Unidas, Comisión Económica para América Latina y el Caribe - CEPAL. Oficinan de Montevideo. Mercado de trabajo juvenil. Situación y políticas. Estudios. Montevideo: CEPAL, Serie. Estudios y perspectivas; 2006. Report No.: ISBN 92-1-323002-8.

78. Dinero. La informalidad cae mientras el desempleo incrementa. Dinero. 2016 Mar.

79. DANE - Departamento Administrativo Nacional de Estadística. MECADO LABORAL DE LA JUVENTUD. INFORMACIÓN DEL TRIMESTRE ENERO 2016 - MARZO 2016. COMUNICADO. DANE - Departamento Administrativo Nacional de Estadística; 2016.

80. DANE - Departamento Administrativo Nacional de Estadística. GRAN ENCUESTA INTEGRADA DE HOGARES. Boletín informativo - Comunicado de Prensa. BOGOTÁ: DANE - Departamento Administrativo Nacional de Estadística, BOGOTÁ, D.C.; 2016.

81. ALCALDÍA MAYOR DE BOGOTÁ. SECRETARÍA DISTRITAL DE PLANEACIÓN BOGOTÁ D.C. ROSTROS Y RASTROS. Razones para construir ciudad. TRANSCURRIR VITAL V. JÓVENES EN BOGOTÁ. BOGOTÁ: ALCALDÍA MAYOR DE BOGOTÁ. SECRETARÍA DISTRITAL DE PLANEACIÓN BOGOTA D.C.; 2014. Report No.: ISBN 978-958-8310-83-1.

82. SECRETARÍA DE INTEGRACIÓN SOCIAL. TRANSCURRIR VITAL V. JÓVENES EN BOGOTÁ. Rostros y Rastros Publicación trimestral de la Dirección de Equidad y Políticas Poblacionales.. BOGOTÁ D.C.: ALCALDÍA MAYO DE BOGOTÁ D.C., BOGOTÁ D.C.; 2015.

83. SECRETARÍA GENERAL DE LA ALCALDÍA MAYOR DE BOGOTÁ D.C. DECRETO 482 DE 2006. 2006 Noviembre $27 . \quad$ Consultado http://www.alcaldiabogota.gov.co/sisjur/normas/Norma1.jsp?i=22240. 
84. Ministerio de Educación. Boletín Educación Superior en Cifras. [Online].; 2015 [cited 2016 Abril 06. Available from: http://www.mineducacion.gov.co/1759/articles350451 recurso 11.pdf.

85. Secretaría de Desarrollo Económico. Observatorio de Desarrollo Económico. Desempleo juvenil en Bogotá fue de 16,8\%. Boletín. Bogotá D.C.: Alcaldía Mayor de Bogotá, Bogotá D.C.; 2016.

86. Bourdieu P, Passeron JC. Los herederos: Los estudiantes y la cultura. 2nd ed. Buenos Aires: SIGLO XXI Editores Argentina; 2009.

87. Ministerio de Trabajo, Empleo y Seguridad Social. Juventud y trabajo en la Argentina: Diagnóstico y visión de los actores. REVISTA DE TRABAJO. 2008 Agosto, Dieimbre;(6).

88. EL PAÍS, MONTEVIDEO. EL PAÍS. [Online]. Montevideo [cited 2016 Julio 23 [Tomado de: http://www.elpais.com.uy/economia-y-mercado/ley-juvenil.html\#article-comments].

Available from: http://www.elpais.com.uy/economia-y-mercado/leyjuvenil.html\#article-comments.

89. NACIONES UNIDAS - CEPAL. LOS JÓVENES Y EL EMPLEO EN AMÉRICA LATINA. DESAFÍOS Y PERSPECTIVAS ANTE EL NUEVO ESCENARIO LABORAL. Primera ed. Bogotá: Mayol Ediciones S.A.; 2006.

90. Ministerio de Trabajo. Ministerio de Trabajo. [Online]. Bogotá [cited 2016 Marzo 25 [Consultado en: http://www.mintrabajo.gov.co/empleo/abece-ley-de-primerempleo.html]. Available from: http://www.mintrabajo.gov.co/empleo/abece-ley-deprimer-empleo.html.

91. EL TIEMPO. Alarma por exceso de deudas y mora en los pequeños negocios. EL TIEMPO. 2016 Febrero 2.

92. Universidad del Rosario. Sala de Prensa. [Online].; 2016 [cited 2016 Junio 12 [Nombre de la publicación: Ley de primer empleo tiene deficiencias en la promoción del empleo juvenil ]. Available from: http://www.urosario.edu.co/sala de prensa/Derecho/Ley-deprimer-empleo-tiene-deficiencias-en-la-prom/.

93. Hernández P. Y. Blog de Lectores MÉXICO SOCIAL. [Online].; 2014 [cited 2016 Julio 5. Available from: http://blectores.mexicosocial.org/2014/06/programa-de-primerempleo-2007-2012-focalizado-o-universal/.

94. FRIEDRICH EBERT STIFTUNG. FRIEDRICH EBERT STIFTUNG. [Online].; 2016 [cited 2016 Septiembre 27 [Tomado de: http://library.fes.de/pdffiles/bueros/kolumbien/12514.pdf]. Available from: http://library.fes.de/pdffiles/bueros/kolumbien/12514.pdf. 
95. Materán A. Redylac. [Online].; 2008 [cited 2015 Octubre 6 [Páginas 243 - 248]. Available from: http://www.redalyc.org/pdf/360/36021230010.pdf.

96. DANE - Departamento Administrativo Nacional de Estadísticas. DANE - Departamento Administrativo Nacional de Estadísticas. [Online]; 2010 [cited 2016 Febrero 15 [Documento encontrado en página web del DANE. Documento PDF.]. Available from: https://www.dane.gov.co/files/censo2005/PERFIL PDF CG2005/00000T7T000.PDF.

97. Guerrero R. El concepto de la protección social. Medio de divulgación - Cuadernos de protección social. Bogotá: Ministerio de la Protección Social, Viceministerio Técnico; 2006.

98. Piñero S. La teoría de las representaciones sociales y la perspectiva de Pierre Bourdieu: Una articulación conceptual. CPU-e, Revista de investigación educativa, 7. 2008 Julio Diciembre.

99. MINISTERIO DE TRABAJO. Abecé de la Ley de Formalización y Genración de Empleo "Ley de Primer Empleo". 2012. Búsqueda: Ley Primer Empleo. http://www.mintrabajo.gov.co/buscar.html?searchword=ley+de+primer+empleo\&sear chphrase=all.

100. Secretaría General de la Alcaldía Mayor de Bogotá D.C. CONSTITUCIÓPN POLÍTICA DE COLOMBIA 1991 Bogotá; 1991.

101. MINISTERIO DE TRABAJO. Noticias/Servicio a la ciudadanía. [Online].; s.f. [cited 2016 Abril 05. Available from: http://unidad.serviciodeempleo.gov.co/index.php/101-nomostrar/410-jovenes.

102. MINISTERIO DE TRABAJO, Fuente de Información Laboral de Colombia - FILCO. Fuente de Información Laboral de Colombia - FILCO. [Online].; 2016 [cited 2016 Abril 01. Available from: http://filco.mintrabajo.gov.co/pages/panoramaMundoLaboral.xhtml.

103. OBSERVATORIO DE DESARROLLO ECONÓMICO, Alcaldía Mayor de Bogotá. OBSERVATORIO DE DESARROLLO ECONÓMICO. [Online].; 2016 [cited 2016 Abril 07. Available from: http://observatorio.desarrolloeconomico.gov.co/base/lectorpublic.php?id=806\#sthash G3bwrBwd.dpbs.

104. Montecinos S. Conexiones metodológicas entre las filosofías de Platón y Hegel: la lectura hegeliana de la dialéctica platónica. BAJO PALABRA. Revista de Filosofía. 2009;(4).

105. MinTrabajo. [Online]. Available from: Abecé de la Ley de Formalización y Generación de Empleo 'Ley de Primer Empleo'. 
106. trabajo M. Miércoles, 04 de Noviembre de 2015 12:19 Eltiempo.com E-mail Imprimir PDF. [Online]. Available from: http://www.mintrabajo.gov.co/medios-noviembre2015/4962-plantean-beneficio-tributario-a-empresas-creadas-por-jovenes.html.

107. Mintrabajo. Mintrabajo radicó proyecto de la Ley del Primer Empleo. [Online]. Available from: $\quad$ http://www.mintrabajo.gov.co/medios-noviembre-2015/4959-mintrabajoradico-proyecto-de-la-ley-del-primer-empleo.html.

108. Mintrabajo. Ministerio del Trabajo anuncia continuidad del Programa '40 mil Primeros Empleos' en 2016. [Online]. Available from: http://www.mintrabajo.gov.co/enero2016/5765-ministerio-del-trabajo-anuncia-continuidad-del-programa-a40-milprimeros-empleosa-en-2016.html.

109. Mintrabajo. 'El reto es vincular laboralmente 23 jóvenes, cada semana': Viceministro de Empleo y Pensiones. [Online]. Available from: http://www.mintrabajo.gov.co/mediosjunio-2016/6060-el-reto-es-vincular-laboralmente-23-jovenes-cada-semanaviceministro-de-empleo-y-pensiones.html.

110. Mintrabajo. El Gobierno recarga baterías para solucionar desempleo en jóvenes. [Online]. Available from: http://www.mintrabajo.gov.co/medios-noviembre2015/4958-el-gobierno-recarga-baterias-para-solucionar-desempleo-en-jovenes.html.

111. Mintrabajo. El desempleo juvenil cayó en $0,8 \%$ en el tercer trimestre. [Online]. Available from: http://www.mintrabajo.gov.co/medios-octubre-2015/4929-el-desempleojuvenil-cayo-en-08--en-el-tercer-trimestre.html.

112. Mintrabajo. 768 mil jóvenes consiguieron empleo en los últimos 5 años: MinTrabajo. [Online]. Available from: http://www.mintrabajo.gov.co/medios-febrero-2016/5804768-mil-jovenes-consiguieron-empleo-en-los-ultimos-5-anos-mintrabajo.html.

113. SECRETARIA DE PLANEACIÓN ALCALDÍA MAYOR DE BOGOTÁ. DIAGNÓSTICO DE LA POBLACIÓN JOVEN DE BOGOTÁ, D.C. 2005-2010. Bogotá:; 2010.

114. Ministerio de la Protección Social. El concepto de la Protección Social técnico V, editor.

115. German Agency for Technical Cooperation. NU. CEPAL. Financiamiento de desarrollo. Inserción laboral, mercados de trabajo y protección social. Documento. Series de la CEPAL. Tomado de: http://repositorio.cepal.org/bitstream/handle/11362/5143/S0600222_es.pdf?sequenc $\mathrm{e}=1$ \&isAllowed $=y$.

116. Alonso LE. La sociedad del trabajo: debates actuales. Materiales inestables para lanzar la discusión. Dialnet - Reis: Revista española de investigaciones sociológicas. 2004;(107): p. 21-48. 
117. Alonso LE. CENTRALIDAD DEL TRABAJO Y COHESIÓN SOCIAL: ¿UNA RELACIÓN NECESARIA? Dialnet - Gaceta sindical: reflexión y debate. 2006;(7): p. 101-126. 


\section{Formato entrevista egresados.}

\section{AUTORIZACIÓN}

Con el fin de garantizar sus derechos, es pertinente mencionarle que esta entrevista se realiza con fines educativos: investigación/tesis. Por virtud de esta autorización, se entiende que la entrevista realizada se podrá incluir exclusivamente en la obra mencionada, a fin de poder reproducirla, editarla, distribuirla, exhibirla y comunicarla en el país y en el extranjero por medios impresos, electrónicos, Cd ROM o Internet, siempre y cuando esté circunscrito a la obra realizada.

\section{DATOS ENTREVISTADO}

\section{PROCESO DEL SUJETO ENTREVISTADO}

\begin{tabular}{|l|l|}
\hline IDENTIFICACIÓN & \\
PERSONA & \\
\hline UNIVERSIDAD & \\
\hline CARRERA & \\
\hline COLEGIO/BACHILLERATO & \\
\hline PROCEDENCIA & \\
\hline $\begin{array}{l}\text { EMPRESA DONDE } \\
\text { LABORA }\end{array}$ & \\
\hline GÉNERO & \\
\hline GRUPO ÉTNICO & \\
\hline
\end{tabular}

- Menciona usted que la profesión elegida fue..... ¿Cómo fue su decisión para elegir la profesión? (Influyeron padres, amigos, conocidos, medios, gustos, campo de salida laboral).

- ¿Usted trabajo mientras se encontraba estudiando? (Lo hizo por gusto, por necesidad, por adquirir experiencia laboral).

- ¿A lo largo de su carrera se preocupó por cómo iba a conseguir empleo?

- ¿En el momento de elegir la universidad y la carrera, se le informó la salida al mercado laboral que tiene su profesión? 
- ¿La universidad por medio de oficinas ayuda a sus estudiantes/egresados a conseguir empleo?

- Cuando se graduó, ¿cuál era su interés con la profesión? (Buscar trabajo, seguir estudiante, viajar).

(Si se encuentra laborando) ¿Cuál es el tipo de contrato que usted tiene?

- ¿Cómo fue su proceso desde que salió del colegio, hasta cuando se graduó de la universidad? (Empatía con la carrera, disgustos académicos, su grado, su experiencia de transición de vida estudiantil a vida laboral).

- ¿Usted cómo construye sus representaciones laborales?

- (Si se encuentra laborando) ¿Usted cree que su salario obedece a las tablas de clasificación laboral? ¿Qué piensa de eso? (Obtiene todas las prestaciones legales por ley: Pensión, salud, cesantías).

- ¿Usted cree que las ofertas laborales en Bogotá son adecuadas para los recién egresados? (Fácil acceso, buenos salarios, buenas oportunidades).

\section{LAS POLÍTICAS Y LAS LEYES DE EMPLEO PARA JÓVENES}

- Usted conoce las políticas públicas diseñadas para el empleo de jóvenes en Colombia. (Si las conoce, ¿qué conoce?) (Por qué no las conoce, desinterés).

- Sabe algo sobre la ley 1429 de 2010? (Si - ¿Qué conoce? ¿Cuál es su opinión frente a la ley?) (No-contexto sobre la ley y preguntar qué opina).

- Fragmento: Ley Por la cual se expide la Ley de Formalización y Generación de Empleo. Tiene por objeto la formalización y la generación de empleo, con el fin de generar incentivos a la formalización en las etapas iniciales de la creación de 
empresas; de tal manera que aumenten los beneficios y disminuyan los costos de formalizarse.

- ¿Qué entiende por formalización en el campo del empleo?

- ¿Qué entiende por primer empleo?

- Si sabemos que la constitución establece el trabajo digno como un derecho, ¿usted cree que esto se refleja en las políticas o en las leyes?

- ¿Ustedes cómo perciben la equidad laboral desde su experiencia? (Existen diferencias por edad, género, grupo étnico).

- ¿Cómo interpreta usted que una ley llamada primer empleo, hable más de emprendimiento empresarial?

2. Formato entrevista a estudiantes

\section{AUTORIZACIÓN}




\section{DATOS ENTREVISTADO}

Con el fin de garantizar sus derechos, es pertinente mencionarle que esta entrevista se realiza con fines educativos: investigación/tesis. Por virtud de esta autorización, se entiende que la entrevista realizada se podrá incluir exclusivamente en la obra mencionada, a fin de poder reproducirla, editarla, distribuirla, exhibirla y comunicarla en el país y en el extranjero por medios impresos, electrónicos, Cd Rom o Internet, siempre y cuando esté circunscrito a la obra realizada.

\section{PROCESO DEL SUJETO ENTREVISTADO}

- Menciona usted que la profesión elegida fue..... ¿Cómo fue su decisión para elegir la profesión? (Influyeron padres, amigos, conocidos, medios, gustos, campo de salida laboral).

\begin{tabular}{|l|l|}
\hline IDENTIFICACIÓN & \\
PERSONA & \\
\hline UNIVERSIDAD & \\
\hline CARRERA & \\
\hline COLEGIO/BACHILLERATO & \\
\hline PROCEDENCIA & \\
\hline EMPRESA DONDE & \\
LABORA & \\
\hline GÉNERO & \\
\hline GRUPO ÉTNICO & \\
\hline
\end{tabular}

- ¿Usted trabajo mientras se encontraba estudiando? (Lo hizo por gusto, por necesidad, por adquirir experiencia laboral).

- ¿A lo largo de su carrera se preocupó por cómo iba a conseguir empleo?

- ¿En el momento de elegir la universidad y la carrera, se le informó la salida al mercado laboral que tiene su profesión? 
- ¿La universidad por medio de oficinas ayuda a sus estudiantes/egresados a conseguir empleo?

- ¿Qué cree que va a pasar cuando se gradué? ¿Cuál es su principal interés al graduarse? (Seguir estudiando, viajar, conseguir empleo).

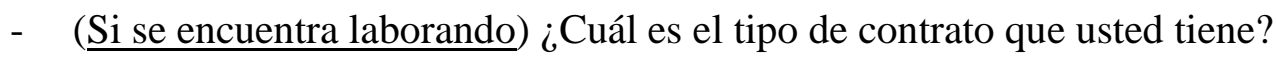

- ¿Cómo ha sido su proceso desde que salió del colegio a la fecha con su profesión? (Empatía con la carrera, disgustos académicos, su experiencia de transición de vida estudiantil a vida laboral).

- ¿Cómo se imagina el proceso luego de salir como profesional? (Si ya se encuentra laborando, está interesado en buscar otras oportunidades) (Búsqueda fácil de trabajo, ayuda con conocidos de familiares, ayuda por medio de amigos y conocidos).

- ¿Está pensando en buscar empleo? ¿Dónde buscaría?

- ( Si se encuentra laborando) ¿Usted cree que su salario obedece a las tablas de clasificación laboral? ¿Qué piensa de eso? (Obtiene todas las prestaciones legales por ley: Pensión, salud, cesantías).

- ¿Usted cree que las ofertas laborales en Bogotá son adecuadas para los recién egresados? (Fácil acceso, buenos salarios, buenas oportunidades).

\section{LAS POLÍTICAS Y LAS LEYES DE EMPLEO PARA JÓVENES}

- Usted conoce las políticas públicas diseñadas para el empleo de jóvenes en Colombia. (Si las conoce, ¿qué conoce?) (Por qué no las conoce, desinterés).

- Sabe algo sobre la ley 1429 de 2010? (Si - ¿Qué conoce? ¿Cuál es su opinión frente a la ley?) (No-contexto sobre la ley y preguntar qué opina). 
Fragmento: Ley Por la cual se expide la Ley de Formalización y Generación de Empleo. Tiene por objeto la formalización y la generación de empleo, con el fin de generar incentivos a la formalización en las etapas iniciales de la creación de empresas; de tal manera que aumenten los beneficios y disminuyan los costos de formalizarse.

- ¿Qué entiende por formalización en el campo del empleo?

- ¿Qué entiende por primer empleo?

- Si sabemos que la constitución establece el trabajo digno como un derecho, ¿usted cree que esto se refleja en las políticas o en las leyes?

- ¿Ustedes cómo perciben la equidad laboral desde su experiencia? (Existen diferencias por edad, género, grupo étnico).

- ¿Cómo interpreta usted que una ley llamada primer empleo, hable más de emprendimiento empresarial? 